
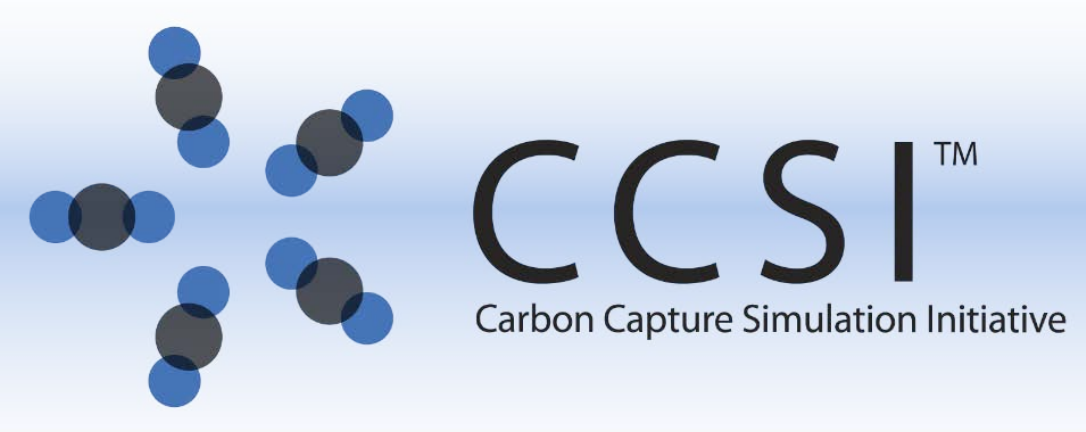

\title{
PNNL Report on the Development of Bench-scale CFD Simulations for Gas Absorption across a Wetted Wall Column
}

\author{
Work Performed Under \\ Activity Number 0004000.6.600.007.002 ARRA
}

Prepared by

Pacific Northwest National Laboratory

Richland, Washington 99352
In collaboration with Los Alamos National Laboratory, Lawrence Livermore National Laboratory, the National Energy Technology Laboratory, and Princeton University
Prepared for the
U.S. Department of Energy
National Energy Technology Laboratory

January 2016
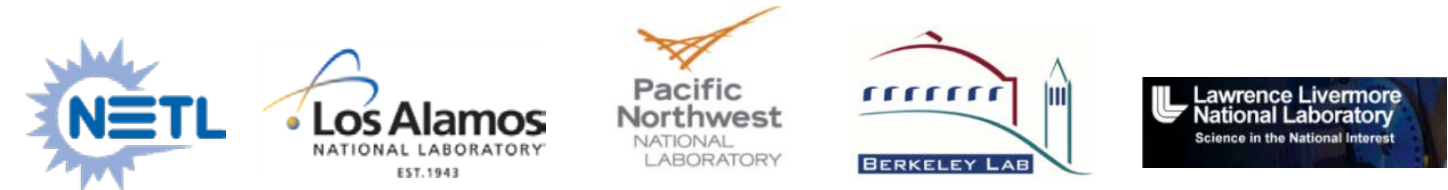


\section{Revision Log}

\begin{tabular}{|c|c|c|c|}
\hline Revision & Date & Revised By: & Description \\
\hline 0.1 & Jan 2016 & Chao Wang & Original draft \\
\hline 0.2 & Jan 202016 & Zhijie Xu & Revised \\
\hline 0.3 & & & \\
\hline 0.4 & & & \\
\hline 1.0 & & & \\
\hline
\end{tabular}

\section{Disclaimer}

This report was prepared as an account of work sponsored by an agency of the United States Government. Neither the United States Government nor any agency thereof, nor any of their employees, makes any warranty, express or implied, or assumes any legal liability or responsibility for the accuracy, completeness, or usefulness of any information, apparatus, product, or process disclosed, or represents that its use would not infringe privately owned rights. Reference herein to any specific commercial product, process, or service by trade name, trademark, manufacturer, or otherwise does not necessarily constitute or imply its endorsement, recommendation, or favoring by the United States Government or any agency thereof. The views and opinions of authors expressed herein do not necessarily state or reflect those of the United States Government or any agency thereof.

\section{Acknowledgment of Funding}

This project was funded under the Carbon Capture Simulation Initiative under the following FWPs and contracts:

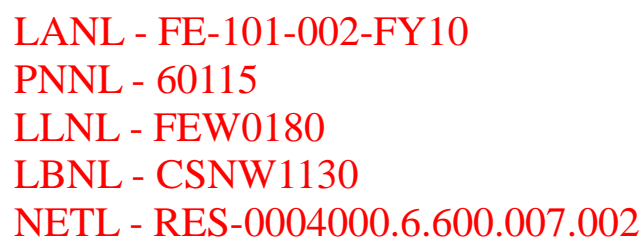




\section{Table of Contents}

1. INTRODUCTION .................................................................................................................... 5

2. EXPERIMENTAL STUDY OF WWC ............................................................................. 6

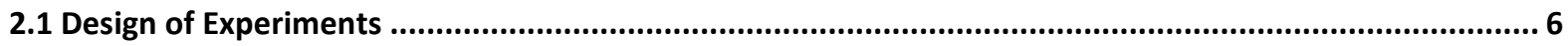

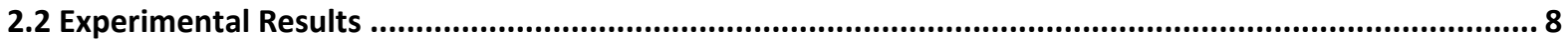

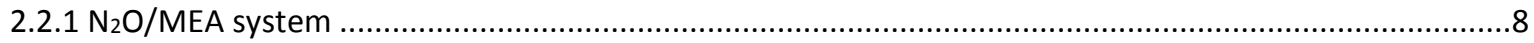

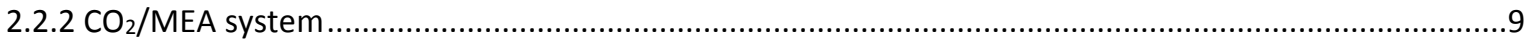

3. NUMERICAL MODELING OF WWC.................................................................................... 11

3.1 General Theory on Mass Transport and Chemistry .................................................................. 11

3.2 Calculation of Model Input Parameters.................................................................................. 14

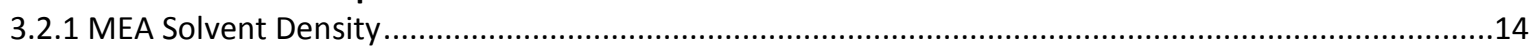

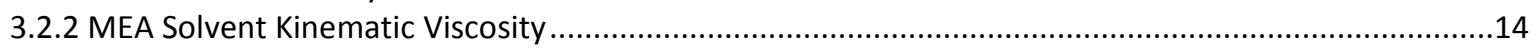

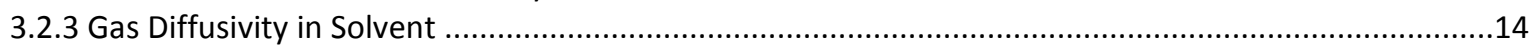

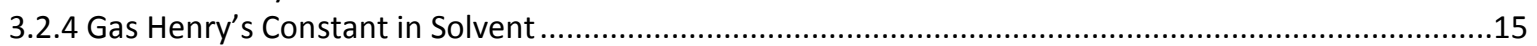

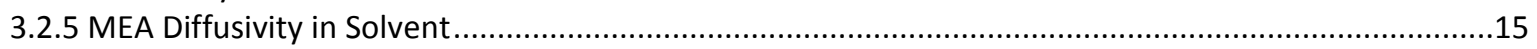

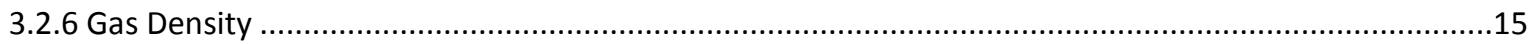

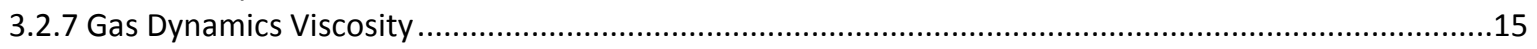

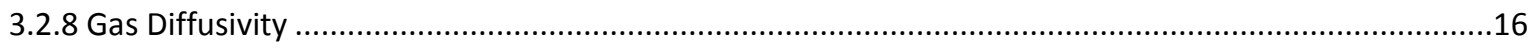

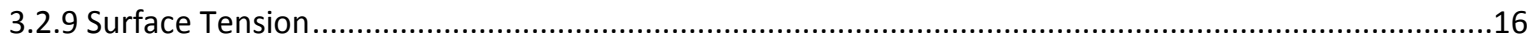

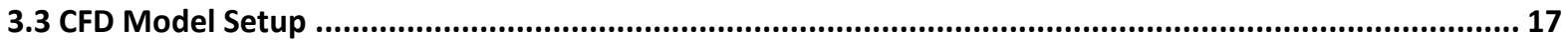

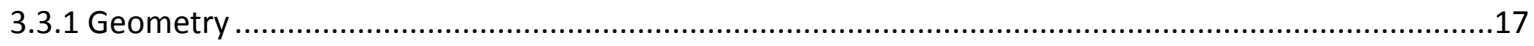

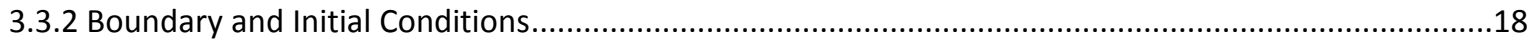

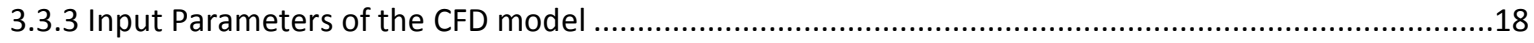

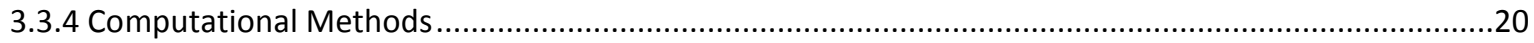

3.4 Calculation of Overall Mass Transfer Coefficient ............................................................................ 20

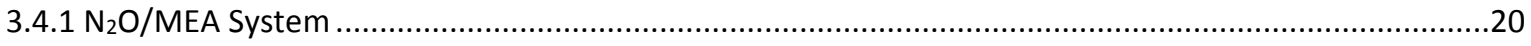

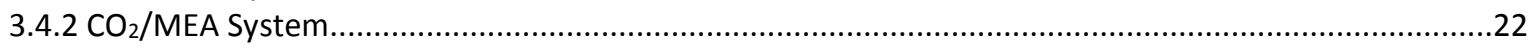

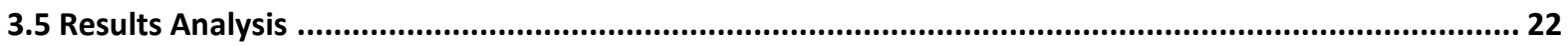

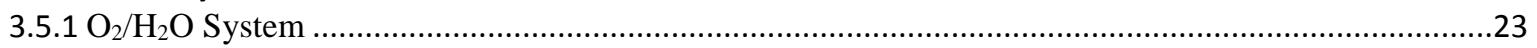

3.5.1.1 Effect of Injection Frequency on Surface Waves...................................................................24

3.5.1.2 Variation of $\mathrm{O}_{2}$ Concentration for Different Frequencies ..........................................................25

3.5.1.3 Variation of $\mathrm{O}_{2}$ Concentration with Controlled Amplitude .......................................................25

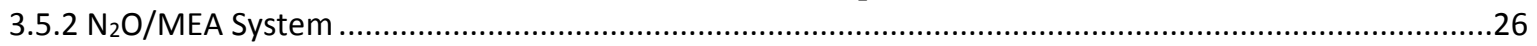

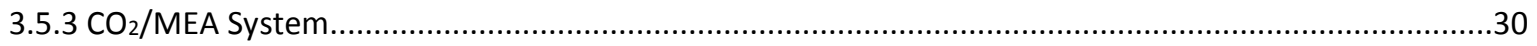

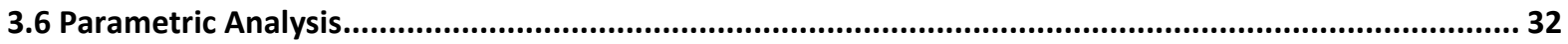

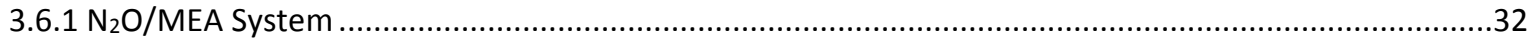

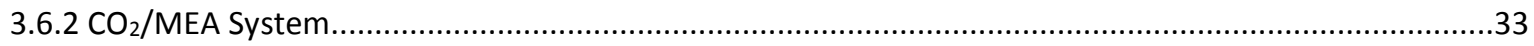

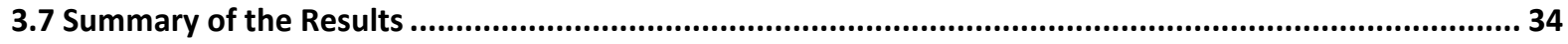


4. MODEL CALIBRATION AND UQ ANALYSIS FOR WWC EXPERIMENTS 35

4.1 $\mathrm{N}_{2} \mathrm{O} / \mathrm{MEA}$ System 35

4.2 $\mathrm{CO}_{2} /$ MEA System 39

ACKNOWLEDGMENTS 42

REFERENCES. 42

APPENDIX. 43

\section{List of Figures}

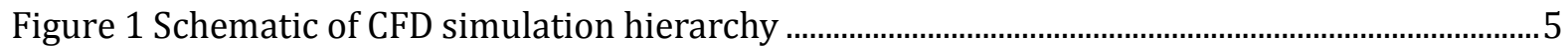

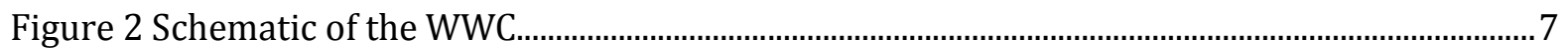

Figure 3 Schematic of WWC Test Setup ................................................................................................... 7

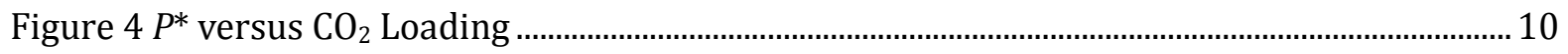

Figure 5 Countercurrent Gas Flow Geometry Schematics.................................................................. 18

Figure 6 Mesh Size Distribution in x Direction.......................................................................................... 20

Figure 7 Sharp Gas-Liquid Interface versus Gas-Liquid Interface Layer ............................................21

Figure 8 Profiles of Falling Film with Increasing Frequencies in Injection Rates (more surface waves can be observed at higher frequencies) .................................................................................... 24

Figure 9 Variation of Gas Concentration Distribution for Different Fluctuation Frequencies (a larger frequency leads to a steeper concentration gradient in the vertical direction and a larger mass transfer across the interface).

Figure 10 Variation of Gas Concentration Distribution for Different Fluctuation Amplitudes in the Injection Rate (a larger amplitude leads to a steeper concentration gradient along the vertical direction)

Figure 11 Numerical Simulation Versus Experimental Data for Overall Mass Transfer Coefficient

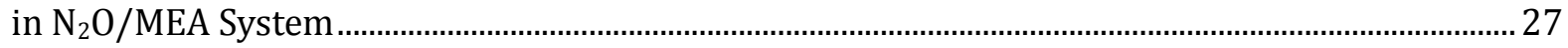

Figure $12 \mathrm{k}_{\mathrm{G}}$ versus Controlled Parameters in $\mathrm{N}_{2} \mathrm{O}$ /MEA Systems......................................................29

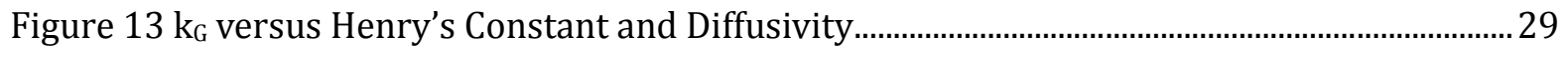

Figure 14 Numerical Simulation Versus Experimental Data for Overall Mass Transfer Coefficient in $\mathrm{CO}_{2}$ /MEA Systems .............................................................................................................................. 30

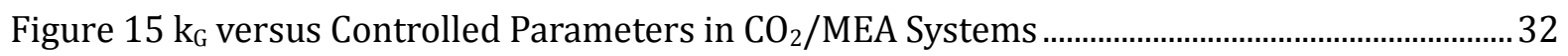

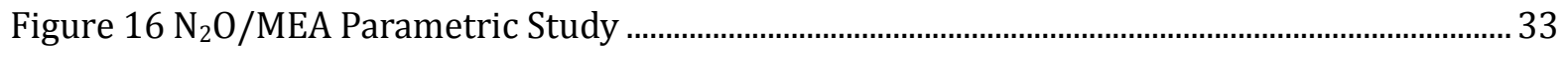

Figure $17 \mathrm{CO}_{2}$ /MEA Parametric Study ………….................................................................................... 34

Figure 18 Estimated Marginal Posterior Distributions for the Calibration Parameters of the

Non-reacting Scenario (blue line segments are the point estimates found in the literature) ........38 
Figure 19 Predictive Diagnostic Plots for the Non-reaction Scenario (both panels compare the experimental data points (black "x") to predicted simulator output (red); refer to the text for more in-depth descriptions).

Figure 20 Estimated Marginal Posterior Distributions for the Calibration Parameters of the Reacting Scenario (blue line segments are the point estimates found in the literature)..

Figure 21 Uncertainty, the Rate Constant, as a Function of Temperature (C) (blue curve is derived from the literature, while the black curve is the median prediction; the dashed lines form pointwise $90 \%$ intervals).

Figure 22 Predictive Diagnostic Plots for the Reacting Scenario (both panels compare the experimental data points (black " $x$ ") to predicted simulator output (red); refer to the text for more in-depth descriptions)

\section{List of Tables}

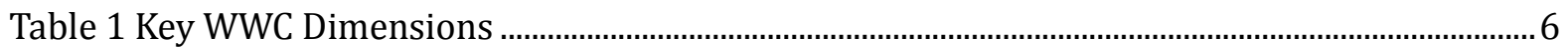

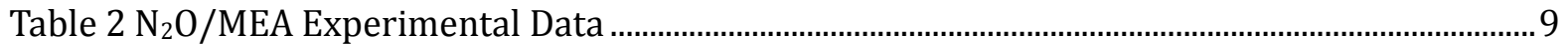

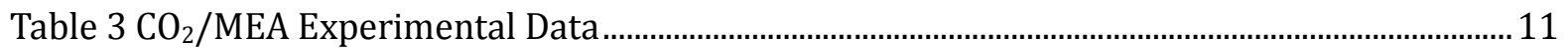

Table 4 Regressed Parameter for Equilibrium Constant KCO2 ............................................................ 13

Table 5 Parameters for Solvent Density Correlation............................................................................. 14

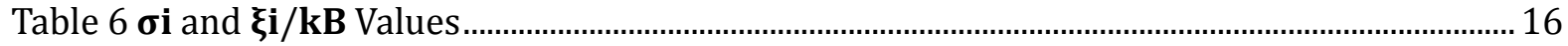

Table 7 Controlled Input Parameters .................................................................................................. 19

Table 8 Direct Model Input Parameters................................................................................................. 19

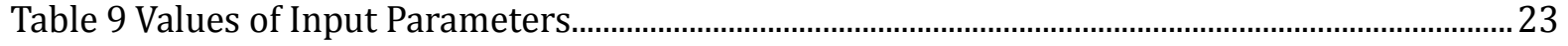

Table 10 Inputs to the Computer Model for the Non-reacting Case ......................................................36

Table 11 Default Relationships between Calibration Inputs and Experimental Inputs for the

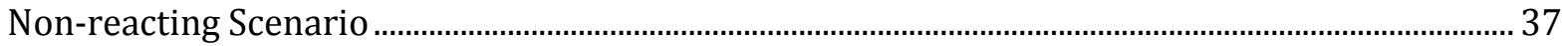

Table 12 Priors for Calibration Parameters............................................................................................... 37

Table 13 Inputs to the Computer Model for the Reacting Case ............................................................... 39

Table 14 Default Relationships for the Reacting Scenario................................................................... 39 


\section{PNNL Report on the Development of Bench-scale CFD Simulations for Gas Absorption across a Wetted Wall Column Chao Wang ${ }^{\mathrm{a}}$, Zhijie Xu ${ }^{\mathrm{a}}$, Kevin Lai ${ }^{\mathrm{a}}$, Greg Whyatt ${ }^{\mathrm{a}}$, Peter William Marcy ${ }^{\mathrm{b}}$, James Gattiker ${ }^{\mathrm{b}}$, Xin Sun ${ }^{\mathrm{a}}$ \\ apacific Northwest National Laboratory, Richland, WA \\ bLos Alamos National Laboratory, Los Alamos, NM}

\section{Introduction}

The Carbon Capture Simulation Initiative (CCSI) develops state-of-the-art computational modeling and simulation tools to accelerate commercialization of carbon capture technologies from discovery to development with eventual widespread deployment to hundreds of power plants through a partnership among national laboratories, industry, and academic institutions. The ultimate goal of the CCSI toolset is to provide end users in industry with a comprehensive, integrated suite of scientifically validated models and deliver uncertainty quantification (UQ), optimization, risk analysis, and decision-making capabilities.

In order to enable the hierarchical prediction of carbon capture efficiency of a solventbased absorption column, a computational fluid dynamics (CFD) model is first developed to simulate the core phenomena of solvent-based carbon capture, i.e., the $\mathrm{CO}_{2}$ physical absorption and chemical reaction, on a simplified geometry of wetted wall column (WWC) at bench scale. Aqueous solutions of ethanolamine (MEA) are commonly selected as a $\mathrm{CO}_{2}$ stream scrubbing liquid. $\mathrm{CO}_{2}$ is captured by both physical and chemical absorption using highly $\mathrm{CO}_{2}$ soluble and reactive solvent, MEA, during the scrubbing process. In order to provide confidence bound on the computational predictions of this complex engineering system, a hierarchical calibration and validation framework is proposed in [1]. The overall goal of this effort is to provide a mechanism-based predictive framework with confidence bound for overall mass transfer coefficient of the wetted wall column (WWC) with statistical analyses of the corresponding WWC experiments with increasing physical complexity.

A series of unit problems is proposed to break the complex multi-physics in solventbased $\mathrm{CO}_{2}$ capture into simpler single physical problems as shown in Figure 1 [1]. The final outcome of this work is the distributions of the effective mass transfer coefficient for a given solvent (MEA here) and the associated posterior distributions of solvent properties including Henry's constant, diffusivity and reaction rate constants.

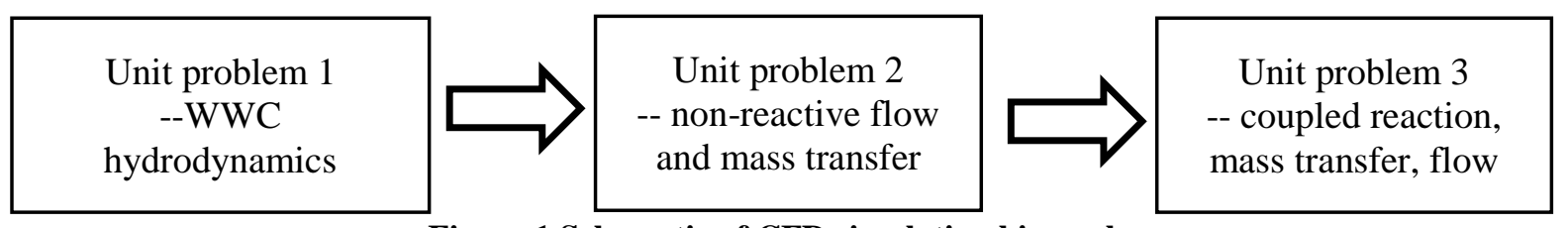

Figure 1 Schematic of CFD simulation hierarchy

Unit problem 1, i.e., flow hydrodynamics of a falling film, has been extensively investigated in the literature. In this study, volume of fluids (VOF)-based CFD simulations were performed for film flowing down the column with various viscosities. The model results are validated by comparison between the simulated steady state film thickness and the theoretical prediction for various viscosities. After that, quantitative confidence in the 
numerical accuracy and code implementation of the open source package (OpenFOAM) for simulating flow hydrodynamics were established. In the present report, we focus on presenting the detailed analysis results of Unit problems 2 and 3. The focus of Unit problem 2 is the coupling of two physical processes, i.e., mass transfer and hydrodynamics between gas and liquid. The gas-liquid pairs of interest include $\mathrm{O}_{2} /$ Water and $\mathrm{N}_{2} \mathrm{O} / \mathrm{MEA}$. In this unit problem, we will first investigate the effects of surface wave frequency and amplitude on the overall mass transfer between $\mathrm{O}_{2}$ and water in WWC with various water injection rates. The coupled mass transfer with hydrodynamics model will be further validated and calibrated with controlled WWC experiments with $\mathrm{N}_{2} \mathrm{O}$ /MEA system. Here $\mathrm{N}_{2} \mathrm{O}$ is used as a surrogate for $\mathrm{CO}_{2}$ without the absorption reaction. Upon completion of Unit problem 2, posterior distributions of Henry's constant and diffusivity can be established with the coupled hydrodynamics and mass transfer model and the corresponding experiments.

Next, Unit problem 3 will be carried out with the same WWC set up, but with the introduction of $\mathrm{CO}_{2}$ in the gas stream. The transport properties of $\mathrm{CO}_{2}$ in $\mathrm{MEA}$ system can be inferred from the posterior distributions obtained in Unit problem 2 for $\mathrm{N}_{2} \mathrm{O}$ based on available literatures [2, 3]. In doing so, the effects of $\mathrm{CO}_{2}$ mass transfer and chemical absorption within MEA can be separated. After this step, more physical insights can be obtained and a systematic calibration of reaction rate constants will be implemented for the $\mathrm{CO}_{2}$ /MEA system. Upon completion of the entire hierarchical simulations of the WWC system, the multiphase CFD models with coupled chemistry and mass transport capabilities can be established to predict the overall $\mathrm{CO}_{2}$ mass transfer rate of the WWC.

\section{Experimental Study of WWC}

\subsection{Design of Experiments}

The transport of $\mathrm{CO}_{2}$ and $\mathrm{N}_{2} \mathrm{O}$ into MEA solvents was measured on a WWC to generate data for WWC model validation. Transport of $\mathrm{N}_{2} \mathrm{O}$ is examined as a non-reactive surrogate molecule for $\mathrm{CO}_{2}$.

Measurements were performed using a custom-built WWC apparatus consisting of a stainless-steel tube contained within a cylinder. Gas enters the column through three 1/8-inch tubes spaced evenly around the annulus' perimeter. The gas flows upward, contacting a liquid film falling down the outside of the tube, then exits through a $1 / 4$-inch tube at the top. The solvent recirculates to a temperature-controlled reservoir, while the gas is delivered using mass flow controllers and vented after passing through the column. To maintain the desired test temperature, oil kept at the test temperature surrounds the inner chamber. Figure 2 shows the column schematic with key dimensions provided in Table 1. Figure 3 illustrates the column schematic, including the gas flow path and analysis train.

Table 1 Key WWC Dimensions

\begin{tabular}{|l|c|}
\hline Inner chamber diameter & $2.30 \mathrm{~cm}$ \\
\hline Outside diameter of center tube & $1.25 \mathrm{~cm}$ \\
\hline Height of center tube & $9.09 \mathrm{~cm}$ \\
\hline Wetted area of the column & $36.93 \mathrm{~cm}^{2}$ \\
\hline Hydraulic diameter & $1.05 \mathrm{~cm}$ \\
\hline
\end{tabular}




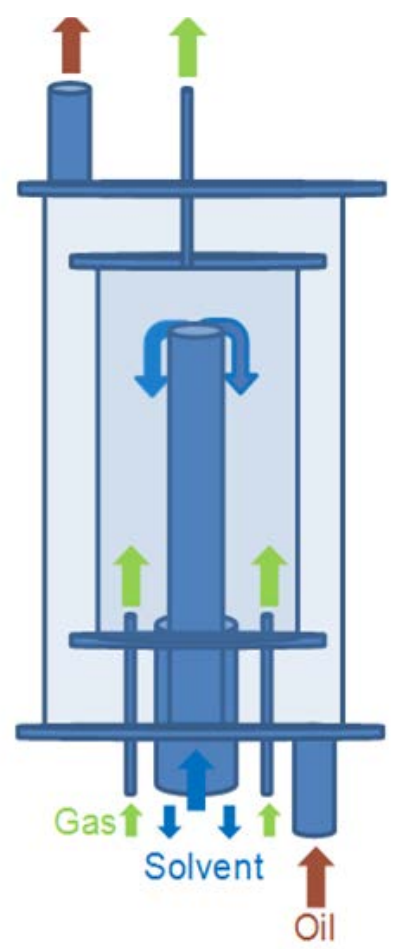

Figure 2 Schematic of the WWC

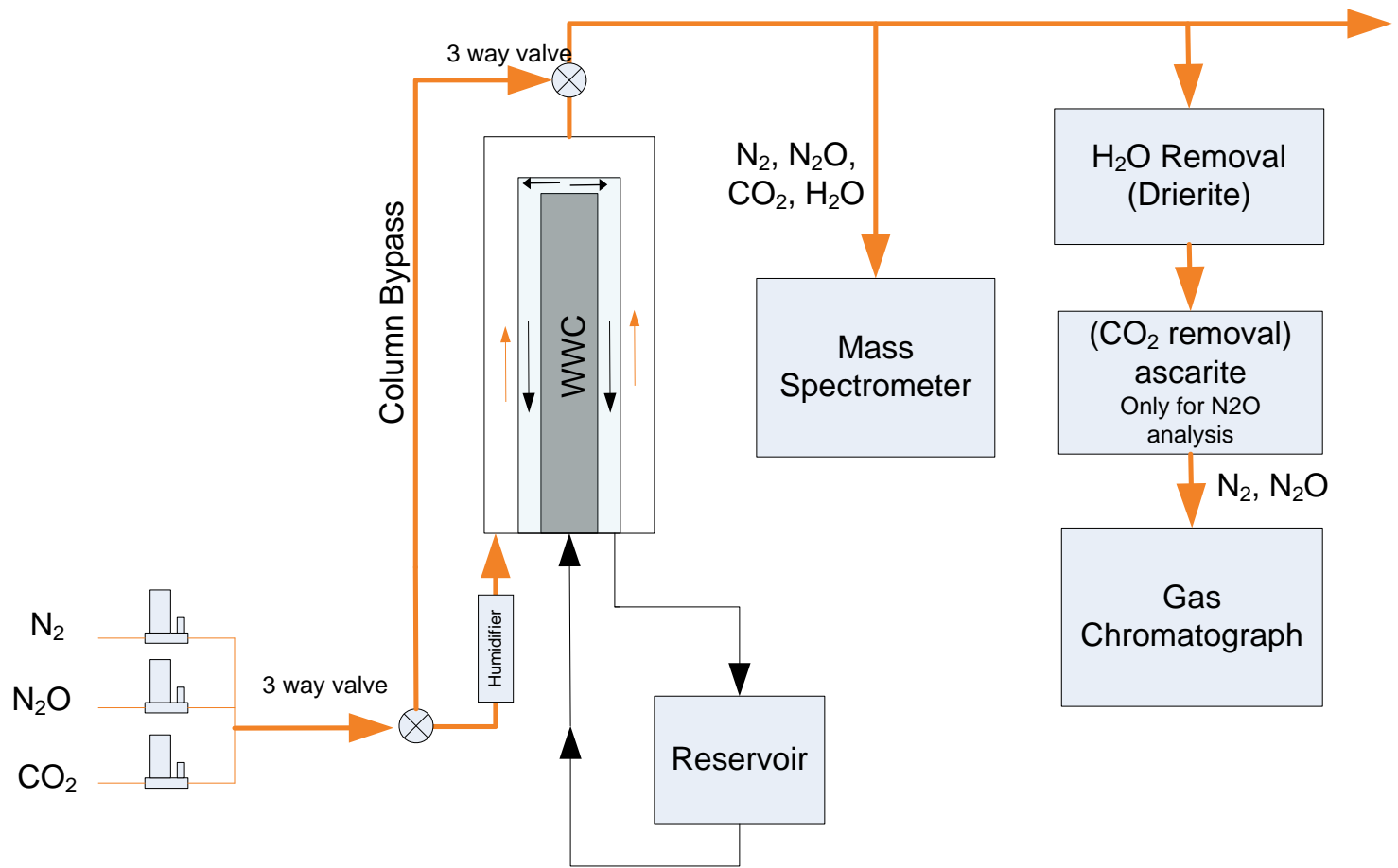

Figure 3 Schematic of WWC Test Setup

Gases are delivered to the column from cylinders via mass flow controllers (MFC). Prior to use, all MFCs were recalibrated for mixture gases using a primary calibrator (Mesa Labs, Model Definer 220) to $\pm 1 \%$ accuracy. Two, three-way valves allow the gas to be configured 
to flow either through the column or a bypass leg. During a test, the gas is first flowed through the bypass leg, then switched to the column, and then back to the bypass leg. The shift in concentration while the gas is routed through the column then is used to deduce the rate at which the gas is being absorbed by the column.

Liquid flow to the column is set via a speed control on a gear pump (Cole Parmer model 75211-30 with \#074012-51 pump head). The gear pump flow is calibrated versus pump speed prior to the test. Then, the speed corresponding to the desired flow is set.

After tests 1 through 6 had been performed without humidifying the gas that entered the column, a Nafion humidifier (model FC125-240-5MP) was added to the system to bring the water vapor pressure of the gas entering the column to a level near that of the equilibrium vapor pressure of the solution being tested. A heated water bath circulated water through the shell side of the humidifier, while the process gas passed through the Nafion tubes. The addition of the humidifier was intended to reduce uncertainty in the concentration driving force related to the timing of the dry gas' dilution with water vapor and to avoid a reduction in mass transfer that could occur due to phase drift as water is transported away from the liquid film in the gas phase. For the purposes of data analysis, the concentration driving force for the first six tests assumed that the gas was humidified immediately upon entering the column.

Gas composition of the stream exiting the WWC has been analyzed using a quadrupole mass spectrometer (MKS, Cirrus $200 \mathrm{amu}$ ) sampling at atmospheric pressure. The mass spectrometer provides an analysis of gas composition at four-second intervals. Because $\mathrm{CO}_{2}$ and $\mathrm{N}_{2} \mathrm{O}$ both have an atomic mass of $44, \mathrm{~N}_{2} \mathrm{O}$ is analyzed on the mass spectrometer at mass 30, corresponding to a nitric oxide (NO) splitting peak. The mass spectrometer samples the gas directly without drying.

A gas chromatograph (Agilent Model 3000A Micro GC) also is used to provide analysis of the gas composition, providing data at four-minute intervals. Of the two instruments, the GC offers a more accurate and sensitive measurement, but the mass spectrometer provides better transient information due to the faster sampling rate. Prior to GC analysis, the sampled gas is dried using a Drierite column. When measuring $\mathrm{N}_{2} \mathrm{O}$ transport, the gas also passes through an Ascarite bed to remove $\mathrm{CO}_{2}$ and prevent possible overlap of $\mathrm{N}_{2} \mathrm{O}$ and $\mathrm{CO}_{2}$ peaks on the GC. The amount of $\mathrm{N}_{2} \mathrm{O}$ absorbed is deduced by the shift in the ratio of $\mathrm{N}_{2} \mathrm{O}$ to $\mathrm{N}_{2}$ as measured on the GC.

Reagent grade (98\%) MEA was purchased from Spectrum Chemical Manufacturing Corp. and blended with deionized water to provide the desired solvent concentration. $\mathrm{N}_{2} \mathrm{O}$ (99.6\%), $\mathrm{CO}_{2}$, and $\mathrm{N}_{2}$ gases (99.998\%) were purchased from OXARC and used without further purification. The initial solvent loading was achieved via mass addition of dry ice to the solvent. The dry ice (99\% purity) also was purchased from OXARC.

\subsection{Experimental Results}

\subsection{1 $\mathrm{N}_{2} \mathrm{O} / \mathrm{MEA}$ system}

The mass transfer coefficient $K_{G}\left(\mathrm{~mol} / \mathrm{Pa} \cdot \mathrm{s} \cdot \mathrm{m}^{2}\right)$ is calculated by

$$
K_{G}=\frac{J}{\Delta P}
$$

where $\Delta P=\left(P_{N_{2} O, \text { in }}-P_{N_{2} O, o u t}\right) / \ln \left(P_{N_{2} O, \text { in }} / P_{N_{2} O, o u t}\right)$ denotes log mean driving force and $J$ $\left(\mathrm{mol} / \mathrm{m}^{2} \cdot \mathrm{s}\right)$ denotes the mass transfer flux at the gas-liquid interface. 
Table 2 N2O/MEA Experimental Data

\begin{tabular}{|c|c|c|c|c|c|c|c|c|c|c|c|}
\hline Summary Table - & -All N2O data & & & & & & values include $\epsilon$ & effect of $\mathrm{CO}_{2}$ an & humidity on & concentration & \\
\hline orange headers indic. & icate the input values t & $s$ that defined the test to & to berun & & & & P_N2O_in & P_N2O_out & LMPD & $\overline{\text { N_N2O }}$ & $\overline{K G}$ \\
\hline Run\# & $\begin{array}{l}\text { MEA_content, } \\
\text { (mass fraction MEA } \\
\text { with water) }\end{array}$ & $\begin{array}{l}\text { CO2_Loading, (mol } \\
\text { CO2 per mol MEA) }\end{array}$ & $\begin{array}{l}\text { Solvent_Flow_Rate, } \\
\text { cc/min (run } \\
\text { calibration on gear } \\
\text { pump using MEA } \\
\text { solution and check } \\
\text { calibration at } 25 \mathrm{C} \\
\text { and } 60 \mathrm{C} \text { to see if } \\
\text { varies with } \\
\text { temperature) }\end{array}$ & $\begin{array}{l}\text { Gas_Flow_Rate, sccm } \\
\text { (Includes } \mathrm{N} 2 \text { and } \mathrm{N} 2 \mathrm{O} \\
\text { but not the flow of } \mathrm{CO} 2 \\
\text { added to match } \\
\text { equilibrium pressure } \\
\text { or water vapor leaving } \\
\text { solution) }\end{array}$ & $\begin{array}{l}\text { N2O_Molar_Conc } \\
\text { (mole fraction N2O } \\
\text { in gas entering } \\
\text { column) **does } \\
\text { not include } \\
\text { humidity** }\end{array}$ & Temperature, C & {$[\mathrm{Pa}]$} & {$[\mathrm{Pa}]$} & {$[\mathrm{Pa}]$} & {$[\mathrm{mol} / \mathrm{m} 2 / \mathrm{s}]$} & {$[\mathrm{mol} / \mathrm{m} 2 / \mathrm{s} / \mathrm{Pa}]$} \\
\hline Run_1 & 0.30 & 0.464 & 350 & 200 & 0.1458 & 35 & $1.42 E+04$ & $1.34 E+04$ & $1.41 E+04$ & $6.42 E-05$ & $4.56 \mathrm{E}-09$ \\
\hline Run_2 & 0.30 & 0.464 & 350 & 200 & 0.1459 & 45 & $1.44 E+04$ & $1.39 \mathrm{E}+04$ & $1.43 E+04$ & 9.39E- 05 & $6.56 \mathrm{E}-09$ \\
\hline Run_3 & 0.30 & 0.464 & 350 & 200 & 0.1459 & 55 & $1.25 E+04$ & $1.06 \mathrm{E}+04$ & $1.24 \mathrm{E}+04$ & $9.12 E-05$ & $7.34 \mathrm{E}-09$ \\
\hline Run_4 & 0.30 & 0.500 & 350 & 200 & 0.1458 & 35 & $1.40 E+04$ & $1.32 E+04$ & $1.39 \mathrm{E}+04$ & $1.07 E-04$ & 7.67E-09 \\
\hline Run_5 & 0.30 & 0.500 & 350 & 200 & 0.1458 & 45 & $1.35 E+04$ & 1.22E+04 & 1.34E+04 & $1.14 \mathrm{E}-04$ & $8.48 \mathrm{E}-09$ \\
\hline Run_6 & 0.30 & 0.500 & 350 & 200 & 0.1459 & 55 & $1.22 E+04$ & $9.92 E+03$ & $1.21 E+04$ & $8.50 \mathrm{E}-05$ & 7.04E-09 \\
\hline Run_7 & 0.25 & 0.300 & 450 & 200 & 0.3250 & 42 & $3.02 E+04$ & 2. $96 \mathrm{E}+04$ & $2.99 \mathrm{E}+04$ & $6.04 E-04$ & $2.02 \mathrm{E}-08$ \\
\hline Run_8 & 0.10 & 0.100 & 509 & 211 & 0.2280 & 40 & $2.11 \mathrm{E}+04$ & $2.01 E+04$ & $2.06 \mathrm{E}+04$ & $5.22 \mathrm{E}-04$ & 2.53E- 08 \\
\hline Run_9 & 0.10 & 0.300 & 586 & 268 & 0.4300 & 37 & 4.03E+04 & $3.87 E+04$ & $3.95 E+04$ & $1.47 E-03$ & 3.73E- 08 \\
\hline Run 10 & 0.10 & 0.500 & 381 & 138 & 0.3510 & 31 & $3.53 E+04$ & $2.50 \mathrm{E}+04$ & $2.99 \mathrm{E}+04$ & $3.57 E-03$ & $1.20 \mathrm{E}-07$ \\
\hline Run_11 & 0.20 & 0.100 & 309 & 300 & 0.4830 & 28 & 4. $65 \mathrm{E}+04$ & $4.52 E+04$ & $4.59 \mathrm{E}+04$ & $1.29 \mathrm{E}-03$ & $2.82 \mathrm{E}-08$ \\
\hline Run_12 & 0.20 & 0.300 & 413 & 256 & 0.2990 & 55 & $2.55 E+04$ & $2.48 E+04$ & $2.52 E+04$ & 4.70E-04 & 1.87E-08 \\
\hline Run_13 & 0.20 & 0.500 & 358 & 100 & 0.4350 & 58 & $3.62 E+04$ & $3.49 E+04$ & $3.56 E+04$ & 5.09E-04 & 1.43E-08 \\
\hline Run_14 & 0.30 & 0.100 & 431 & 232 & 0.2030 & 34 & $1.95 E+04$ & $1.88 \mathrm{E}+04$ & $1.91 \mathrm{E}+04$ & 4.04E-04 & $2.11 \mathrm{E}-08$ \\
\hline Run_15 & 0.30 & 0.500 & 350 & 200 & 0.1500 & 45 & $1.35 E+04$ & $1.31 E+04$ & $1.33 E+04$ & $2.34 \mathrm{E}-04$ & $1.76 \mathrm{E}-08$ \\
\hline Run_16 & 0.30 & 0.500 & 350 & 200 & 0.1500 & 55 & $1.24 E+04$ & $1.21 E+04$ & $1.22 \mathrm{E}+04$ & 2.49E-04 & $2.04 \mathrm{E}-08$ \\
\hline Run_17 & 0.40 & 0.100 & 451 & 182 & 0.2890 & 43 & $2.67 E+04$ & $2.59 \mathrm{E}+04$ & $2.63 E+04$ & 3.63E-04 & $1.38 \mathrm{E}-08$ \\
\hline Run_18 & 0.40 & 0.300 & 558 & 170 & 0.3860 & 53 & $3.38 E+04$ & $3.31 E+04$ & $3.34 E+04$ & $2.96 \mathrm{E}-04$ & $8.86 \mathrm{E}-09$ \\
\hline Run_19 & 0.40 & 0.500 & 536 & 158 & 0.1650 & 47 & $1.49 E+04$ & $1.47 E+04$ & $1.48 E+04$ & $8.75 E-05$ & $5.92 \mathrm{E}-09$ \\
\hline Run_20 & 0.25 & 0.300 & 450 & 200 & 0.3250 & 42 & $3.01 E+04$ & $2.93 E+04$ & $2.97 E+04$ & $5.79 \mathrm{E}-04$ & $1.95 \mathrm{E}-08$ \\
\hline
\end{tabular}

Table 2 provides a summary of the first 20 test conditions for the $\mathrm{N}_{2} \mathrm{O}$ /MEA system. The gas flow rates vary over the range from 100 to $300 \mathrm{sccm}$, which is much lower than the 6 slpm typically used for reactive transport evaluation. The lower flow stems from the much slower transport, which is necessary to obtain a concentration shift that can be accurately determined to achieve an accurate value for $K_{G}$. Only the overall mass transfer coefficient $K_{G}$ is determined and reported as the model being validated includes both gas and liquid film transport phenomenon. Reported results are based on the GC analysis, although a comparison to the mass spectrometer analysis is conducted to check for consistency. In addition, tests are highlighted in yellow where the mass spectrometer analysis differed from the GC result by $15 \%$ to $25 \%$, while runs 7 and 13 are highlighted in pink because of the $>25 \%$ deviation between the GC and mass spectrometer result. The GC, the more sensitive and accurate analysis, is used to calculate the reported results, so it is not known if there is any issue with the highlighted results. The highlight's purpose is only to call attention to the possibility of error in case these appear to be outliers during model validation. During run No. 10 (data in red on Table 2), there was an unknown experimental error. Hence, any data for run No. 10 should not be used. The GC analysis detected oxygen in the sample, and the data based on the mass spectrometer indicated an abnormally high rate of transport.

\subsection{2 $\mathrm{CO}_{2} / \mathrm{MEA}$ system}

The mass transfer coefficient for a $\mathrm{CO}_{2} / \mathrm{MEA}$ system also can be calculated using Eq. (1), except the equilibrium $\mathrm{CO}_{2}$ pressure, $P_{\mathrm{CO}_{2}}^{*}$ must be taken into consideration in the log mean driving force, which is shown in Eq. (2).

$$
\Delta P=\frac{\left(P_{C_{2}, \text { in }}-P_{\mathrm{CO}_{2}}^{*}\right)-\left(P_{\mathrm{CO}_{2}, \text { in }}-P_{\mathrm{CO}_{2}}^{*}\right)}{\ln \left[\frac{P_{\mathrm{CO}_{2}, \text { in }}-P_{\mathrm{CO}_{2}}^{*}}{P_{\mathrm{CO}_{2}, \text { out }}-P_{\mathrm{CO}_{2}}^{*}}\right]}
$$


As shown in Figure 4, if $\mathrm{CO}_{2}$ loading exceeds $0.4, P^{*}$ may vary significantly for a small change in loading [6]. This makes the measurement of $P^{*}$ important for determining the $\log$ mean driving force.

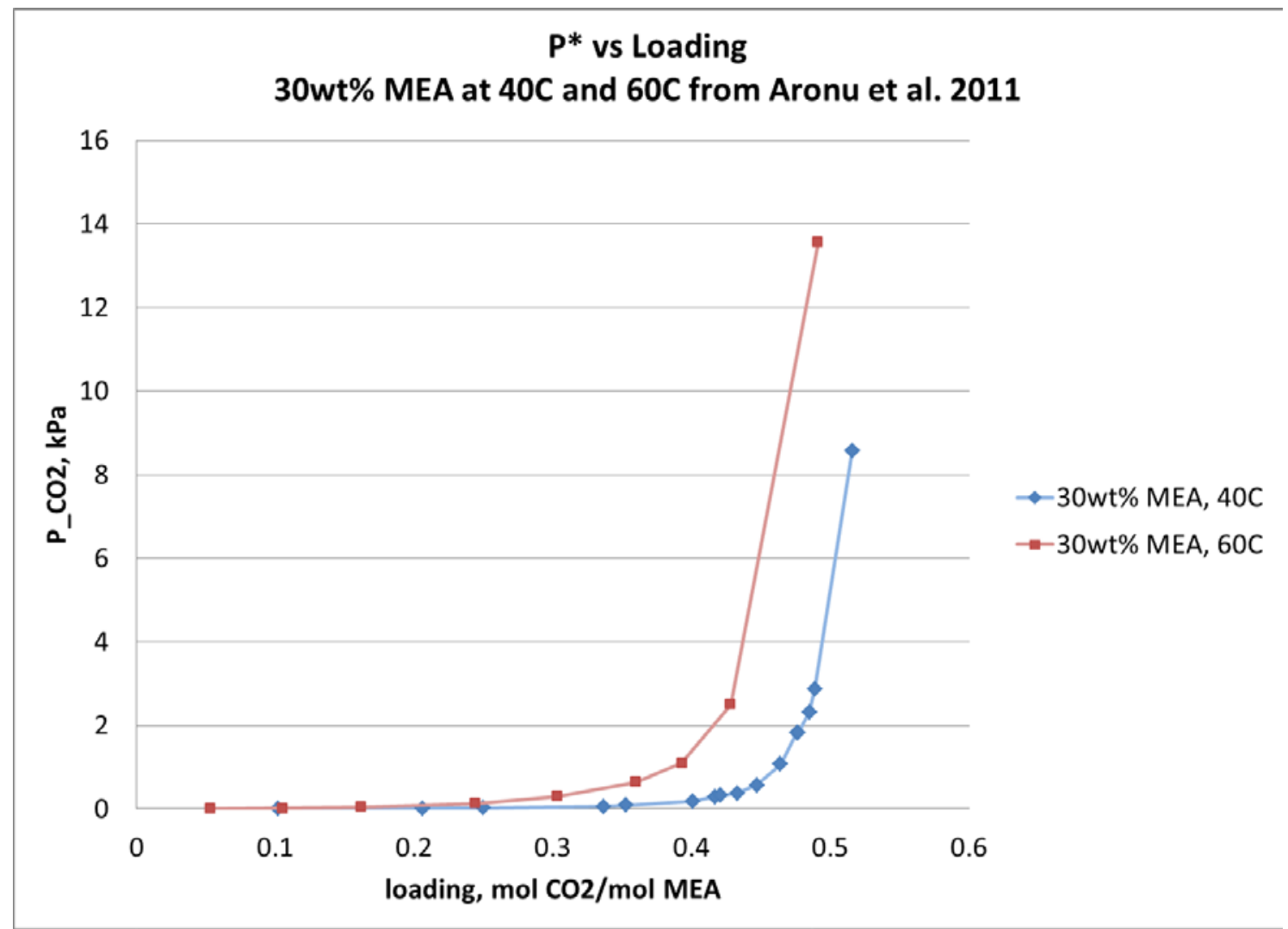

Figure $4 P^{*}$ versus $\mathrm{CO}_{2}$ Loading

Table 3 depicts the data for $\mathrm{CO}_{2}$-related measurements. The orange cells indicate the targeted test conditions. The teal cells provide the actual delivered flow based on the mass flow controller calibrations. These are quite close to the targeted flows and are provided so that the model validation can employ the most accurate value available. Included is a column for the $P^{*}$ used in calculating the driving force. Two approaches are engaged to determine the $P^{*}$ to be used in calculating the driving force. For solution loadings and temperatures that were expected to produce a $P^{*}$ less than $1.5 \%$ of the pressure in the gas phase, the $P^{*}$ value is zero. This could result in a small overestimate of the driving force, which would bias the overall mass transfer coefficient low by up to $1.5 \%$. However, this level of error was deemed to be within our experimental accuracy. If the $P^{*}$ is expected to be more than $1.5 \%$ of the overall driving force, then three points are taken, and the $\mathrm{x}$-axis intercept of a linear fit of the plot of flux versus $\mathrm{CO}_{2}$ pressure is used to estimate $P^{*}$. The $P^{*}$ is taking into account for run No. 26-28, 33-35, 40, 41, 48, 49, and 52. 
Table $3 \mathrm{CO}_{2} / \mathrm{MEA}$ Experimental Data

\begin{tabular}{|c|c|c|c|c|c|c|c|c|c|c|c|c|c|c|}
\hline \multicolumn{3}{|c|}{ Summary Table -All $\mathrm{CO} 2$ data } & & & & & & & \multicolumn{2}{|c|}{ Rev 2 Corrections in Yellow } & \multirow[b]{3}{*}{$\begin{array}{l}\text { P* used in } \\
\text { LMPD Calc }\end{array}$} & \multirow[b]{3}{*}{ LMPD } & \multirow[b]{3}{*}{ N_CO2 } & \multirow[b]{3}{*}{ KG } \\
\hline \multicolumn{9}{|c|}{ orange headers indicate the input values that defined the test to be run } & & & & & & \\
\hline Run\# & $\begin{array}{l}\text { MEA_content, } \\
\text { (mass fraction MEA } \\
\text { with water) }\end{array}$ & $\begin{array}{l}\text { CO2_Loadin } \\
\text { g. (mol CO2 } \\
\text { per mol } \\
\text { MEA) }\end{array}$ & $\begin{array}{l}\text { Solvent_Flow_ } \\
\text { Rate }\end{array}$ & $\begin{array}{l}\text { Gas. Flow Rate, sccm } \\
\text { (Includes N2 and CO2 } \\
\text { but not watervapor } \\
\text {-added to gas beforere } \\
\text { entering column) }\end{array}$ & $\begin{array}{l}\text { CO2_Molar_Conc (mole } \\
\text { fraction Co2 in gas } \\
\text { entering column prior } \\
\text { to humidification) }\end{array}$ & $\begin{array}{l}\text { As Delivered, Gas } \\
\text { Flow total }(\mathrm{N2}+\mathrm{CO} 2)\end{array}$ & $\begin{array}{l}\text { As delivered } \mathrm{CO} \\
\text { molar fraction (dry) }\end{array}$ & Temperature, $\mathrm{C}$ & P_CO2_in & P_CO2_out & & & & \\
\hline & mass fraction & $\mathrm{mol} / \mathrm{mol}$ & $\mathrm{cc} / \mathrm{min}$ & $\mathrm{sccm}$ & mol fraction & {$[\mathrm{sccm}]$} & mol fraction & ${ }^{\circ} \mathrm{C}$ & {$[\mathrm{Pa}]$} & {$[\mathrm{Pa}]$} & {$[\mathrm{Pa}]$} & {$[\mathrm{Pa}]$} & {$[\mathrm{mol} / \mathrm{m} 2 / \mathrm{s}]$} & {$[\mathrm{mol} / \mathrm{m} 2 / \mathrm{s} / \mathrm{Pa}]$} \\
\hline Run_21 & 0.25 & 0.30 & 450 & 4000 & 0.115 & 3959 & 0.1149 & 42 & $1.07 E+04$ & $9.14 E+03$ & 0 & $9.87 E+03$ & $1.30 \mathrm{E}-02$ & $1.32 \mathrm{E}-06$ \\
\hline Run_22 & 0.10 & 0.10 & 495 & 4344 & 0.070 & 4295 & 0.0695 & 45 & $6.36 \mathrm{E}+03$ & $5.37 E+03$ & 0 & $5.85 \mathrm{E}+03$ & $9.17 \mathrm{E}-03$ & $1.57 \mathrm{E}-06$ \\
\hline Run_23 & 0.10 & 0.20 & 590 & 2126 & 0.191 & 2083 & 0.1923 & 27 & $1.85 \mathrm{E}+04$ & $1.55 \mathrm{E}+04$ & 0 & $1.70 E+04$ & $1.47 \mathrm{E}-02$ & $8.64 \mathrm{E}-07$ \\
\hline Run_24 & 0.10 & 0.20 & 352 & 2724 & 0.086 & 2678 & 0.0855 & 49 & $7.58 \mathrm{E}+03$ & $6.31 E+03$ & 0 & $6.92 \mathrm{E}+03$ & $7.71 \mathrm{E}-03$ & $1.11 \mathrm{E}-06$ \\
\hline Run_25 & 0.10 & 0.30 & 550 & 2558 & 0.164 & 2520 & 0.1643 & 55 & $1.39 \mathrm{E}+04$ & $1.21 \mathrm{E}+04$ & 0 & $1.30 \mathrm{E}+04$ & $1.13 \mathrm{E}-02$ & $8.69 \mathrm{E}-07$ \\
\hline Run_26 & 0.10 & 0.40 & 318 & 2284 & 0.183 & 2240 & 0.1841 & 47 & $1.64 \mathrm{E}+04$ & $1.48 E+04$ & $1.18 \mathrm{E}+03$ & $1.44 \mathrm{E}+04$ & $8.71 \mathrm{E}-03$ & $6.04 E-07$ \\
\hline Run_27 & 0.10 & 0.40 & 404 & 3474 & 0.158 & 3426 & 0.1587 & 59 & $1.28 \mathrm{E}+04$ & $1.23 E+04$ & $6.14 \mathrm{E}+03$ & $6.42 E+03$ & $4.46 \mathrm{E}-03$ & $6.94 \mathrm{E}-07$ \\
\hline Run_28 & 0.10 & 0.50 & 558 & 2681 & 0.056 & 2634 & 0.0550 & 32 & $5.23 \mathrm{E}+03$ & $5.02 E+03$ & $1.39 \mathrm{E}+03$ & $3.73 \mathrm{E}+03$ & 1.10E-03 & 2.95E-07 \\
\hline Run_29 & 0.20 & 0.10 & 322 & 2342 & 0.032 & 2304 & 0.0301 & 30 & $2.87 \mathrm{E}+03$ & $2.18 E+03$ & 0 & $2.51 \mathrm{E}+03$ & 3.19E-03 & 1.27E-06 \\
\hline Run_30 & 0.20 & 0.20 & 426 & 3735 & 0.142 & 3694 & 0.1420 & 31 & $1.35 \mathrm{E}+04$ & $1.15 E+04$ & 0 & $1.25 \mathrm{E}+04$ & $1.65 \mathrm{E}-02$ & $1.32 \mathrm{E}-06$ \\
\hline Run_31 & 0.20 & 0.20 & 466 & 3899 & 0.064 & 3857 & 0.0632 & 38 & $5.89 \mathrm{E}+03$ & $4.92 E+03$ & 0 & $5.39 \mathrm{E}+03$ & $7.69 \mathrm{E}-03$ & 1.43E-06 \\
\hline Run_32 & 0.20 & 0.30 & 338 & 5549 & 0.134 & 5503 & 0.1341 & 53 & 1.16E+04 & $1.06 \mathrm{E}+04$ & 0 & $1.11 \mathrm{E}+04$ & $1.43 \mathrm{E}-02$ & $1.29 \mathrm{E}-06$ \\
\hline Run_33 & 0.20 & 0.40 & 410 & 3345 & 0.127 & 3300 & 0.1270 & 43 & 1.17E+04 & $1.07 E+04$ & $7.24 E+02$ & $1.05 E+04$ & 7.37E-03 & $7.06 \mathrm{E}-07$ \\
\hline Run_34 & 0.20 & 0.40 & 475 & 3635 & 0.043 & 3598 & 0.0421 & 56 & $3.56 \mathrm{E}+03$ & $3.51 E+03$ & $3.09 E+03$ & $4.42 E+02$ & $3.86 \mathrm{E}-04$ & $8.74 \mathrm{E}-07$ \\
\hline Run_35 & 0.20 & 0.50 & 521 & 2861 & 0.147 & 2816 & 0.1475 & 39 & $1.38 \mathrm{E}+04$ & $1.32 E+04$ & $2.45 E+03$ & 1.10E+04 & $3.92 \mathrm{E}-03$ & $3.56 \mathrm{E}-07$ \\
\hline Run_36 & 0.30 & 0.10 & 363 & 4682 & 0.106 & 4636 & 0.1059 & 41 & $9.88 \mathrm{E}+03$ & $8.04 E+03$ & 0 & $8.93 E+03$ & $1.85 \mathrm{E}-02$ & $2.08 \mathrm{E}-06$ \\
\hline Run_37 & 0.30 & 0.20 & 532 & 5130 & 0.175 & 5085 & 0.1753 & 33 & $1.68 \mathrm{E}+04$ & $1.48 \mathrm{E}+04$ & 0 & $1.57 \mathrm{E}+04$ & $2.41 \mathrm{E}-02$ & $1.53 \mathrm{E}-06$ \\
\hline Run_38 & 0.30 & 0.20 & 375 & 5241 & 0.049 & 5195 & 0.0486 & 56 & 4.14E+03 & $3.49 E+03$ & 0 & $3.80 \mathrm{E}+03$ & $7.77 \mathrm{E}-03$ & $2.04 \mathrm{E}-06$ \\
\hline Run_39 & 0.30 & 0.30 & 488 & 3107 & 0.110 & 3062 & 0.1098 & 52 & $9.61 \mathrm{E}+03$ & $7.99 E+03$ & 0 & $8.77 \mathrm{E}+03$ & 1.16E-02 & $1.33 \mathrm{E}-06$ \\
\hline Run_40 & 0.30 & 0.40 & 432 & 4189 & 0.102 & 4144 & 0.1018 & 41 & $9.46 \mathrm{E}+03$ & $8.65 E+03$ & $-8.20 E+00$ & $9.05 E+03$ & $7.40 \mathrm{E}-03$ & $8.17 \mathrm{E}-07$ \\
\hline Run_-41 & 0.30 & 0.40 & 458 & 4839 & 0.079 & 4799 & 0.0785 & 51 & $6.95 \mathrm{E}+03$ & $6.46 \mathrm{E}+03$ & $1.17 \mathrm{E}+03$ & $5.54 \mathrm{E}+03$ & $5.34 \mathrm{E}-03$ & $9.64 \mathrm{E}-07$ \\
\hline Run_42 & 0.30 & 0.50 & 308 & 5991 & 0.196 & 5942 & 0.1966 & 25 & $1.92 \mathrm{E}+04$ & $1.89 \mathrm{E}+04$ & 0 & $1.90 \mathrm{E}+04$ & $5.04 \mathrm{E}-03$ & 2.65E-07 \\
\hline Run_43 & 0.40 & 0.10 & 537 & 4431 & 0.116 & 4386 & 0.1158 & 46 & $1.06 \mathrm{E}+04$ & $8.23 E+03$ & 0 & $9.36 \mathrm{E}+03$ & $2.33 \mathrm{E}-02$ & 2.49E-06 \\
\hline Run_44 & 0.40 & 0.20 & 513 & 4066 & 0.121 & 4020 & 0.1211 & 36 & 1. $15 \mathrm{E}+04$ & $9.54 E+03$ & 0 & $1.05 E+04$ & 1.69E-02 & $1.61 \mathrm{E}-06$ \\
\hline Run_45 & 0.40 & 0.20 & 570 & 5673 & 0.179 & 5628 & 0.1794 & 59 & $1.52 \mathrm{E}+04$ & $1.29 E+04$ & 0 & $1.40 \mathrm{E}+04$ & $3.31 \mathrm{E}-02$ & $2.36 \mathrm{E}-06$ \\
\hline Run_46 & 0.40 & 0.30 & 378 & 5301 & 0.040 & 5259 & 0.0393 & 34 & $3.76 \mathrm{E}+03$ & $3.39 E+03$ & 0 & $3.57 E+03$ & $4.02 \mathrm{E}-03$ & $1.13 \mathrm{E}-06$ \\
\hline Run_47 & 0.40 & 0.40 & 588 & 5790 & 0.093 & 5742 & 0.0929 & 28 & $9.05 E+03$ & $8.51 E+03$ & 0 & $8.78 E+03$ & $6.44 \mathrm{E}-03$ & 7.34E- 07 \\
\hline Run_48 & 0.40 & 0.40 & 449 & 4869 & 0.153 & 4825 & 0.1532 & 49 & $1.39 \mathrm{E}+04$ & $1.28 E+04$ & $5.35 \mathrm{E}+02$ & $1.28 \mathrm{E}+04$ & $1.27 \mathrm{E}-02$ & 9.93E- 07 \\
\hline Run_49 & 0.40 & 0.50 & 395 & 3189 & 0.078 & 3145 & 0.0774 & 37 & $7.36 \mathrm{E}+03$ & $7.07 E+03$ & $1.84 \mathrm{E}+03$ & $5.38 \mathrm{E}+03$ & $1.74 \mathrm{E}-03$ & $3.23 \mathrm{E}-07$ \\
\hline Run_50 & 0.25 & 0.30 & 450 & 4000 & 0.115 & 3959 & 0.1149 & 42 & $1.06 \mathrm{E}+04$ & $9.15 E+03$ & 0 & $9.87 E+03$ & $1.30 \mathrm{E}-02$ & $1.31 \mathrm{E}-06$ \\
\hline Run_51 & 0.10 & 0.20 & 590 & 2126 & 0.191 & 2083 & 0.1923 & 27 & $1.85 E+04$ & $1.52 E+04$ & 0 & $1.68 \mathrm{E}+04$ & $1.58 \mathrm{E}-02$ & $9.41 \mathrm{E}-07$ \\
\hline Run_52 & 0.40 & 0.40 & 449 & 4869 & 0.153 & 4823 & 0.1532 & 49 & $1.38 \mathrm{E}+04$ & $1.27 E+04$ & $5.67 E+01$ & $1.32 E+04$ & $1.34 \mathrm{E}-02$ & $1.01 \mathrm{E}-06$ \\
\hline
\end{tabular}

\section{Numerical Modeling of WWC}

\subsection{General Theory on Mass Transport and Chemistry}

A volume of fluid (VOF) model is employed to solve for two Newtonian, incompressible, isothermal, and immiscible fluid flows by tracking the volume fraction $\left(\alpha_{i}\right)$ of each phase (the subscript $i=L$ or $g$ stands for liquid or gas phase) in the volume fraction equation. The volume fraction equation is introduced as

$$
\frac{\partial}{\partial t}\left(\alpha_{L}\right)+\nabla \cdot\left(\alpha_{L} \boldsymbol{u}\right)=0,
$$

where $\boldsymbol{u}=(u, v, w)$ denotes the velocity in $\mathrm{x}, \mathrm{y}$, and $\mathrm{z}$ direction, respectively. The volume fraction of gas phase $\alpha_{g}$ can be computed as

$$
\alpha_{g}=1-\alpha_{L}
$$

The continuity and Navier-Stokes equations are given by

$$
\begin{gathered}
\frac{\partial \rho}{\partial t}+\nabla \cdot(\rho \boldsymbol{u})=0, \\
\frac{\partial}{\partial t}(\rho \boldsymbol{u})+\nabla \cdot(\rho \boldsymbol{u} \boldsymbol{u})=-\nabla \mathrm{p}+\nabla \cdot\left[\mu\left(\nabla \boldsymbol{u}+\nabla \boldsymbol{u}^{T}\right)\right]+\rho \boldsymbol{g}-\boldsymbol{F}_{s t},
\end{gathered}
$$

where density $\rho$ and viscosity $\mu$ can be defined by a volume fraction averaged form as

$$
\begin{aligned}
& \rho=\alpha_{L} \rho_{L}+\alpha_{g} \rho_{g}, \\
& \mu=\alpha_{L} \mu_{L}+\alpha_{g} \mu_{g} .
\end{aligned}
$$

The surface tension force, $\boldsymbol{F}_{s t}$ in Eq. (4) can be expressed using the continuum surface force (CSF) model proposed by Brackbill et al. [7]:

$$
\boldsymbol{F}_{s t}=\frac{\sigma_{s t} \rho \kappa \nabla \alpha_{L}}{2\left(\rho_{L}+\rho_{g}\right)}
$$


where $\sigma_{s t}$ is the surface tension coefficient, $\kappa=-\nabla \cdot \widetilde{\boldsymbol{n}}$ represents the curvature of the surface, and $\widetilde{\boldsymbol{n}}$ is the unit interface normal vector, which can be defined as

$$
\widetilde{\boldsymbol{n}}=\frac{\boldsymbol{n}}{|\boldsymbol{n}|},
$$

where $\boldsymbol{n}=\left(n_{x}, n_{y}, n_{z}\right)=-\nabla \alpha_{L}$ is the vector along the interface normal.

The one-fluid equation [8] considering convection, diffusion, interface mass transport, and chemical reactions will be implemented to calculate gas concentration in both phases by using only one equation for the entire domain:

where

$$
\frac{\partial c_{i}}{\partial t}+\nabla \cdot\left(\boldsymbol{u} c_{i}-\mathrm{D}_{i} \nabla c_{i}-\Gamma_{i}\right)-W_{i}=0
$$

$$
\begin{gathered}
\Gamma_{i}=-\mathrm{D}_{i} \frac{c_{i}\left(1-k_{i}\right)}{\alpha_{L}+k_{i}\left(1-\alpha_{L}\right)} \nabla \alpha_{L}, \\
D_{i}=\frac{D_{i, L} D_{i . g}}{\alpha_{L} D_{i, g}+\left(1-\alpha_{L}\right) D_{i, L}}
\end{gathered}
$$

Here, $c_{i}$ represents the concentration for species $i$. The diffusivity $D_{i}$ is computed by the harmonic interpolation, $k_{i}=c_{i, g}^{I} / c_{i, L}^{I}$ denotes the dimensionless Henry's constant, where $c_{i, g}^{I}$ and $c_{i, L}^{I}$ are the gas phase and liquid phase concentration of species $i$ at the gas-liquid interface. Please note that the concentration of any species in gas and liquid phase normally has a discontinuity across the interface because of the different solubility in each phase. The term $\Gamma$ in Eq. (11) accounts for this discontinuity unless $\Gamma$ approaches zero for $k_{i}=1$ (same solubility in both phases). The last term $W_{i}$ is the production term is related to the chemical reaction.

The chemical reactions of $\mathrm{CO}_{2}$ absorption by MEA have been extensively investigated and three sub-reactions indicate vital influence on the $\mathrm{CO}_{2} / \mathrm{MEA}$ reaction $[9,10]$. They can be expressed as:
Carbamate formation:
$\mathrm{CO}_{2}+2 \mathrm{RNH}_{2} \rightarrow \mathrm{RNHCOO}^{-}+\mathrm{RNH}_{3}^{+}$
Bicarbonate formation:
$\mathrm{CO}_{2}+\mathrm{RNH}_{2}+\mathrm{H}_{2} \mathrm{O} \rightarrow \mathrm{HCO}_{3}^{-}+\mathrm{RNH}_{3}^{+}$
Carbamate reversion:
$\mathrm{RNHCOO}^{-}+\mathrm{CO}_{2}+2 \mathrm{H}_{2} \mathrm{O} \rightarrow \mathrm{HCO}_{3}^{-}+2 \mathrm{RNH}_{3}^{+}$,

where $\mathrm{R}=\mathrm{CH}_{2} \mathrm{CH}_{2} \mathrm{OH}$. It is suggested by Astarita et al. [9] that the rate of bicarbonate formation is negligible because of MEA carbamate's high stability. In addition, the overall absorption rate can be approximated as irreversible, making the carbamate reversion insignificant. As a result, the overall $\mathrm{CO}_{2}$ /MEA reaction rate will dominate by the carbamate formation.

When chemical equilibrium state is reached in the liquid phase, the chemical equilibrium reaction and equilibrium constant of the carbamate formation can be written as

$$
\begin{gathered}
\mathrm{RNHCOO}^{-}+\mathrm{RNH}_{3}^{+} \stackrel{\mathrm{K}_{\mathrm{CO}_{2}}^{\prime}}{\Longleftrightarrow} \mathrm{CO}_{2}(\mathrm{aq})+2 \mathrm{RNH}_{2} \\
\mathrm{~K}_{\mathrm{CO}_{2}}^{\prime}=\frac{\left[\mathrm{CO}_{2}(\mathrm{aq})\right]\left[\mathrm{RNH}_{2}\right]^{2}}{\left[\mathrm{RNHCOO}^{-}\right]\left[\mathrm{RNH}_{3}^{+}\right]^{\prime}}
\end{gathered}
$$


where $\mathrm{CO}_{2}(\mathrm{aq})$ denotes the absorbed $\mathrm{CO}_{2}$ in aqueous solution of MEA and $\mathrm{K}_{\mathrm{CO}_{2}}^{\prime}$ is the chemical equilibrium constant for $\mathrm{CO}_{2}$ absorption reaction. The molar fraction of MEA and the products can be introduced as

$$
\begin{aligned}
{\left[\mathrm{RNH}_{2}\right] } & =(1-2 \alpha) x, \\
{\left[\mathrm{RNHCOO}^{-}\right] } & =\left[\mathrm{RNH}_{3}^{+}\right]=\alpha x,
\end{aligned}
$$

where $\alpha$ is the $\mathrm{CO}_{2}$ loading (mol of $\mathrm{CO}_{2} / \mathrm{mol}$ of MEA) and $x$ is the MEA molar fraction (mol of MEA/(mol of $\mathrm{H}_{2} \mathrm{O}+$ mol of MEA $)$ ).

Upon substituting Eqs. (13) and (14) back to Eq. (12), the molar fraction of $\mathrm{CO}_{2}$ dissolved in the MEA solution can be written as

$$
\left[\mathrm{CO}_{2}(a q)\right]=K_{\mathrm{CO}_{2}}^{\prime} \frac{\alpha^{2}}{(1-2 \alpha)^{2}} .
$$

By applying Henry's law, the partial pressure of $\mathrm{CO}_{2}$ can be expressed as

$$
p_{\mathrm{CO}_{2}}=K_{\mathrm{CO}_{2}} \frac{\alpha^{2}}{(1-2 \alpha)^{2}}
$$

where $\mathrm{K}_{\mathrm{CO}_{2}}=\mathrm{K}_{\mathrm{CO}_{2}}^{\prime} \mathrm{H}$ represents the combined Henry's law and chemical equilibrium constant for $\mathrm{CO}_{2}$ partial pressure $(\mathrm{kPa})$ and $H$ is the Henry's constant $(\mathrm{kPa})$. The expression for $\mathrm{K}_{\mathrm{CO}_{2}}$ is given by Gabrielsen et al. [11]:

$$
\ln K_{\mathrm{CO}_{2}}=\mathrm{A}+\frac{B}{\mathrm{~T}}+\mathrm{C} \alpha x,
$$

where $A$ and $B$ denote the standard temperature dependence of the chemical equilibrium constant, and $C$ represents the nonidealities in the system caused by $\mathrm{CO}_{2}$ loading. Table 4 lists the regressed parameters for equilibrium constant.

Table 4 Regressed Parameter for Equilibrium Constant $\mathrm{K}_{\mathrm{CO}_{2}}$

\begin{tabular}{|c|c|c|c|}
\hline & A & B & C \\
\hline Value & $30.96 \pm 1.86$ & $-10584 \pm 670$ & $-7.187 \pm 4.27$ \\
\hline
\end{tabular}

Then, equilibrium aqueous $\mathrm{CO}_{2}$ concentration dissolved in MEA solution, $c_{\mathrm{CO}_{2}(a q)}$ can be computed as

$$
c_{\mathrm{CO}_{2}(a q)}=\frac{p_{\mathrm{CO}_{2}}}{R T} \frac{1}{k}
$$

where $k$ is the dimensionless Henry's constant.

The chemical reaction related term in Eq. (11) then can be computed as

$$
W_{\mathrm{CO}_{2}}=\mathrm{r}\left(c_{\mathrm{CO}_{2}}-c_{\mathrm{CO}_{2}(\mathrm{aq})}\right) c_{\mathrm{MEA}} \alpha_{\mathrm{L}} \text {. }
$$

The reaction rate constant $r(l / \mathrm{mol} \cdot s)$ in Eq. (19) then can be calculated based on the correlation proposed by Hikita et al. [12]:

$$
\log _{10} r=10.99-2152 / T \text {. }
$$

By introducing the equilibrium $\mathrm{CO}_{2}$ concentration, $c_{\mathrm{CO}_{2}(a q)}$, the numerical model has the ability to simulate both chemical absorption and desorption of $\mathrm{CO}_{2}$ in MEA. Also, for nonreactive gas absorption across liquid films, the reaction rate constant $r$ needs to be set to zero to drop the chemical-reaction-related term $W$ in Eq. (11). 


\subsection{Calculation of Model Input Parameters}

The input parameters used in the CFD modeling include MEA solvent density, MEA solvent kinematic viscosity, gas diffusivity in solvent, gas Henry's constant in solvent, MEA diffusivity in solvent, gas density, gas dynamics viscosity, gas diffusivity, and surface tension. The values of these parameters are taken from literature.

\subsubsection{MEA Solvent Density}

MEA solution density is calculated by the average molecular weight divided by its overall molar volume.

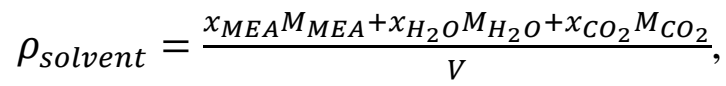

where $\rho_{\text {solvent }}$ is solvent density $(\mathrm{g} / \mathrm{mL}), V$ is molar volume of the solvent $(\mathrm{mL} / \mathrm{mol}), x$ is molar fraction, and $M$ is molecular weight $(\mathrm{g} / \mathrm{mol})$.

The solvent's molar volume can be expressed as [3]:

where

$$
V=x_{M E A} V_{M E A}+x_{\mathrm{H}_{2} \mathrm{O}} V_{\mathrm{H}_{2} \mathrm{O}}+x_{\mathrm{CO}_{2}} V_{\mathrm{CO}_{2}}+x_{M E A} x_{\mathrm{H}_{2} \mathrm{O}} V^{*}
$$

$$
V_{M E A}=\frac{M_{M E A}}{a T^{2}+b T+c} .
$$

Table 5 provides the parameters used in preceding equation.

Table 5 Parameters for Solvent Density Correlation

\begin{tabular}{|l|l|l|c|c|c|}
\hline $\mathrm{a}$ & $\mathrm{b}$ & $\mathrm{c}$ & $V_{\mathrm{H}_{2} \mathrm{O}}$ & $V_{\mathrm{CO}_{2}}$ & $V^{*}$ \\
\hline$-5.35162 \times 10^{-7}$ & $-4.51417 \times 10^{-4}$ & 1.19451 & 18.02 & 0.04747 & -1.8218 \\
\hline
\end{tabular}

\subsubsection{MEA Solvent Kinematic Viscosity}

The solvent dynamics viscosity of MEA (Pa.s) is obtained from [3]:

$$
\mu_{\text {solvent }}=\exp \left\{\frac{(21.186 w+2373)[\alpha(0.01015 w+0.0093 T-2.2589)+1] w}{T^{2}}\right\} \mu_{w a t e r}
$$

where $w$ is the mass percentage of MEA, $T$ is the temperature in Kelvin, $\alpha$ is the $\mathrm{CO}_{2}$ loading, and $\mu_{\text {water }}$ is a function of temperature which can be expressed as

$$
\mu_{\text {water }}=A \times 10^{B /(T-C)}
$$

with $A=2.414 \times 10^{-5} \mathrm{~Pa} \cdot \mathrm{s}, B=247.8 \mathrm{~K}$, and $C=140 \mathrm{~K}$.

The kinematic viscosity of solvent $\left(\mathrm{m}^{2} / \mathrm{s}\right)$ can therefore be expressed as

$$
v_{\text {solvent }}=\frac{\mu_{\text {solvent }}}{\rho_{\text {solvent }}} \text {. }
$$

\subsubsection{Gas Diffusivity in Solvent}

The diffusivity $\left(\mathrm{m}^{2} / \mathrm{s}\right)$ of $\mathrm{N}_{2} \mathrm{O}$ and $\mathrm{CO}_{2}$ in water can be computed as [2] [13]:

$$
\begin{aligned}
& D_{\mathrm{N}_{2} \mathrm{O}, \text { water }}=5.07 \times 10^{-6} \exp \left(\frac{-2371}{T}\right), \\
& D_{\mathrm{CO}_{2}, \text { water }}=2.35 \times 10^{-6} \exp \left(\frac{-2119}{T}\right),
\end{aligned}
$$

where $T$ is the temperature in Kelvin. 
The diffusivity of $\mathrm{CO}_{2}$ in MEA solution can be computed as [13]:

$$
D_{\mathrm{CO}_{2}, M E A}=D_{\mathrm{CO}_{2}, \text { water }}\left(\frac{\mu_{\text {water }}}{\mu_{\text {solvent }}}\right)^{0.8} \text {. }
$$

The diffusivity of $\mathrm{N}_{2} \mathrm{O}$ in MEA solution can be computed as [2]:

$$
D_{N_{2} O}, M E A=D_{C O_{2}, M E A} \frac{D_{N_{2} O}, \text { water }}{D_{C O_{2}}, \text { water }} \text {. }
$$

\subsubsection{Gas Henry's Constant in Solvent}

The dimensionless Henry's constant of $\mathrm{N}_{2} \mathrm{O}$ and $\mathrm{CO}_{2}$ in water can be computed as [2] [13]:

$$
\begin{gathered}
H_{N_{2} O}, \text { water }=R T / 8.5470 \times 10^{-6} \exp \left(\frac{-2284}{T}\right) \\
H_{C_{2}, \text { water }}=R T / 2.8249 \times 10^{-6} \exp \left(\frac{-2044}{T}\right),
\end{gathered}
$$

where $R$ is the ideal gas constant $(\mathrm{J} / \mathrm{K} \cdot \mathrm{mol})$ and $T$ is the temperature $(\mathrm{K})$.

The dimensionless Henry's constant of $\mathrm{CO}_{2}$ in MEA solution can be computed as [13]:

$$
H_{C_{2}, M E A}=0.01 R T / 10^{\left(5.3-0.035 c_{M E A}-1140 / T\right)},
$$

where $c_{M E A}$ is the MEA molar concentration $\left(\mathrm{mol} / \mathrm{m}^{3}\right)$.

The dimensionless Henry's constant of $\mathrm{N}_{2} \mathrm{O}$ in MEA solution can be computed as [2]:

$$
\mathrm{H}_{\mathrm{N}_{2} \mathrm{O}, \mathrm{MEA}}=\mathrm{H}_{\mathrm{CO}_{2}, \mathrm{MEA}} \frac{\mathrm{H}_{\mathrm{N}_{2} \mathrm{O}, \text { water }}}{\mathrm{H}_{\mathrm{CO}_{2}, \text { water }}} \text {. }
$$

\subsubsection{MEA Diffusivity in Solvent}

The diffusivity of MEA in solvent $\left(\mathrm{m}^{2} / \mathrm{s}\right)$ with the operative range of the temperature and MEA concentration can be described as [14]:

$$
\ln \left(D_{M E A}\right)=-13.275-\frac{2198.3}{T}-7.8142 e^{-5} c,
$$

where

$$
\begin{gathered}
43<c<5016 \mathrm{~mol} / \mathrm{m}^{3}, \\
298<T<333 \mathrm{~K} .
\end{gathered}
$$

\subsubsection{Gas Density}

Assuming the gas input into the domain is a gas mixture, the mixture's density $\left(\mathrm{kg} / \mathrm{m}^{3}\right)$ can be expressed as

$$
\rho_{\text {gas }}=\frac{c_{i}}{x_{i}} \sum x_{i} M_{i}
$$

where $x_{i}$ is the molar fraction of the species $i, c_{i}$ is the molar concentration $\left(\mathrm{mol} / \mathrm{m}^{3}\right)$, and $M_{i}$ is the molar mass $(\mathrm{kg} / \mathrm{mol})$.

\subsubsection{Gas Dynamics Viscosity}

For a multicomponent gas system, the general dynamics viscosity (Pa·s) can be expressed as [15]: 


$$
\mu_{\text {gas }}=\sum_{i=1}^{n} \frac{\mu_{i}}{1+\frac{1}{x_{i}} \sum_{\substack{j=1 \\ j \neq i}}^{n} x_{j} \phi_{i j}}
$$

where

$$
\phi_{i j}=\frac{\left[1+\left(\mu_{i} / \mu_{j}\right)^{1 / 2}\left(M_{i} / M_{j}\right)^{1 / 4}\right]^{2}}{4 \sqrt{2}\left[1+\left(M_{i} / M_{j}\right)\right]^{1 / 2}},
$$

$x$ is the molar fraction of, $\mu$ is dynamics viscosity $(\mathrm{Pa} \cdot \mathrm{s})$, and $M$ is molar mass $(\mathrm{g} / \mathrm{mol})$.

\subsubsection{Gas Diffusivity}

The binary diffusion coefficient can be determined from the Chapman-Enskog theory [16]:

$$
D_{\mathrm{i}, \mathrm{j}}=0.0018583\left(\frac{1}{M_{i}}+\frac{1}{M_{j}}\right)^{1 / 2} \frac{T^{2 / 3}}{P \epsilon_{\mathrm{i}, \mathrm{j}}^{2} \Omega_{D}}
$$

where $M$ is molar weight (g/mol), $P$ is pressure (atm), $\epsilon_{\mathrm{i}, \mathrm{j}}$ is the collision diameter in $\AA$, and $\Omega_{D}$ is collision integral. The equations for calculating $\epsilon_{\mathrm{i}, \mathrm{j}}$ and $\Omega_{D}$ can be expressed as

$$
\begin{gathered}
\epsilon_{\mathrm{i}, \mathrm{j}}=\frac{\epsilon_{\mathrm{i}}+\epsilon_{\mathrm{j}}}{2} \\
\Omega_{D}=\frac{1.06}{t^{0.156}}+\frac{0.193}{\exp (0.476 t)}+\frac{1.036}{\exp (1.53 t)}+\frac{1.765}{3.894 \mathrm{t}},
\end{gathered}
$$

where $t$ is determined by

$$
\mathrm{t}=\frac{\mathrm{k}_{\mathrm{B}} \mathrm{T}}{\xi_{\mathrm{i}, \mathrm{j}}}
$$

The Boltzmann constant $\mathrm{k}_{\mathrm{B}}=1.38066 \times 10^{-23}\left(\mathrm{~J} \cdot \mathrm{K}^{-1}\right)$, and $\xi_{\mathrm{i}, \mathrm{j}}$ is the Lennard-Jones potential energy function that can be expressed as

$$
\xi_{i, j}=\sqrt{\xi_{i} \xi_{j}}
$$

Table 6 includes listed $\epsilon_{\mathrm{i}}$ and $\xi_{\mathrm{i}} / \mathrm{k}_{\mathrm{B}}$ values for several commonly used gases [16].

Table $6 \sigma_{\mathrm{i}}$ and $\xi_{\mathrm{i}} / \mathbf{k}_{\mathrm{B}}$ Values

\begin{tabular}{|c|l|l|l|l|l|l|l|}
\hline & $\mathrm{N}_{2}$ & $\mathrm{O}_{2}$ & $\mathrm{CH}_{4}$ & $\mathrm{H}_{2} \mathrm{O}$ & $\mathrm{CO}$ & $\mathrm{H}_{2}$ & $\mathrm{CO}_{2}$ \\
\hline$\epsilon_{\mathrm{i}}$ & 3.798 & 3.467 & 3.758 & 2.641 & 3.69 & 2.827 & 3.941 \\
\hline$\xi_{\mathrm{i}} / \mathrm{k}_{\mathrm{B}}$ & 71.4 & 106.7 & 148.6 & 809.1 & 91.7 & 59.7 & 195.2 \\
\hline
\end{tabular}

\subsubsection{Surface Tension}

The surface tension $\left(\mathrm{kg} / \mathrm{s}^{2}\right)$ of MEA solution can be expressed as [17]:

$$
\begin{gathered}
\sigma=x_{\mathrm{H}_{2} \mathrm{O}} \sigma_{\mathrm{H}_{2} \mathrm{O}}+x_{M E A} \sigma_{M E A}+\left[-0.567+1.05 w_{M E A}-\right. \\
\left.0.552 w_{M E A}^{2}\right] T x_{\mathrm{H}_{2} \mathrm{O}} x_{M E A}+\left[6175.83 w_{\text {ref } 1}+2828.87 w_{r e f 1}^{2}\right] / T+ \\
27494.72 \alpha w_{\text {ref } 2} / T
\end{gathered}
$$


where

$$
\begin{gathered}
w_{\text {ref } 1}=\frac{\frac{\alpha w_{M E A}{ }^{M} C O_{2}}{M_{M E A}}+\alpha w_{M E A} / \alpha_{\max }}{1+\frac{\alpha w_{M E A^{M} C O_{2}}}{M_{M E A}}}, \\
w_{\text {ref } 2}=\frac{1-\alpha / \alpha_{\max }}{1+\frac{\alpha w_{M E A^{M} C O_{2}}}{M_{M E A}}}
\end{gathered}
$$

$w$ is mass fraction, $x$ is molar fraction, $\alpha$ is $\mathrm{CO}_{2}$ loading, $T$ is operating temperature $(\mathrm{K}), M$ is molar mass $(\mathrm{g} / \mathrm{mol}), \sigma_{i}$ is the surface tension of pure component $i$ at operating temperature, and $\alpha_{\max }$ is the maximum $\mathrm{CO}_{2}$ loading. $\alpha_{\max }$ is a function of both temperature and MEA mass fraction, and the value of $\alpha_{\max }$ can be found in [17].

\subsection{CFD Model Setup}

\subsubsection{Geometry}

Figure 5 shows the counter-current gas flow geometry with solvent falling down the vertical wall, which resembles the experimental WWC device in Figure 2. The solvent inlet and outlet are respectively located at the top-left and bottom-left corners, while the gas inlet and outlet are located at the bottom-right and top-right corners. The wall height, $H$, is 90.9 $\mathrm{mm}$, and the width, $W$, is $5.25 \mathrm{~mm}$. Inlet and outlet sizes for both gas and solvent are set to be $1 \mathrm{~mm}$, except for non-reactive $\mathrm{N}_{2} \mathrm{O}$ absorption across MEA where the solvent outlet size is set to $2 \mathrm{~mm}$. To capture the change of mass transfer from gas to solvent, Section 2 explains how gas flow rates for the non-reactive $\mathrm{N}_{2} \mathrm{O}$ /MEA system must be one order of magnitude smaller than that of the reactive system, and the small gas flow rate usually varies between 100-300 sccm. However, if this small gas flow rate is implemented in a numerical simulation, the $1 \mathrm{~mm}$ solvent outlet will not be large enough to allow solvent to exit, hence there will be liquid accumulation of liquid at the bottom of the geometry. To be more specific, when it starts falling from the solvent inlet, the leading edge of the solvent flow forms a teardrop shape and continues developing its size along the wall toward the outlet. At some point, the thickness of solvent leading edge will be greater than the solvent outlet, eventually triggering solvent flooding. Therefore, the solvent outlet must be increased to avoid solvent flooding. Hence, a $2 \mathrm{~mm}$ solvent outlet is selected after several testing runs.

The relationship between the flow rate and inlet velocity for gas and solvent can be computed as

$$
\begin{gathered}
V_{L}=v_{L} \pi\left\{\left(11.5 \times 10^{-3}\right)^{2}-\left[\left(11.5-L_{L}\right) \times 10^{-3}\right]^{2}\right\} \\
V_{g}=v_{g} \pi\left\{\left(11.5 \times 10^{-3}\right)^{2}-\left[\left(11.5-L_{g}\right) \times 10^{-3}\right]^{2}\right\},
\end{gathered}
$$

where $V$ represents the volumetric flow rate $\left(\mathrm{m}^{3} / \mathrm{s}\right), v$ is the velocity $(\mathrm{m} / \mathrm{s}), L$ is the inlet size (m), and subscript $L$ or $g$ represents solvent or gas. 


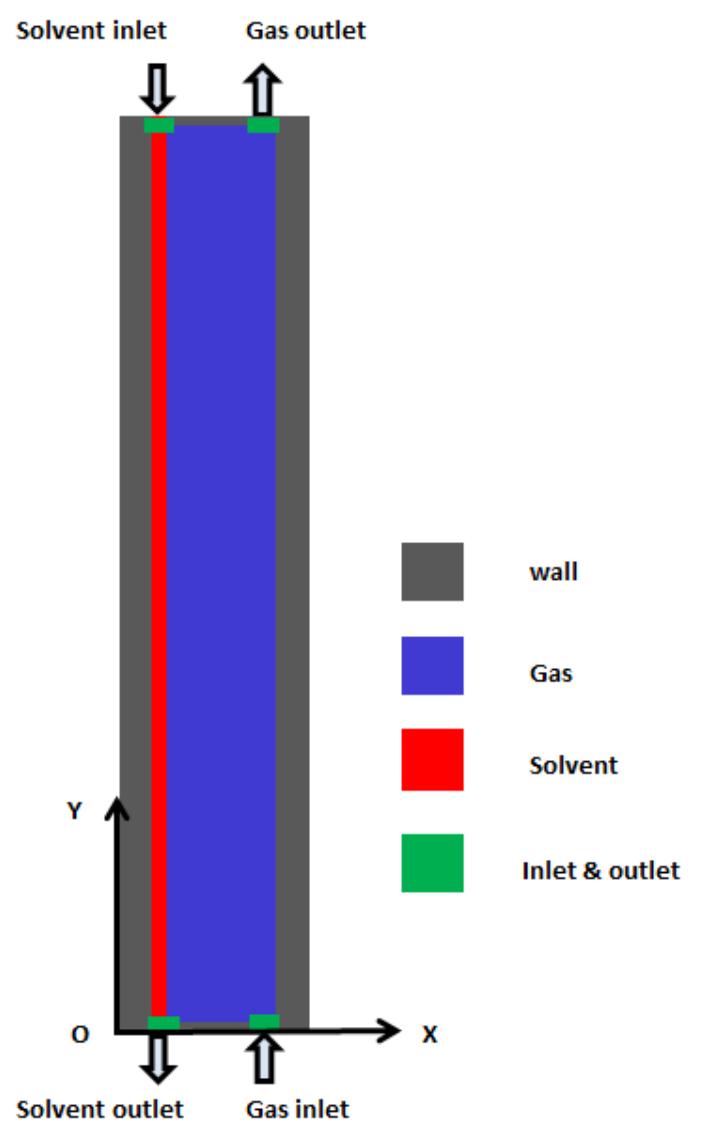

Figure 5 Countercurrent Gas Flow Geometry Schematics

\subsubsection{Boundary and Initial Conditions}

The boundary condition for the left, right, bottom, and top walls is set to be a non-slip condition. At the solvent inlet, a laminar flow velocity, together with the concentrations of solvent species, should be given. At the solvent outlet, the mass concentration gradient $(d c / d y=0)$ is given at zero because the flow is assumed to be fully developed [18]. For the gas inlet, concentrations of gas species, as well as gas inlet velocity, should be specified. For incompressible flow, relative pressure (pressure difference), rather than absolute pressure, is more important. Therefore, the pressure value at the gas outlet is set to zero.

For initial conditions, the testing domain is placed at zero atm pressure, and the domain is filled with a given concentration of gases.

\subsubsection{Input Parameters of the CFD model}

Table 7 lists six controlled parameters. Note that these parameters also serve as controlled operational conditions for the WWC experiments. 
Table 7 Controlled Input Parameters

\begin{tabular}{|l|l|}
\hline \multicolumn{1}{|c|}{ Parameters } & \multicolumn{1}{c|}{ Unit } \\
\hline MEA mass fraction & dimensionless \\
\hline MEA $\mathrm{CO}_{2}$ loading & $\left(\mathrm{mol}\right.$ of $\mathrm{CO}_{2} / \mathrm{mol}$ of $\left.\mathrm{MEA}\right)$ \\
\hline Solvent flow rate & $\mathrm{ml} / \mathrm{min}$ \\
\hline Gas flow rate & $\mathrm{sccm}$ \\
\hline Operating temperature & ${ }^{\circ} \mathrm{C}$ \\
\hline Gas inlet molar fraction & dimensionless \\
\hline
\end{tabular}

For any given controlled parameters, the model input parameters listed in Table 8 can be calculated from the equations introduced in Section 3.2.

Table 8 Direct Model Input Parameters

\begin{tabular}{|l|l|}
\hline \multicolumn{1}{|c|}{ Parameters } & \multicolumn{1}{|c|}{ Unit } \\
\hline Solvent inlet velocity & $\mathrm{m} / \mathrm{s}$ \\
\hline Gas inlet velocity & $\mathrm{m} / \mathrm{s}$ \\
\hline Inlet concentration (solvent, gas) & $\mathrm{mol} / \mathrm{m}^{3}$ \\
\hline Diffusivity (solvent, gas) & $\mathrm{m}^{2} / \mathrm{s}$ \\
\hline Gas diffusivity in solvent & $\mathrm{m}^{2} / \mathrm{s}$ \\
\hline Solvent contact angle & 40 (fixed) \\
\hline Density (solvent, gas) & $\mathrm{kg} / \mathrm{m}^{3}$ \\
\hline Kinematic viscosity (solvent, gas) & $\mathrm{m}^{2} / \mathrm{s}$ \\
\hline Surface tension & $\mathrm{kg} / \mathrm{s}^{2}$ \\
\hline Henry's constant & Dimensionless \\
\hline CO 2 absorption rate constants & $\mathrm{l} / \mathrm{mol}^{3} \mathrm{~s}$ \\
\hline Equilibrium CO 2 concentration & $\mathrm{mol} / \mathrm{m}^{3}$ \\
\hline
\end{tabular}




\subsubsection{Computational Methods}

The multiphase flow solver InterFOAM in the OpenFOAM CFD software package is customized so that the one-fluid formulation can be solved and coupled with the continuity, momentum, and volume fraction equations. All cases are simulated until a steady-state condition is reached.

A mesh sensitivity study was performed by $\mathrm{Hu}$ et al. [19] and $\mathrm{Xu}$ et al. [20]. They concluded that the mesh size of $0.1 \mathrm{~h}$ (where $\mathrm{h} \sim 0.4 \mathrm{~mm}$ is the average film thickness) is sufficient to capture wave behavior of the liquid film. Based on their studies, we have adopted the mesh size to be $0.0125 \mathrm{~mm}$ between $\mathrm{x}=0$ and $1 \mathrm{~mm}$ (Figure 6, Section 1), which is $\sim 0.035 \mathrm{~h}$. As such, the simulation results are not affected by the mesh size, yet they still are computationally affordable. For $x=4.25-5.25 \mathrm{~mm}$ (Figure 6, Section 3), a coarse mesh size is selected to be $0.05 \mathrm{~mm}$. Between $\mathrm{x}=1$ and $4.25 \mathrm{~mm}$ (Figure 6, Section 2), a total of 120 non-uniform mesh grids with the same expansion ratio are employed to make the ratio of the last grid to the first grid in this region equal to 4 . In the y direction, a total of 1,000 grids are uniformly distributed in the domain. The maximum time step size is adjusted to be $10^{-5}$ seconds for the current simulation after several testing runs. OpenFOAM dynamically adjusts the actual time step. It takes about nine CPU hours for 16 processors to run 1 second of simulation.

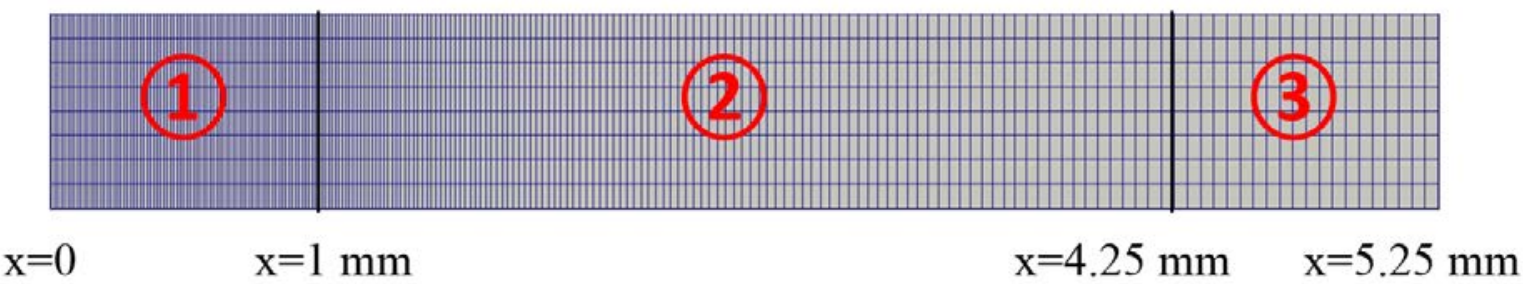

Figure 6 Mesh Size Distribution in $\mathrm{x}$ Direction

\subsection{Calculation of Overall Mass Transfer Coefficient}

\subsection{1 $\mathrm{N}_{2} \mathrm{O} / \mathrm{MEA}$ System}

The overall mass transfer coefficient, $K_{G}\left(\mathrm{~mol} / \mathrm{Pa} \cdot \mathrm{s} \cdot \mathrm{m}^{2}\right)$ can be calculated via Eq. (1). By applying the ideal gas law, $\Delta P$ can be written as a function of temperature and $\mathrm{N}_{2} \mathrm{O}$ concentration at the gas inlet and outlet:

$$
\Delta P=\frac{\left(c_{N_{2} O, \text { in }}-c_{N_{2} O, \text { out }}\right) R T}{\ln \left[\frac{c_{N_{2} O, \text { in }}}{c_{N_{2} O, \text { out }}}\right]},
$$

where $R$ is the ideal gas constant $(\mathrm{J} / \mathrm{K} \cdot \mathrm{mol})$ and $T$ is the temperature in the unit of $\mathrm{K}$.

Based on the conservation law, the amount of $\mathrm{N}_{2} \mathrm{O}$ dissolved in MEA from the gas-liquid interface should be identical to the amount of $\mathrm{N}_{2} \mathrm{O}$ removed by MEA from the solvent outlet. Therefore, the mass transfer flux $J\left(\mathrm{~mol} / \mathrm{m}^{2} \cdot \mathrm{s}\right)$ at gas-liquid interface can be calculated as

$$
J=\frac{\int_{0}^{x=a} \alpha_{L} c_{N_{2}} o\left|u_{y}\right| d x}{H},
$$

where $a$ is the size of the solvent outlet, $\alpha_{L}$ is liquid phase volume fraction, $\left|u_{y}\right|$ is the velocity magnitude in y direction, and $H$ is the domain height.

A discontinuous jump of $\mathrm{N}_{2} \mathrm{O}$ concentration at the gas-liquid interface is physically anticipated because of the different solubility of $\mathrm{N}_{2} \mathrm{O}$ in gas and liquid phases. The 
discontinuity of $\mathrm{N}_{2} \mathrm{O}$ concentration is expected to be sharp across the interface (shown in Figure 7 (a)). However, using extremely small grids to resolve this sharp concentration change across the interface is not computationally feasible. As a result, a gas-liquid interface layer $\left(0<\alpha_{L}<1\right)$ consisting of several grids is observed, and $\mathrm{N}_{2} \mathrm{O}$ concentration will drop gradually instead of sharply within this interlayer (shown in Figure 7 (b)). Based on the preceding discussion, it can be concluded that Eq. (42) overestimates the mass transfer flux by including an additional contribution of $\mathrm{N}_{2} \mathrm{O}$ from the non-zero gas-liquid interface layer.

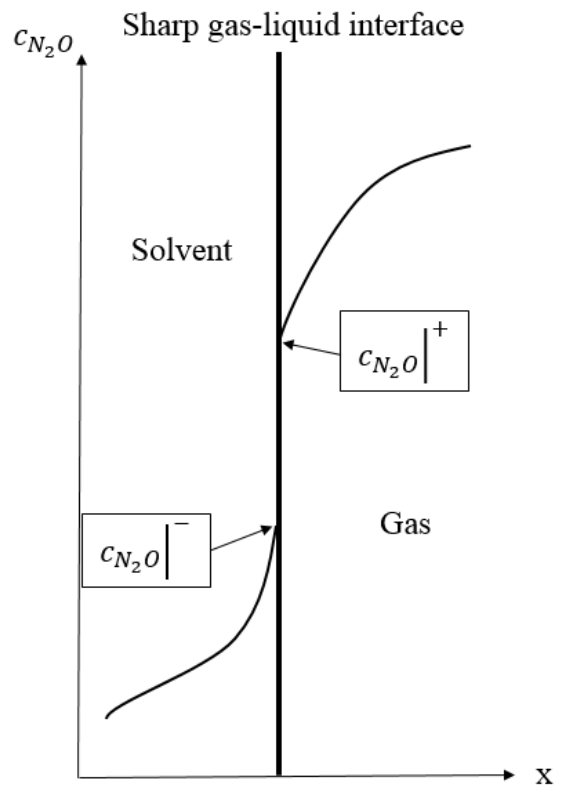

(a)

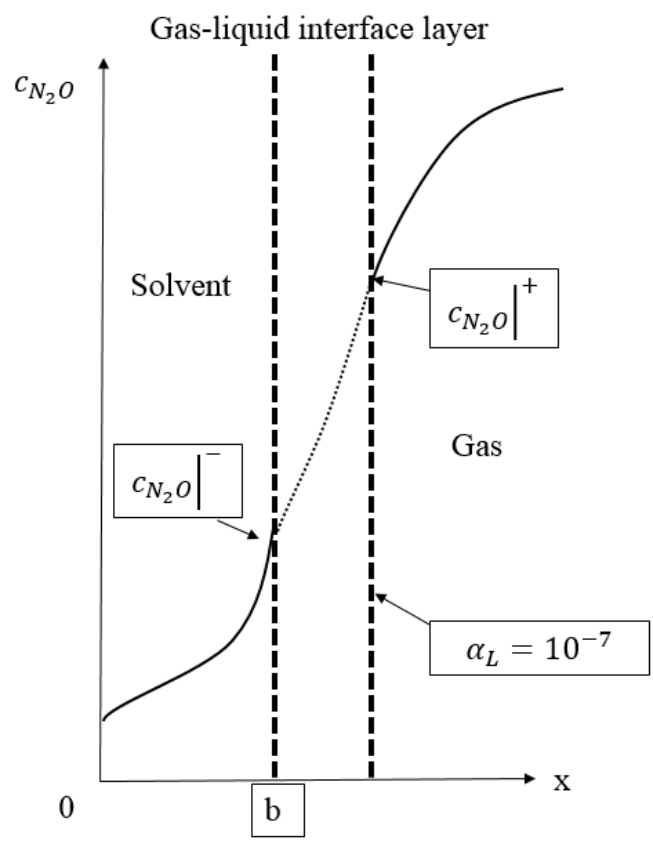

(b)

Figure 7 Sharp Gas-Liquid Interface versus Gas-Liquid Interface Layer

An alternative way to estimate the mass transfer flux is to neglect the effects from the interlayer. In Figure 7, the $\left.c_{N_{2} O}\right|^{+}$and $\left.c_{N_{2} O}\right|^{-}$represent the $\mathrm{N}_{2} \mathrm{O}$ concentration at the gasliquid interface layer on the gas and liquid sides, respectively. Given the Henry's constant and $\left.c_{N_{2} O}\right|^{+}$, we can calculate $\left.c_{N_{2} O}\right|^{-}$:

$$
\left.c_{N_{2} O}\right|^{-}=\frac{c_{N_{2} O} I^{+}}{k}
$$

where $k$ denotes the dimensionless Henry's constant. Note the $\mathrm{N}_{2} \mathrm{O}$ concentration on the gas side of the interface is approximated by the concentration where $\alpha_{L}=10^{-7}$.

Then the mass transfer flux can be introduced as

$$
J=\frac{\int_{0}^{b} c_{N_{2} O}\left|u_{y}\right| d x}{H}
$$

and $\mathrm{b}$ is the location where the $\mathrm{N}_{2} \mathrm{O}$ concentration drops to $\left.c_{\mathrm{N}_{2} \mathrm{O}}\right|^{-}$.

Essentially, if the mesh size can be sufficiently small, both approaches will obtain the same results. However, it has been determined that the numerical results obtained from the first method are twice as large as the experimental measurements, while the second method 
can provide comparable numerical and experimental results ( $15 \%$ difference) by adopting the current mesh size. In addition, the second method is more computationally efficient and will reach experimental results faster if the mesh size is continually reduced. Therefore, the second approach is adopted to compute the overall mass transfer coefficient.

\subsection{2 $\mathrm{CO}_{2} /$ MEA System}

Eq. (1) still will be used to calculate the overall mass transfer coefficient for the $\mathrm{CO}_{2}$ /MEA system. However, the mass transfer flux at the gas-liquid interface consists of two parts. In addition to the physical dissolution of $\mathrm{CO}_{2}$ in MEA, the chemical absorption of $\mathrm{CO}_{2}$ in MEA also needs to be taken into consideration. In the previous section, the mass transfer flux due to physical dissolution of $\mathrm{CO}_{2}$ in MEA has been illustrated using $\mathrm{N}_{2} \mathrm{O}$ as a surrogate of $\mathrm{CO}_{2}$. The absorption/desorption of $\mathrm{CO}_{2}$ stemming from a chemical reaction can be calculated by the conservation law:

$$
N=N_{1}+N_{2}-N_{3}-N_{4}
$$

where $N$ is molar flow rate $(\mathrm{mol} / \mathrm{m} \cdot \mathrm{s})$ per unit depth, $N_{1}$ represents $\mathrm{CO}_{2}$ molar flow rate coming in from the gas inlet per unit depth, $N_{2}$ represents $\mathrm{CO}_{2}$ molar flow rate coming in from the solvent inlet per unit depth, $N_{3}$ represents $\mathrm{CO}_{2}$ molar flow rate going out of the solvent outlet per unit depth, and $N_{4}$ represents $\mathrm{CO}_{2}$ molar flow rate going out of the gas outlet per unit depth. By calculating the difference between the amount of $\mathrm{CO}_{2}$ coming in from both the gas and solvent inlets and the amount of $\mathrm{CO}_{2}$ going out from both the gas and solvent outlets, we can determine the absorbed/desorbed amount of $\mathrm{CO}_{2}$, which is $N$ in Eq. (45).

Then, the overall mass transfer flux can be introduced as

$$
J=\frac{\int_{0}^{b} c_{\mathrm{CO}_{2}}\left|u_{y}\right| d x+N}{H} .
$$

\subsection{Results Analysis}

CFD simulations have been run for the WWC using customized OpenFOAM code to systematically investigate the effects of the following on the overall mass transfer coefficient of the WWC:

a) MEA concentration (mol of $\mathrm{MEA} /\left(\mathrm{mol}\right.$ of $\mathrm{H}_{2} \mathrm{O}+\mathrm{mol}$ of $\left.\mathrm{MEA}\right)$ )

b) $\mathrm{MEA} \mathrm{CO}$ loading ( $\mathrm{mol}$ of $\mathrm{CO}_{2} / \mathrm{mol}$ of $\mathrm{MEA}$ )

c) Solvent flow rate

d) Gas flow rate

e) Inlet gas concentration

f) Testing temperature

g) $\mathrm{CO}_{2}$ absorption rate constants of the MEA solvent system

h) Transport properties, i.e., Henry’s constant; gas diffusivity in solvent.

Specifically, the effects of surface wave with various frequencies and amplitudes on the overall mass transfer have been investigated for a countercurrent gas-liquid flow of oxygen and water. The surface waves are generated by applying a time-dependent injection rate at the liquid inlet. 
Mass transfer, with hydrodynamics, was investigated for the non-reactive $\mathrm{N}_{2} \mathrm{O}$ /MEA system. The objective is to use experimental data to systemically calibrate two transport parameters, i.e., Henry's constant and gas diffusivity in solvent, without taking the chemical reaction into consideration. A total of 20 experiment and 151 simulation cases have been designed and run for the calibration of these two parameters.

After this process, chemical reaction coupled with mass transfer and hydrodynamics were investigated for the $\mathrm{CO}_{2}$ /MEA system. The available experimental data will be used to calibrate $\mathrm{CO}_{2}$ absorption rate constants. Two batches of simulations with a total of 241 runs and 32 experiments have been designed and run for this parameter calibration.

\subsubsection{O $2 / \mathrm{H}_{2} \mathrm{O}$ System}

Table 9 lists all relevant parameters used in the model. An oscillating injection rate is prescribed at the liquid inlet as a sinusoidal function:

$$
v_{s}=0.1485\left[1+\varepsilon \sin \left(2 \pi f_{c} t\right)\right] \text {, }
$$

where the non-dimensionless number $\varepsilon$ denotes the amplitude of fluctuation that varies between 0 and 1 and $f_{c}$ represents the controlled frequency of the fluctuation in the injection rate.

At the gas inlet, $0.1 \mathrm{~mol} / \mathrm{m}^{3}$ oxygen gas is released into the column at a rate of $v_{g}=1.384$ $\mathrm{m} / \mathrm{s}$. The entire column initially is filled with $0.1 \mathrm{~mol} / \mathrm{m}^{3}$ oxygen gas.

Table 9 Values of Input Parameters

\begin{tabular}{|c|c|}
\hline Parameters & Value and Unit \\
\hline Temperature & $25^{\circ} \mathrm{C}$ \\
\hline Pressure & 0 atm \\
\hline Solvent inlet velocity & $0.148 \mathrm{~m} / \mathrm{s}$ \\
\hline Gas inlet velocity & $1.384 \mathrm{~m} / \mathrm{s}$ \\
\hline Inlet O $_{2}$ concentration & $0.1 \mathrm{~mol} / \mathrm{m}^{3}$ \\
\hline O $_{2}$ diffusivity in gas & $1.6 \mathrm{e}-5 \mathrm{~m}{ }^{2} / \mathrm{s}$ \\
\hline O $_{2}$ diffusivity in solvent & $1.0 \mathrm{e}-9 \mathrm{~m}{ }^{2} / \mathrm{s}$ \\
\hline Solvent contact angle & 40 \\
\hline Density (solvent, gas) & $1000,1 \mathrm{~kg} / \mathrm{m}^{3}$ \\
\hline Kinematic viscosity(solvent, gas) & $1 \mathrm{e}-6,1.48 \mathrm{e}-5 \mathrm{~m}^{2} / \mathrm{s}$ \\
\hline Surface tension & $0.07 \mathrm{~kg} / \mathrm{s}^{2}$ \\
\hline Henry’s constant of O 2 in water & 31.437 \\
\hline
\end{tabular}




\subsubsection{Effect of Injection Frequency on Surface Waves}

Figure 8 shows the profile of falling film with increasing frequency $f_{c}$ when simulations reach the steady state. The film has a relatively flat surface for a constant injection rate without any fluctuation. The Reynolds number $\mathrm{Re}$ is computed to be $\sim 53$, indicating a laminar flow by using the film layer thickness as the characteristic length. Based on the Nusselt number estimation [19], the liquid film thickness can be calculated as $\left(3 \operatorname{Re} \mu^{2} / \rho_{L}^{2} g\right)^{1 / 3}=0.35 \mathrm{~mm}$. The film thickness obtained from numerical simulation is consistent with this prediction.

By increasing the frequency $f_{c}$ to $20 \mathrm{~Hz}$ with a fixed amplitude of $\varepsilon=0.05$, a wave starts to develop on the film's surface. It can be clearly seen that the falling film begins to expand along the wall when approaching the liquid outlet and reaches a maximum thickness close to the outlet. However, the injection rate fluctuation is not sufficiently large to generate surface waves with significant amplitude. At a frequency of $40 \mathrm{~Hz}$, surface waves (fluctuation in film thickness) can be plainly observed. When the frequency increases to $60 \mathrm{~Hz}$, the waves further develop in a similar pattern but with shorter wavelengths (almost three wave cycles along the entire wall). This indicates that the number of waves increases (or equivalently the wavelength decreases) with the frequency. At the largest frequency, $100 \mathrm{~Hz}$, waves are nearly head-to-tail connected, and wavelength is reduced further with about four wave cycles along the wall. At this frequency, the maximum and minimum film thickness is observed to be $\sim 0.475 \mathrm{~mm}$ and $\sim 0.15 \mathrm{~mm}$, respectively.
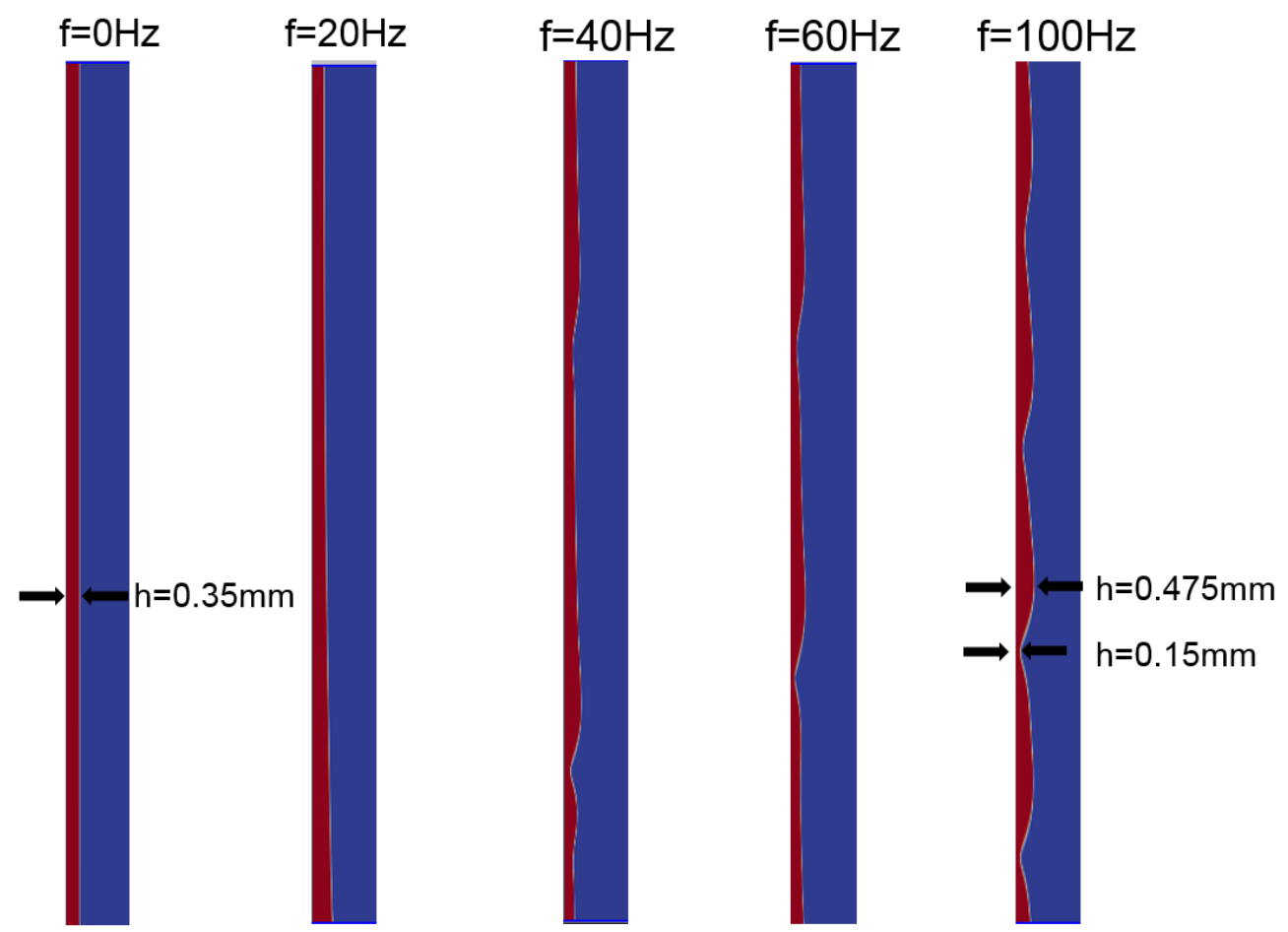

Figure 8 Profiles of Falling Film with Increasing Frequencies in Injection Rates (more surface waves can be observed at higher frequencies) 


\subsubsection{Variation of $\mathrm{O}_{2}$ Concentration for Different Frequencies}

Figure 9 shows the oxygen concentration distribution along the vertical direction with different injection frequencies. Four cases with different frequencies $\left(f_{c}=20,40,60\right.$, and 100 $\mathrm{Hz})$ but a fixed amplitude $(\varepsilon=0.05)$ are simulated. The horizontal axis in Figure 9 represents the height along the wall $(\mathrm{x}=0$ and $0.0909 \mathrm{~m}$ are the gas inlet and outlet locations, respectively), and the vertical axis denotes the concentration of oxygen (in $\mathrm{mol} / \mathrm{m}^{3}$ ) along the vertical line connecting the gas inlet and outlet. The concentration is collected along the central line from gas inlet to outlet.

In Figure 9, the outlet concentration will depend on the mass transfer between two phases, i.e., decreasing with increasing mass transfer. The concentration profile in the figure demonstrates that the outlet concentration decreases with increasing frequency $f_{c}$, indicating an enhanced mass transfer between two phases with increasing frequency, which can correlate to the increasing surface waves shown in Figure 8.

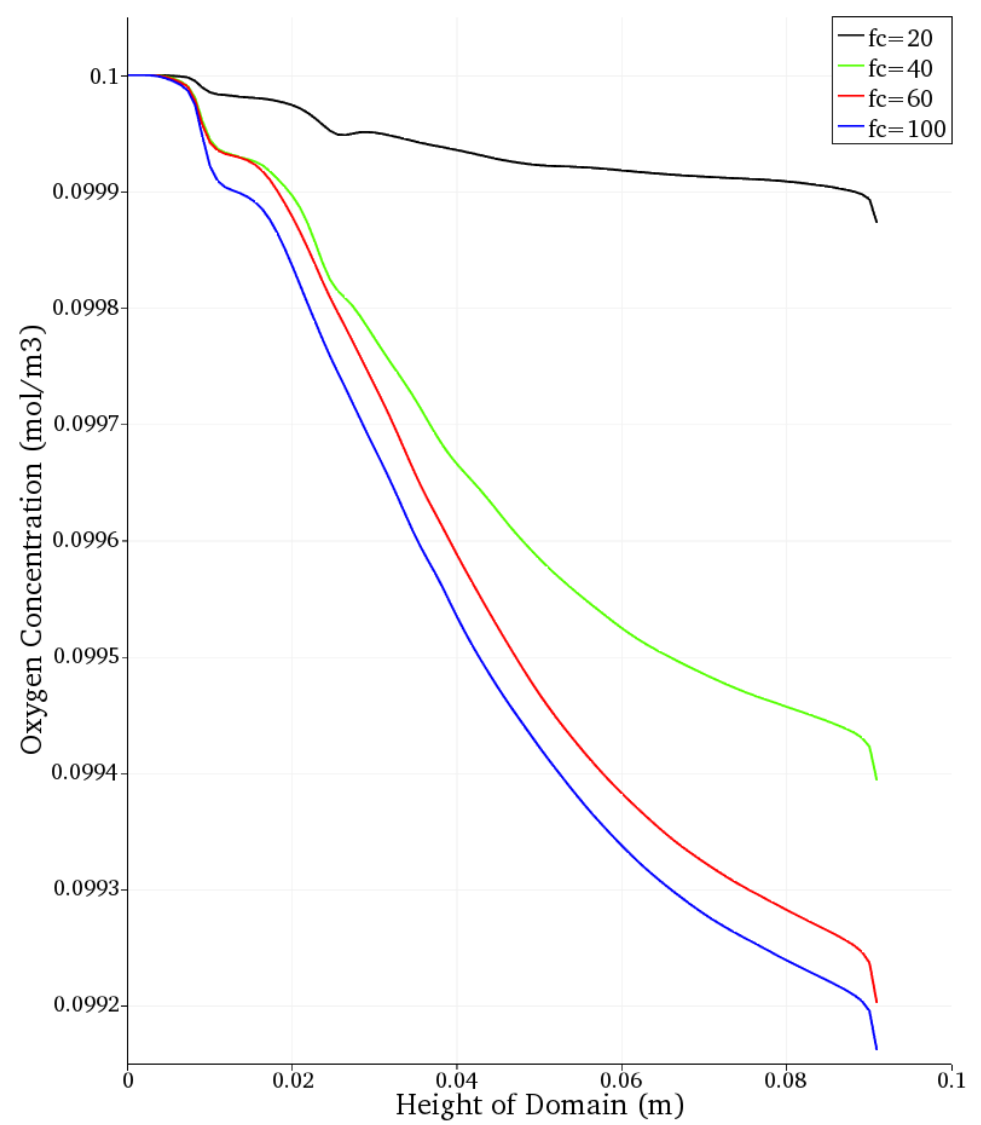

Figure 9 Variation of Gas Concentration Distribution for Different Fluctuation Frequencies (a larger frequency leads to a steeper concentration gradient in the vertical direction and a larger mass transfer across the interface)

\subsubsection{Variation of $\mathrm{O}_{2}$ Concentration with Controlled Amplitude}

Next, the effect of fluctuation amplitude on the mass transfer is investigated by fixing the controlled frequency $f_{c}$ of the injection rate at $20 \mathrm{~Hz}$ but varying the amplitude $(\varepsilon=0.05,0.1$, 0.15 , and 0.2 ). Figure 10 plots the same concentration profile along the central line from gas 
inlet to outlet. The increase in fluctuation amplitude will result in an immediate decrease in outlet concentration, indicating an enhancement of mass transfer at larger amplitudes. This is expected because surface waves with larger amplitude create large surface area and breathe in more gas along the moving path to enhance the gas absorption [19].

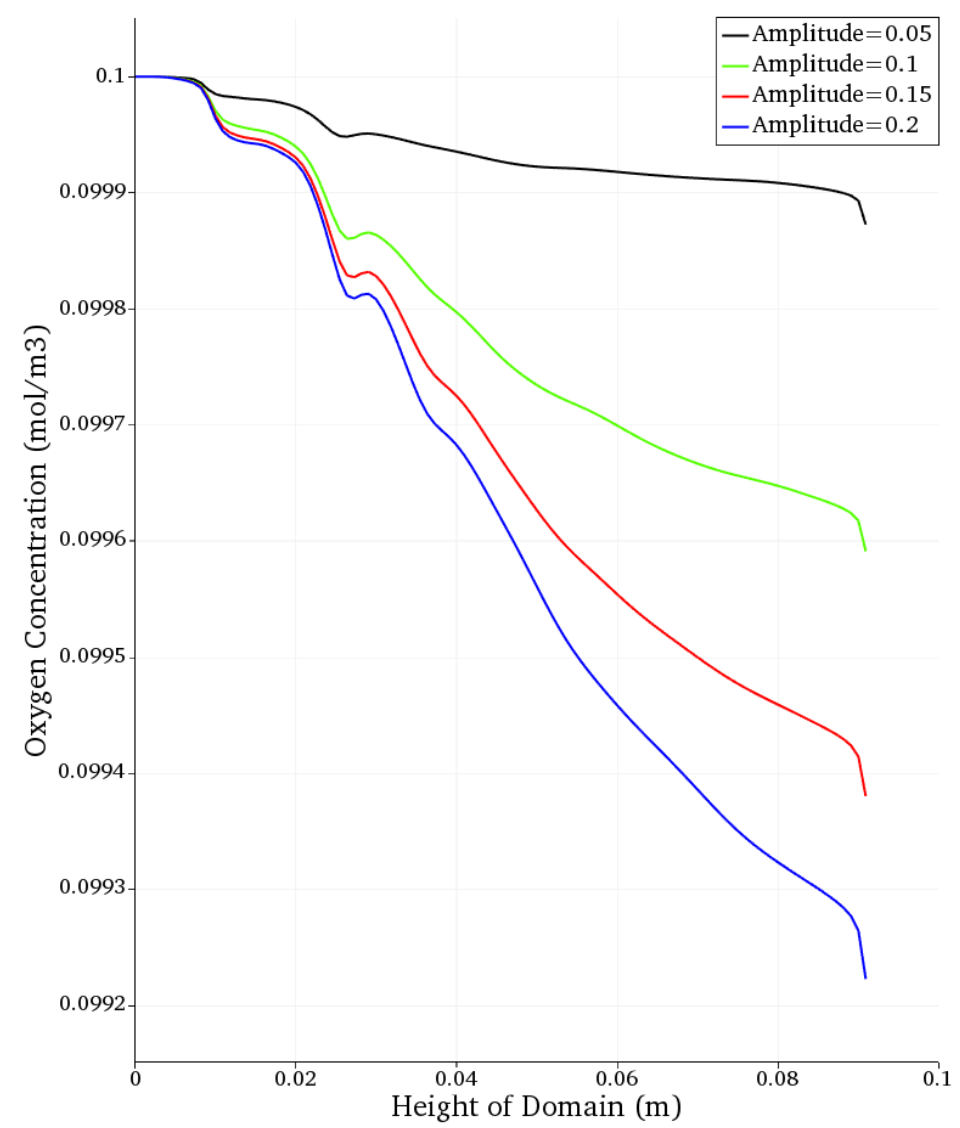

Figure 10 Variation of Gas Concentration Distribution for Different Fluctuation Amplitudes in the Injection Rate (a larger amplitude leads to a steeper concentration gradient along the vertical direction)

\subsection{2 $\mathrm{N}_{2} \mathrm{O} /$ MEA System}

A total of 151 numerical simulation cases have been performed for the $\mathrm{N}_{2} \mathrm{O}-\mathrm{MEA}$ nonreactive system.

1) Run No. 1-20. The controlled input parameters are the same as the experimental settings. The calibrated parameters are calculated from the equations introduced in Section 3.2.

2) Run No. 21-43. The controlled input parameters are identical to those of case No. 7 but with different samplings of calibrated parameters, i.e., gas diffusivity in solvent and Henry's constant.

3) Run No. 43-151. Both controlled and calibrated parameters are systemically tuned to facilitate calibration of the two key parameters.

The model input for controlled and calibrated parameters and numerical results of overall mass transfer coefficient for all 151 cases can be found in the Appendix of this document. 
During the simulation campaigns, the solvent density must be changed to $800 \mathrm{~kg} / \mathrm{m}^{3}$ for some cases to avoid crashing the simulations. The run numbers for these cases are: No. 1-6, 10, 11, 13, 16, 44-46, 53-58, 62-64, 80-85, and 89-91. In Section 3.6, we have provided a detailed sensitivity study on solvent density, and the results show this factor has no impact on the mass transfer coefficient, instead merely helping computational convergence. Figure 11 illustrates the comparison between the computed overall mass transfer coefficient and experimental measurement for the first 20 runs, excluding a total of seven unreliable experimental results (No. 1-6, and 10). Section 2 provides detailed information regarding these unreliable data. In addition, there is also one failed simulation case (No. 13) because of numerical instability $\left(800 \mathrm{~kg} / \mathrm{m}^{3}\right.$ solvent density will fail the numerical computation and no other solvent density values were evaluated). By excluding those 8 data points, the remaining 12 points shown in Figure 11 scatter around the dash line (slope of 1 indicating a perfect match), indicating that reasonably good agreement between numerical simulation and experimental results has been obtained.

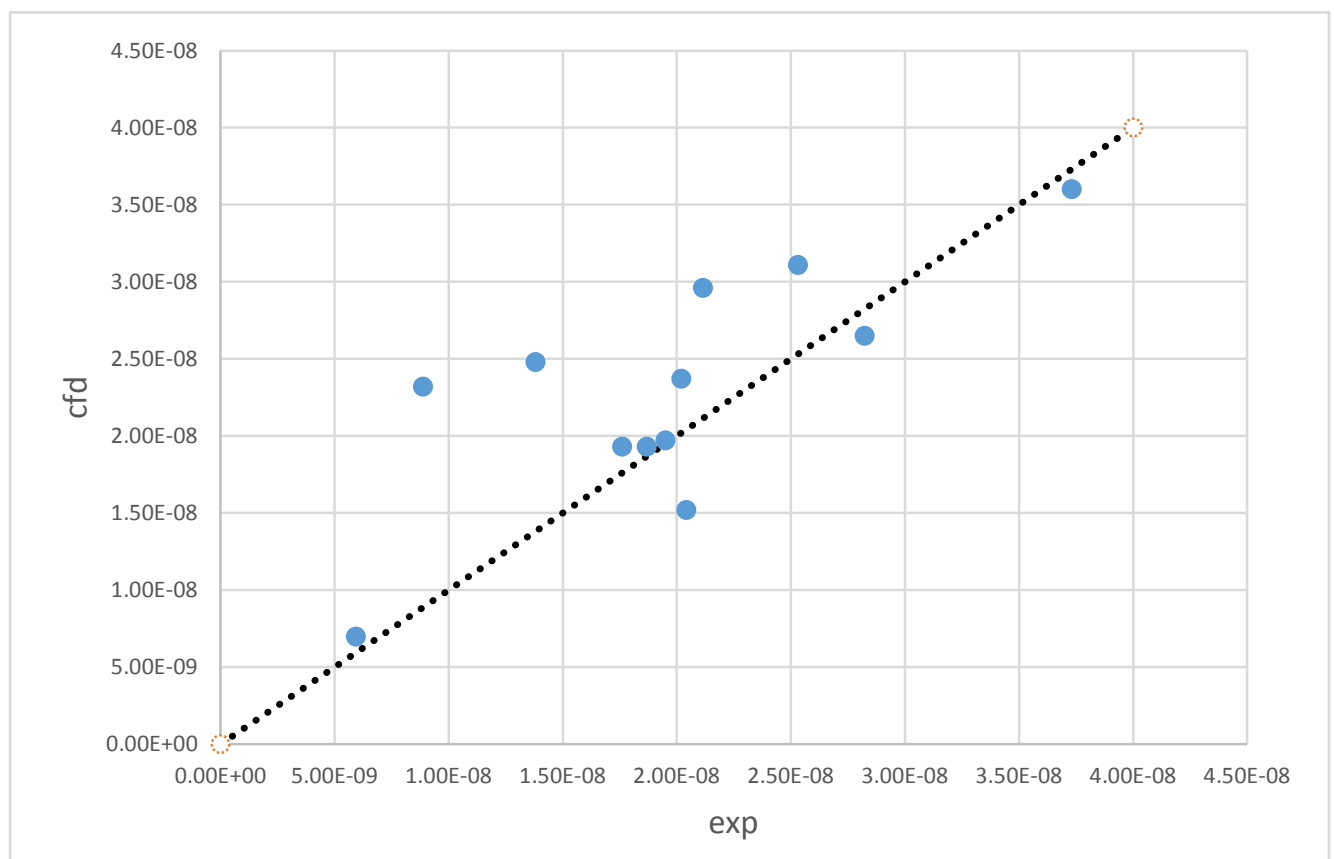

Figure 11 Numerical Simulation Versus Experimental Data for Overall Mass Transfer Coefficient in $\mathrm{N}_{2} \mathrm{O} / \mathrm{MEA}$ System

Figure 12 shows the results of overall mass transfer coefficient versus all six controlled parameters. The orange dots represent numerical results from 12 cases, while the blue dots represent experimental results. It can be observed that mass transfer decreases with MEA mass fraction. On one hand, an increase in MEA mass fraction will increase solvent viscosity, slow down the diffusion process of $\mathrm{N}_{2} \mathrm{O}$ in MEA, and decelerate the $\mathrm{N}_{2} \mathrm{O}$ mass transfer. Meanwhile, thickness of the falling solvent film will increase with solvent viscosity for higher MEA mass fraction solvent which leads to a decrease of the average solvent velocity and the advection of falling film if solvent flow rate is kept unchanged. Since $\mathrm{N}_{2} \mathrm{O}$ concentration in the liquid phase is not uniformly distributed and the region of high $\mathrm{N}_{2} \mathrm{O}$ concentration locates near the gas-liquid interface, a decrease of advection will reduce the 
mass transfer rate as indicated by eqn. (42). Moreover, the overall mass transfer coefficient also increases with gas flow rate. Theoretically speaking, transport within the liquid phase should control the $\mathrm{N}_{2} \mathrm{O}$ absorption for a well-mixed gas mixture. In Section 3.6, a parametric study has been performed for small gas flow rate, which proves this factor has only trivial impact on the $\mathrm{N}_{2} \mathrm{O}$ /MEA mass transfer because the $\mathrm{N}_{2} \mathrm{O}$ concentration distribution does not have noticeable change for gas flow rates varying from 100 to $300 \mathrm{sccm}$. There is no obvious tendency observed for the remaining four controlled parameters: temperature, $\mathrm{N}_{2} \mathrm{O}$ molar fraction, $\mathrm{CO}_{2}$ loading, and solvent flow rate.
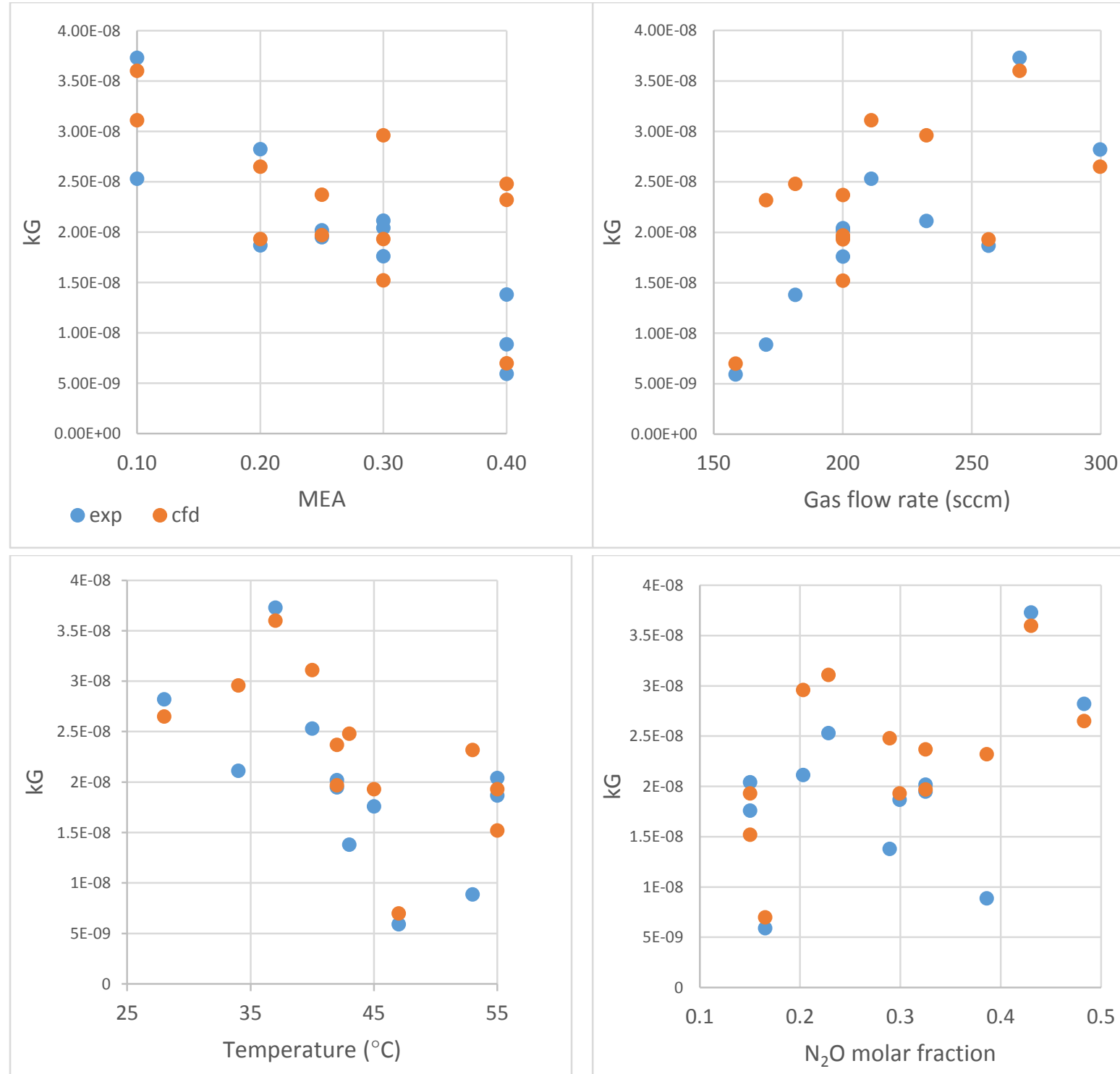

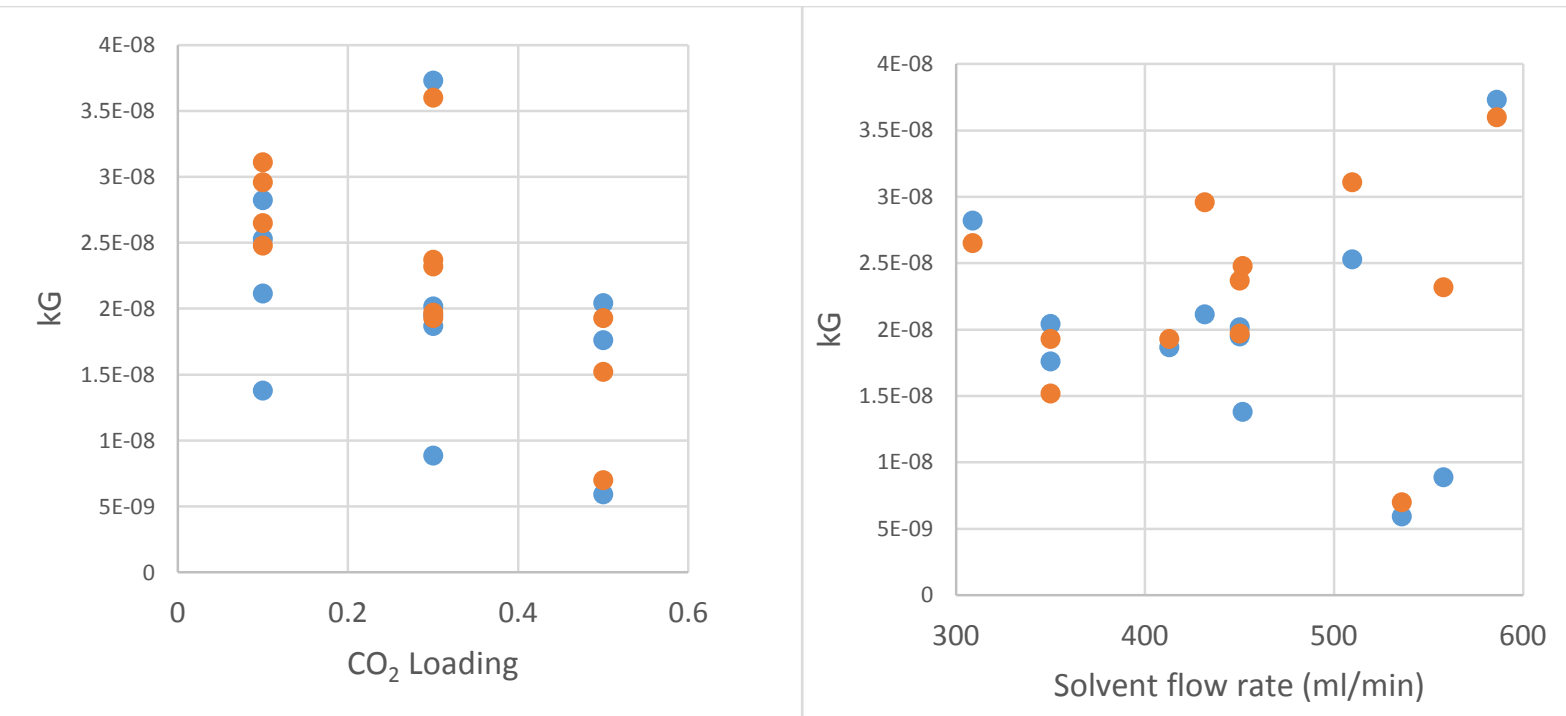

Figure 12 kg versus Controlled Parameters in $\mathrm{N}_{2} \mathrm{O} / \mathrm{MEA}$ Systems

Figure 13 shows how mass transfer changes with the two transport parameters, i.e., Henry's constant and diffusivity. The two dashed lines indicate the replicated experimental results for mass transfer coefficient: $1.95 \mathrm{e}-8$ and $2.02 \mathrm{e}-8\left(\mathrm{~mol} / \mathrm{Pa} \cdot \mathrm{s} \cdot \mathrm{m}^{2}\right)$, respectively. In Figure 13, Henry's constant has significant impact on the $\mathrm{N}_{2} \mathrm{O}$ mass transfer. Based on the definition of Henry's constant (described in Section 3.1), larger Henry's constant indicates higher solubility of gas in the solvent, which enhances the mass transfer rate into the solvent. Conversely, an increase in gas diffusivity in the solvent only slightly increases the mass transfer coefficient. This is expected because the advection contribution should be much larger compared to that from diffusion on the falling film.
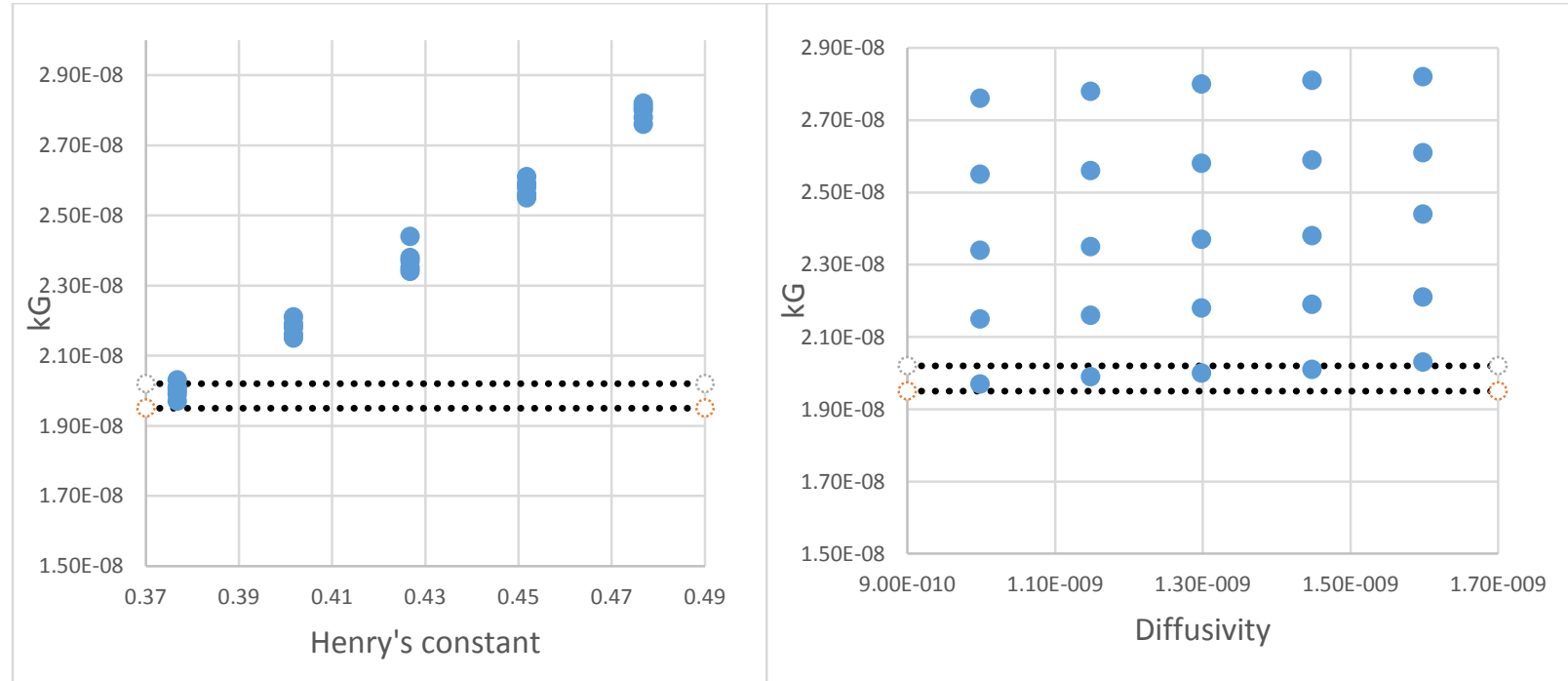

Figure 13 kg versus Henry’s Constant and Diffusivity 


\subsection{3 $\mathrm{CO}_{2} /$ MEA System}

The first batch of simulations contains a total of 167 cases. For each experimental run, the corresponding numerical simulations employ the same controlled parameters but with three different values for each calibrated parameter, i.e., Henry's constant, gas diffusivity in solvent, and $\mathrm{CO}_{2}$ reaction rate constant. The calibrated parameters are systemically adjusted to facilitate the calibration. Five numerical testing cases were conducted for each experimental run (No. 2-29), while a total of 27 numerical testing cases were designed for experimental run No. 1. Detailed model input and numerical results of the overall mass transfer coefficient for all 167 cases can be found in the Appendix within this document.

Like the $\mathrm{N}_{2} \mathrm{O} / \mathrm{MEA}$ system, the solvent density must be changed to $800 \mathrm{~kg} / \mathrm{m}^{3}$ for the following runs in $\mathrm{CO}_{2}$ /MEA system to ensure numerical stability: No. 38-42, 48-57, 63-67, 78-87, 98-102, 108-112, 128-132, and 148-152. In addition, for run No. 43-47, 153-157, and 163-167, the solvent outlet size has to be expanded from $1 \mathrm{~mm}$ to $1.5 \mathrm{~mm}$ to avoid solvent flooding due to large solvent viscosity. One additional run was carried out to see if a 50\% increase in solvent outlet size would significantly affect the mass transfer coefficient. Run No. 1 was selected as the basis, and the solvent outlet size was adjusted from $1 \mathrm{~mm}$ to 1.5 $\mathrm{mm}$. Nevertheless, the simulation result differs only by $0.2 \%$, which demonstrates the result is not sensitive to the solvent outlet's size.

Figure 14 compares the predicted mass transfer coefficient and experimental measurement results for the $\mathrm{CO}_{2} / \mathrm{MEA}$ system. Sets 1 through 5 represent five different numerical designs for each experimental run. In general, the mass transfer coefficients predicted by numerical simulations are in good agreement with the corresponding experimental results. However, numerical simulations predict slightly lower mass transfer coefficients than the experimental measurements, particularly for conditions with relatively large overall mass transfer coefficients.

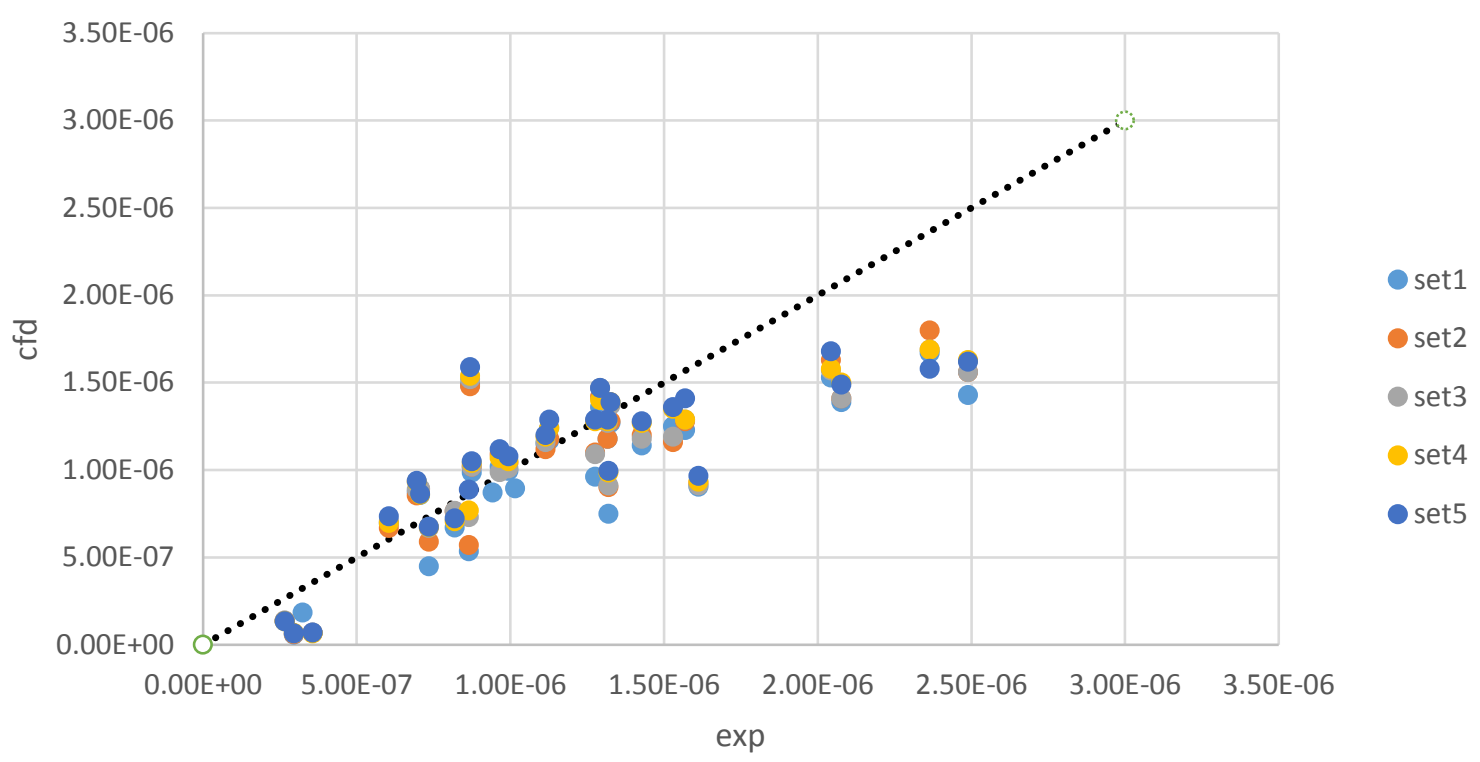

Figure 14 Numerical Simulation Versus Experimental Data for Overall Mass Transfer Coefficient in $\mathrm{CO}_{2} / \mathrm{MEA}$ Systems 
Figure 15 shows how overall mass transfer coefficients vary with controlled parameters. Dots denote the numerical simulation results, while the green diamonds denote the experimental measurements. It is observable that $\mathrm{CO}_{2}$ loading is a key factor in influencing the mass transfer coefficient (mass transfer coefficients decrease with increasing $\mathrm{CO}_{2}$ loading). With higher $\mathrm{CO}_{2}$ loading, more MEA is consumed, resulting in a lower amount of $\mathrm{CO}_{2}$ absorption and a lower overall mass transfer coefficient.

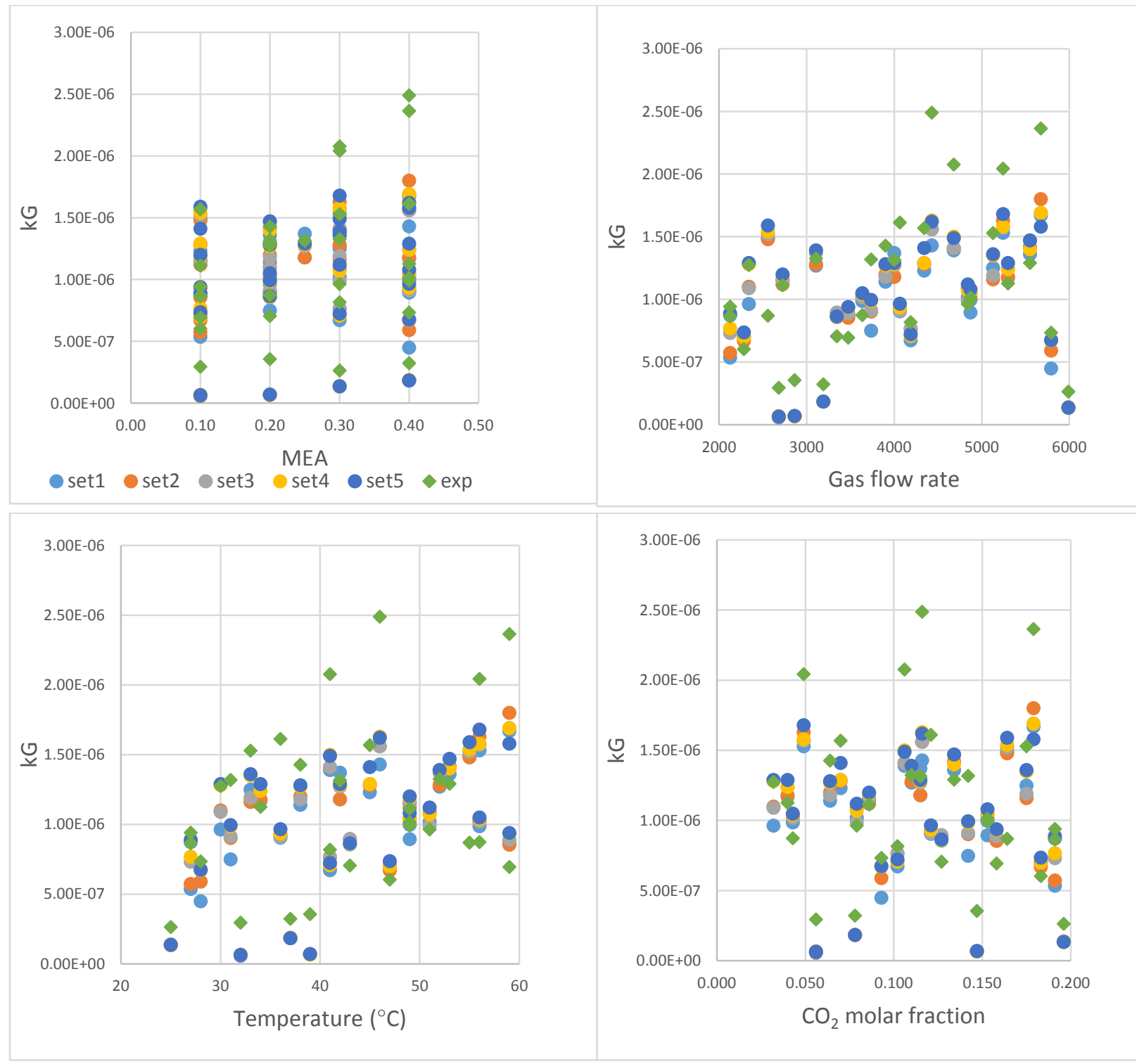



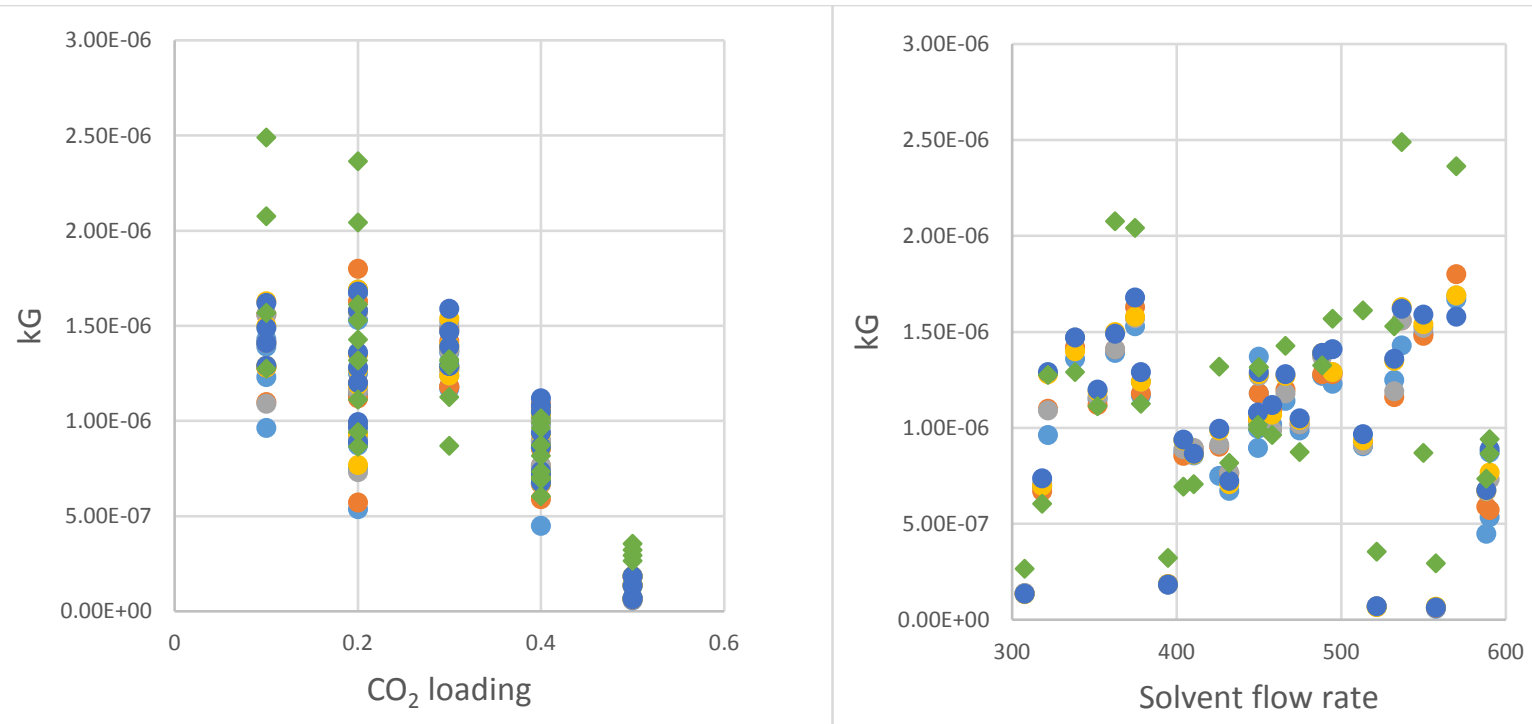

Figure $15 \mathrm{k}_{\mathrm{G}}$ versus Controlled Parameters in $\mathrm{CO}_{2} / \mathrm{MEA}$ Systems

The second batch simulation with a total of 74 runs was performed to calibrate reaction rate constants. The controlled parameters in the numerical model are the same as the experimental run No. 1s but with two different operating temperatures: 42 and $30^{\circ} \mathrm{C}$, respectively. Detailed model input and numerical results of the overall mass transfer coefficient for all 74 cases can be found in this document's Appendix. Parameter calibration and UQ analyses presented in Section 4 will use this batch of results to calibrate the rate constants.

Finally, with the overall mass transfer coefficient in the $\mathrm{CO}_{2} / \mathrm{MEA}$ system almost two orders of magnitude larger than that of the $\mathrm{N}_{2} \mathrm{O}$ /MEA system, it is evident that chemical absorption is much larger than physical absorption of $\mathrm{CO}_{2}$ in MEA solvent.

\subsection{Parametric Analysis}

A parametric study has been performed, varying only one input parameter at a time. For each parameter, three different values are tested.

\subsection{1 $\mathrm{N}_{2} \mathrm{O}$ /MEA System}

Figure 16 shows the results of the parametric study for the $\mathrm{N}_{2} \mathrm{O}$ /MEA system. The four most sensitive parameters are Henry's constant, gas diffusivity in solvent, solvent viscosity, and solvent flow rate. The effects of the remaining parameters on the mass transfer coefficient are not significant. 


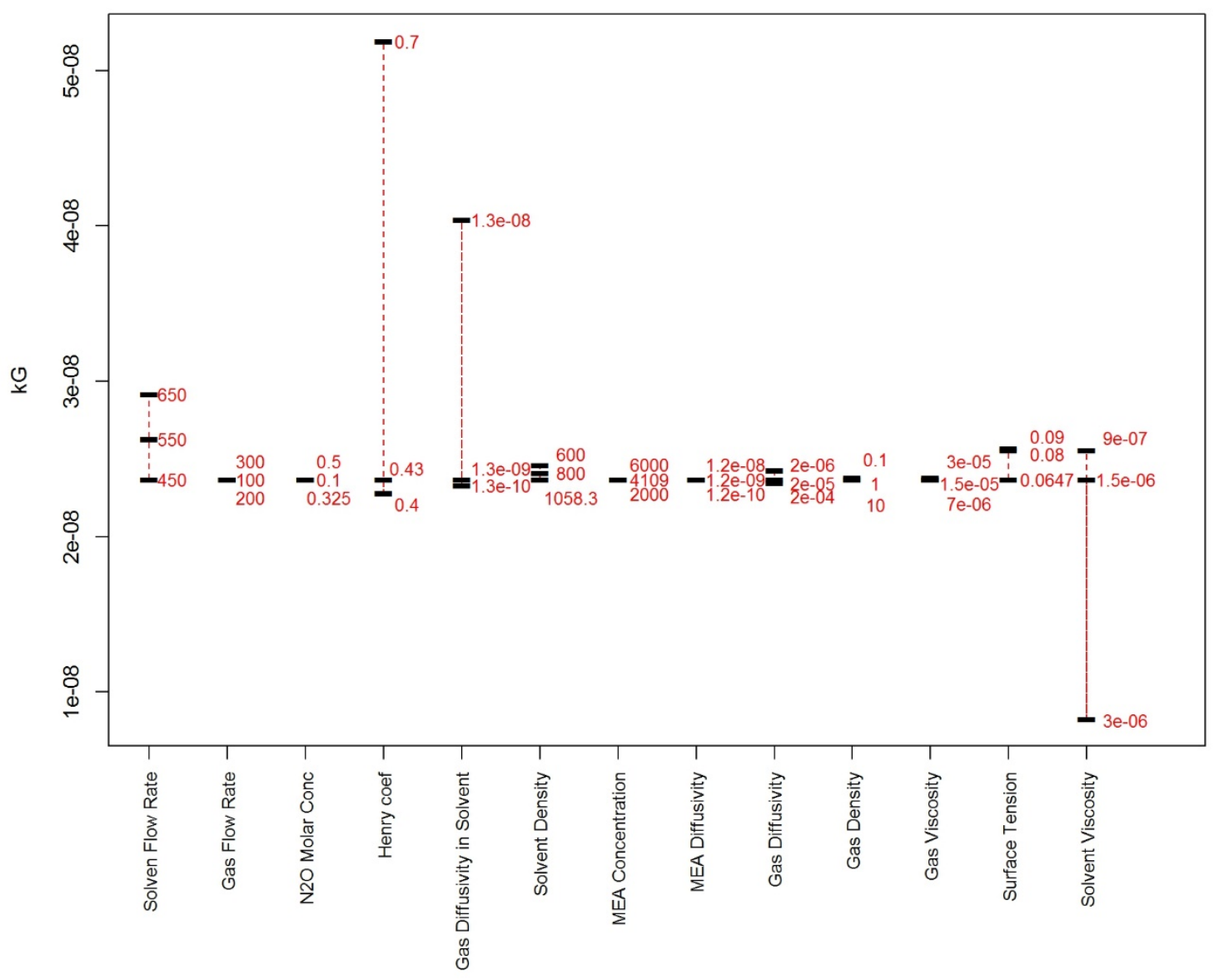

Figure $16 \mathrm{~N}_{2} \mathrm{O} / \mathrm{MEA}$ Parametric Study

A larger Henry's constant will increase the mass transfer coefficient. Gas diffusivity in solvent will start to affect gas mass transfer once it becomes comparable with the gravitydriven advection from the falling film. Solvent viscosity can differ for different MEA fractions. An increase in solvent viscosity for higher MEA fraction in solvent will reduce advection of the solvent due to the expansion of the falling film thickness. Meanwhile, lower gas diffusivity in solvent and hence significantly decreases the gas-liquid mass transfer. In addition, larger solvent flow rate will help increase the mass transfer by supplying more fresh solvent in unit time. The rest parameters do not have major influence on the predicted mass transfer coefficient.

\subsection{2 $\mathrm{CO}_{2} /$ MEA System}

Figure 17 depicts the results of a parametric study for the $\mathrm{CO}_{2} / \mathrm{MEA}$ system. Because chemical absorption is a major contributor in gas-liquid mass transfer, larger gas diffusivity in both phases will increase the reaction rate by providing more available $\mathrm{CO}_{2}$ near the gasliquid interface. On the contrary, the Henry's constant and solvent viscosity become less important because the effect of physical absorption only takes up a small portion of the overall mass transfer coefficient. 


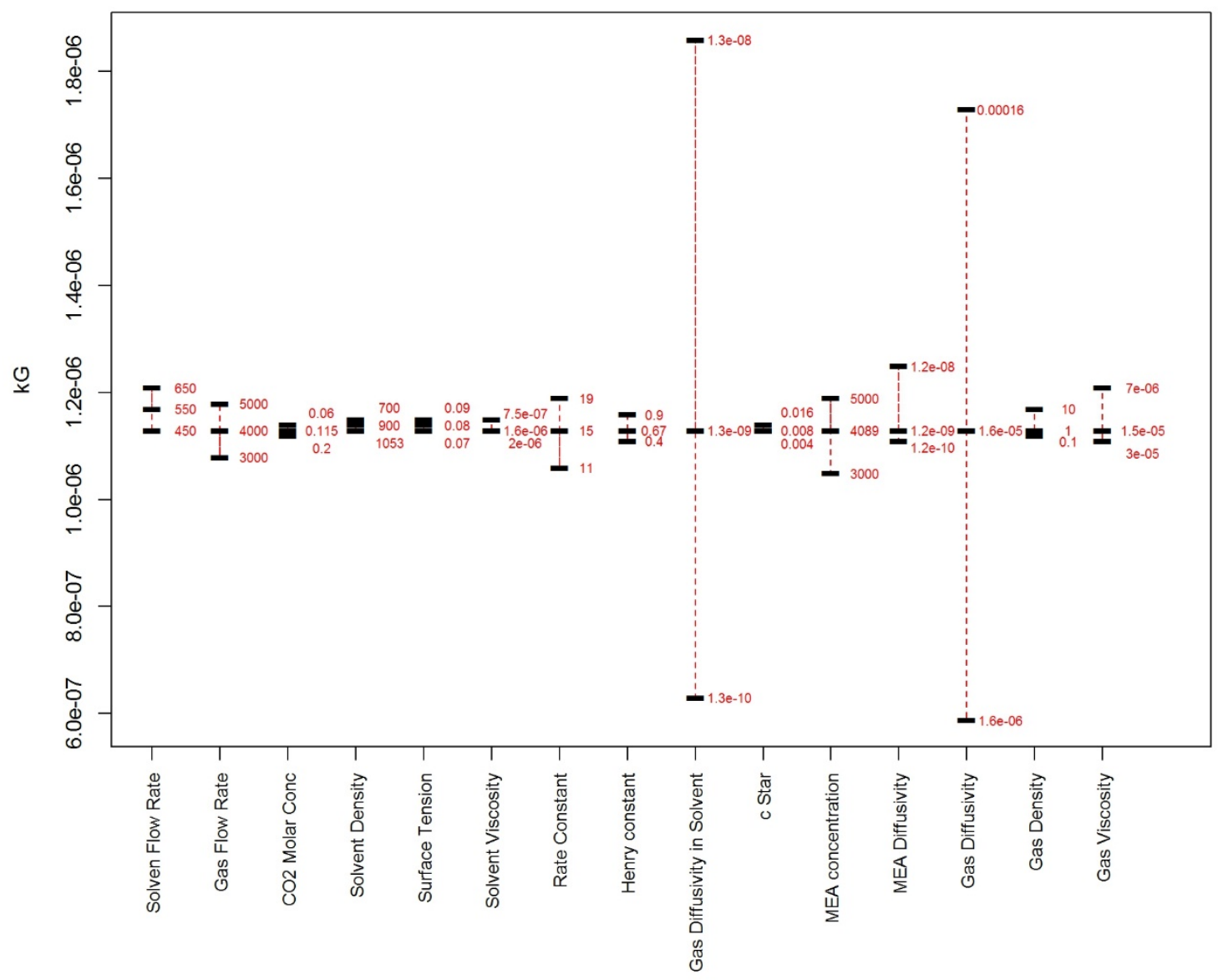

Figure $17 \mathrm{CO}_{2} / \mathrm{MEA}$ Parametric Study

\subsection{Summary of the Results}

Fully coupled multiphase flow CFD simulations with hydrodynamics, mass transfer, and chemical reactions have been implemented to compute the mass transfer coefficient in WWC using OpenFOAM, a free and open-source CFD software package with a custom solver. The effects of surface wave frequency and amplitude on the overall mass transfer have been investigated for $\mathrm{O}_{2}$ /water systems. Simulation results have been validated via comparison to experimental measurements. A parametric study has been performed to systematically examine the influential factors for WWC performance. Some preliminary findings from the CFD study are summarized as follows:

1) Both wave frequency and amplitude enhance the mass transfer rate for $\mathrm{O}_{2} /$ water systems.

2) The mass transfer coefficient decreases with MEA mass fraction for non-reactive $\mathrm{N}_{2} \mathrm{O} / \mathrm{MEA}$ systems.

3) The mass transfer coefficient decreases with $\mathrm{CO}_{2}$ loading for reactive $\mathrm{CO}_{2} / \mathrm{MEA}$ systems.

4) Chemical absorption is the major contribution to $\mathrm{CO}_{2}$ capture compared to physical absorption. 
5) Henry's constant, gas diffusivity in solvent, solvent viscosity and solvent flow rate are key parameters determining the physical absorption rate in $\mathrm{N}_{2} \mathrm{O} / \mathrm{MEA}$ systems.

6) Gas diffusivity in both phases plays an important part in the overall mass transfer for the chemical absorption in $\mathrm{CO}_{2}$-MEA system.

\section{Model Calibration and UQ Analysis for WWC Experiments}

Statistical calibration is the process of combining experimental and simulated data to probabilistically infer simulator settings that make its output most consistent with the physical data [21]. A calibration exercise begins by identifying one or more response variables $(y)$ that can be measured in physical experiments and also obtained as output from the corresponding computer model. The identification of experimental and calibration inputs follows. The experimental variables (collected in the vector $\boldsymbol{x}$ ) are common to both and are selected because of their potential effect on the response. The calibration inputs $t$ are unique to the computer and inference on their most plausible values $\boldsymbol{\theta}$ is desired. After a prior distribution is assigned to $\boldsymbol{\theta}$, a Bayesian Markov chain Monte Carlo algorithm is used to combine that prior with the information given in the simulated and experimental data. Specific and technical details can be found in [21]. The end result of a calibration exercise is a posterior probability distribution on $\boldsymbol{\theta}$ and information about a discrepancy function $\delta(\boldsymbol{x})$ that attempts to capture the misfit of the simulated model to the real physical system.

For the WWC experiments, the output of interest is the mass transfer coefficient $\left(k_{G}\right)$ that relates flux to partial pressure. The following experimental conditions were identified as relevant $x$ s to vary between experiments: operating temperature, MEA mass fraction, $\mathrm{CO}_{2}$ loading in MEA, solvent flow rate, gas flow rate (either $\mathrm{N}_{2} \mathrm{O}$ or $\mathrm{CO}_{2}$ ), and inlet gas concentration. Ranges of feasible values also were determined, and these are given in Table 10 and Table 13 for non-reacting $\left(\mathrm{N}_{2} \mathrm{O} / \mathrm{MEA}\right)$ and reacting $\left(\mathrm{CO}_{2} / \mathrm{MEA}\right)$ cases, respectively. The simulation model takes these conditions, and calibration inputs, as inputs. For the nonreacting scenario, these inputs are Henry's coefficient and diffusivity. The reacting scenario has an additional parameter, reaction rate constant. Specifically, Henry's constant and diffusivity are transport properties that will be calibrated in Unit Problem 2 by a laboratoryscale WWC experiment of the $\mathrm{N}_{2} \mathrm{O}$ /MEA system. The posterior transport properties will be used as the input a priori in Unit Problem 3, and the rate constant of $\mathrm{CO}_{2}$ will be calibrated in Unit Problem 3 with a laboratory-scale WWC experiment of $\mathrm{CO}_{2} / \mathrm{MEA}$ systems.

All calibration inputs actually are functions of the experimental settings, and these correlations from the literature are given in Table 11 and Table 14. Hence, the goal becomes calibrating the coefficients within the functional relationships and comparing them to their previous estimates expressed in the literature (those estimates also are in the aforementioned tables). This is done for the non-reacting scenario first, then the reacting case.

\section{1 $\mathrm{N}_{2} \mathrm{O}$ /MEA System}

The statistical design for the experimental data points (i.e., the matrix of how to vary $\boldsymbol{x}$ between different experiments) was chosen to accommodate the fact that few experiments can be conducted with the given budget. First, a $4 \times 5$ factorial design was devised using the levels $\{0.1,0.2,0.3$, and 0.4$\}$ for MEA mass fraction and $\{0.1,0.2,0.3,0.4$, and 0.5$\}$ for $\mathrm{CO}_{2}$ loading. From these, 11 points were selected so they were sufficiently "spread out." These 
values were combined with a space-filling Latin hypercube design in the remaining four variables, subject to their respective ranges. From the resulting design of 11 points in six input variables, one point was chosen to be a replicate. In addition, the central value of the design space (given in Table 10) was used for two more replicate points. Thus, the final experimental design had 14 total points with some carefully chosen replicates.

Table 10 Inputs to the Computer Model for the Non-reacting Case

\begin{tabular}{|c|c|}
\hline Input & Range / Units \\
\hline $\begin{array}{l}\text { Experimental, } x \text { : } \\
\text { Temperature } \\
\text { MEA mass fraction } \\
\mathrm{CO}_{2} \text { loading in MEA } \\
\text { Solvent flow rate } \\
\text { Gas flow rate } \\
\text { Inlet } \mathrm{N}_{2} \mathrm{O} \text { molar concentration }\end{array}$ & $\begin{array}{l}{[25,60]{ }^{\circ} \mathrm{C}} \\
{[0.1,0.4] \mathrm{g} \mathrm{MEA} / \mathrm{g} \text { total }} \\
{[0.0,0.5] \mathrm{mol} \mathrm{CO} 2 / \mathrm{mol} \mathrm{MEA}} \\
{[300,600] \mathrm{ccm}} \\
{[100,300] \mathrm{sccm}} \\
{[0.15,0.50] \mathrm{mol} / \mathrm{L}}\end{array}$ \\
\hline $\begin{array}{l}\text { Calibration, } \boldsymbol{t} \text { : } \\
\qquad \begin{array}{l}\left(H_{\mathrm{N} 2 \mathrm{O}}\right) \text { Henry's coefficient } \\
\left(D_{\mathrm{N} 2 \mathrm{O}}\right) \text { Diffusivity }\end{array}\end{array}$ & $\begin{array}{l}{[0.2,0.9] \text { unitless; }} \\
\text { converted from “ } H_{\mathrm{N} 2 \mathrm{O}, \text { units" }} \\
{[5 \mathrm{e}-10,5 \mathrm{e}-08] \mathrm{m}^{2} / \mathrm{s}}\end{array}$ \\
\hline
\end{tabular}

To determine a simulation design and prior distributions of the calibration parameters, it first was necessary to parameterize Henry's coefficient and diffusivity (the functional relationships from the literature are given in Table 11). From these correlations, somewhat conservative priors were determined. They are conservative in the sense that they allow for more uncertainty in the true values of Henry's coefficient and diffusivity than the literature. These priors can be found in Table 12.

Two batches of simulations were run resulting in a total sample size of 151 . The statistical design for each used heuristic reasoning as well as formal principles: points were selected to be sufficiently "spread out" while still being close to the experimental data in the $\boldsymbol{x}$-space. 
Table 11 Default Relationships between Calibration Inputs and Experimental Inputs for the Nonreacting Scenario

\begin{tabular}{|c|c|}
\hline Relationship & Reference / Notes \\
\hline $\begin{array}{c}H_{\mathrm{N} 2 \mathrm{O}, \text { units }}=H_{\mathrm{N} 2 \mathrm{O}, \mathrm{H} 2 \mathrm{O}} \cdot x_{\mathrm{H} 2 \mathrm{O}}+H_{\mathrm{N} 2 \mathrm{O}, \mathrm{MEA}} \cdot x_{\mathrm{MEA}} \\
+c_{1} \cdot\left(x_{\mathrm{H} 2 \mathrm{O}} \cdot x_{\mathrm{MEA}}\right)^{2}\left(1-T / c_{2}\right) \\
\cdot \exp \left(-c_{3} \cdot x_{\mathrm{MEA}}\right)+c_{4} \\
c_{1}=3524641.533 \\
c_{2}=324.718 \\
c_{3}=13.219 \\
c_{4}=0\end{array}$ & Penttila et al. [22] Eq. (5) \\
\hline $\begin{aligned} H_{\mathrm{N} 2 \mathrm{O}, \mathrm{H} 2 \mathrm{O}}= & \exp (158.245-9048.596 / T \\
& -20.860 \cdot \ln T-0.00252 \cdot T) \\
H_{\mathrm{N} 2 \mathrm{O}, \mathrm{MEA}}= & -9172.50+39.598 \cdot T\end{aligned}$ & $\begin{array}{l}\text { Eq. (3) with Table } 1 \\
\text { Eq. (4) with Table } 1\end{array}$ \\
\hline $\begin{aligned} D_{\mathrm{N} 2 \mathrm{O}}=\mathrm{C}_{5} \cdot \exp \left(-c_{6} / T\right) \cdot\left(\mu_{\mathrm{sln}} / \mu_{\mathrm{H} 2 \mathrm{O}}\right)_{-}{ }^{{ }^{7} 7} \\
c_{5}=5.07 \mathrm{e}-06 \\
c_{6}=2371 \\
c_{7}=0.8\end{aligned}$ & Versteeg and van Swaaij [23] Eqs. (9),(11) \\
\hline
\end{tabular}

Table 12 Priors for Calibration Parameters

\begin{tabular}{|c|c|}
\hline$\left[c_{1}, c_{2}, c_{3}, c_{4}\right]$ & $\begin{array}{ll}\text { Uniform on } & {[\exp (14.5), \exp (15.5)]} \\
& \times[200,333.15] \\
& \times[10,50] \\
& \times[-3000,3000] \\
\text { such that } \quad 2000 \leq \min \left(H_{\mathrm{N} 2 \mathrm{O}, \text { units }}\right) \leq 6000 \\
\text { and } \quad 6000 \leq \max \left(H_{\mathrm{N} 2 \mathrm{O}, \text { units }}\right) \leq 12000\end{array}$ \\
\hline$\left[c_{5}, c_{6}, c_{7}\right]$ & $\begin{array}{ll}\text { Uniform on } & {[\exp (-15), \exp (-10)]} \\
& \times[2200,2500] \\
& \times[0,1.5] \\
\text { Such that } 5 \mathrm{e}-10 \leq & \min \left(D_{\mathrm{N} 2 \mathrm{O}}\right) \\
\text { and } & \max \left(D_{\mathrm{N} 2 \mathrm{O}}\right) \leq 5 \mathrm{e}-08\end{array}$ \\
\hline
\end{tabular}

The experimental and simulated data were combined using a Bayesian Gaussian processbased calibration algorithm, and the Markov Chain Monte Carlo routine therein was run for 60,000 iterations (at which point it was determined that the algorithm had reached steady state). Figure 18 and Figure 19 summarize some of the results.

Figure 18 contains the estimated one-dimensional marginal distributions (histograms) for each of the seven parameters that parameterize Henry's coefficient and diffusivity. It is evident that there is considerable uncertainty in each parameter, and the posterior means and modes do not necessarily agree with the default values (in blue) found in the literature. However, this probably just reflects the limited amount of experimental data.

The two panels in Figure 19 contain predictive summaries drawn from the simulated data together with the experimental data. On the left, the red dots are the posterior means (point estimates, or "best guesses”) of what the simulator data's response surface would predict the 
experimental data should be, conditioned on the fact that the true values of the calibration parameters are unknown. The vertical red line segment widths encapsulate the uncertainty in the true calibration inputs. From this, it can be seen that there is considerable variability in the response surface built from the simulated data alone. The "calibrated prediction" in the right panel refers to predictions built upon all existing data. That is, predictions that incorporate the inferred discrepancy between simulated and experimental. Here, it shows that both bias and variance are reduced after including model discrepancy.
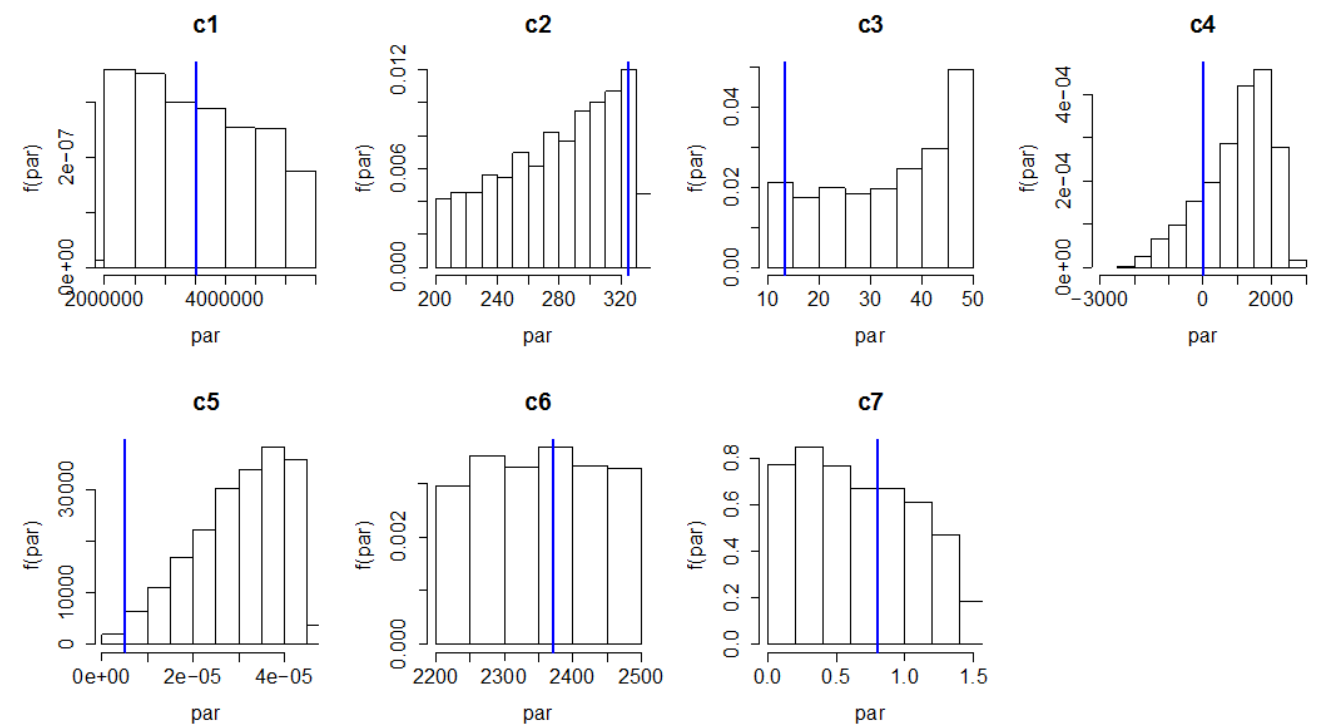

Figure 18 Estimated Marginal Posterior Distributions for the Calibration Parameters of the Nonreacting Scenario (blue line segments are the point estimates found in the literature)
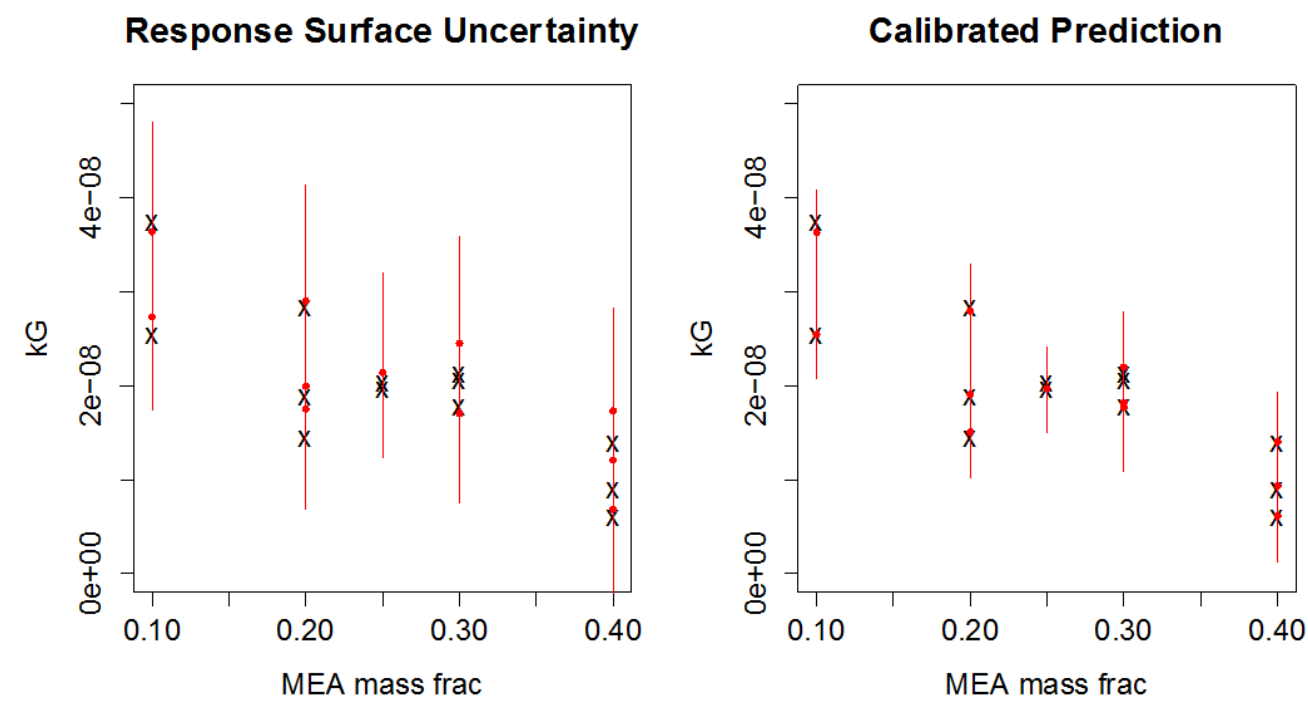

Figure 19 Predictive Diagnostic Plots for the Non-reaction Scenario (both panels compare the experimental data points (black " $x$ ") to predicted simulator output (red); refer to the text for more indepth descriptions) 


\section{2 $\mathrm{CO}_{2} /$ MEA System}

The method used to obtain a statistical design for the experimental reacting data is similar to that of the non-reacting data. However, for this scenario, a set of 32 experiments was planned in such a way so that the $x$-space would be "covered" by 29 points, and three of those points would be replicated to better estimate true experimental uncertainty. Two batches of simulations resulted in a total of 241 runs.

Parametric distributions were fit to the posteriors from the non-reacting results, and these were used as the priors in the present analysis. This can be done because the Stokes-Einstein equations given in Table 14 relate the Henry's coefficient (or diffusivity) for $\mathrm{N}_{2} \mathrm{O}$ to that of $\mathrm{CO}_{2}$ via a ratio. Two more parameters were added to characterize the rate constant $\left(c_{8}, c_{9}\right)$. The priors on these were uniform on the hyperrectangle $[15,25] \times[3500,7500]$, subject to the constraint that $k_{2}$ at the highest temperature could not be smaller than 10 or greater than 70 .

Table 13 Inputs to the Computer Model for the Reacting Case

\begin{tabular}{|l|l|}
\hline Input & Range / Units \\
\hline Experimental, $\boldsymbol{x}:$ & \\
Temperature & {$[25,60]{ }^{\circ} \mathrm{C}$} \\
MEA mass fraction & {$[0.1,0.4] \mathrm{g} \mathrm{MEA} / \mathrm{g}$ total } \\
$\mathrm{CO}_{2}$ loading in MEA & {$[0.0,0.5] \mathrm{mol} \mathrm{CO} / \mathrm{mol} \mathrm{MEA}$} \\
Solvent flow rate & {$[300,600] \mathrm{ccm}$} \\
Gas flow rate & {$[2000,6000] \mathrm{sccm}$} \\
Inlet CO molar concentration & {$[0.03,0.20] \mathrm{mol} / \mathrm{L}$} \\
\hline Calibration, $\boldsymbol{t}:$ & {$[0.2,0.9]$ unitless; } \\
$\left(H_{\mathrm{N} 2 \mathrm{O}}\right)$ Henry's coefficient & Converted from “ $H_{\mathrm{N} 2 \mathrm{O}, \text { units" }}$ \\
& {$[5 \mathrm{e}-10,5 \mathrm{e}-08] \mathrm{m} \mathrm{m}^{2} / \mathrm{s}$} \\
$\left(D_{\mathrm{N} 2 \mathrm{O}}\right)$ Diffusivity & {$[0,70] \mathrm{m}^{3} /(\mathrm{mol} \cdot \mathrm{s})$} \\
$\left(k_{2}\right)$ Rate Constant &
\end{tabular}

Table 14 Default Relationships for the Reacting Scenario

\begin{tabular}{|c|c|}
\hline Relationship & Reference / Notes \\
\hline$H_{\mathrm{CO} 2 \text {,units }}=H_{\mathrm{N} 2 \mathrm{O} \text {,units }} \cdot\left(H_{\mathrm{CO} 2, \mathrm{H} 2 \mathrm{O}} / H_{\mathrm{N} 2 \mathrm{O}, \mathrm{H} 2 \mathrm{O}}\right)$ & Li and Lai [2] Eq. (1) \\
\hline $\begin{aligned} H_{\mathrm{CO} 2, \mathrm{H} 2 \mathrm{O}}= & \exp (145.369-8172.355 / T \\
& -19.303 \cdot \ln T) \\
H_{\mathrm{N} 2 \mathrm{O}, \mathrm{H} 2 \mathrm{O}}= & (\text { given previously })\end{aligned}$ & $\begin{array}{r}\text { Penttila et al.[22] Eq. (2) } \\
\text { Eq. (3) with Table } 1\end{array}$ \\
\hline $\begin{aligned} D_{\mathrm{CO} 2}=D_{\mathrm{N} 2 \mathrm{O}} \cdot\left(D_{\mathrm{CO} 2, \mathrm{H} 2 \mathrm{O}} / D_{\mathrm{N} 2 \mathrm{O}, \mathrm{H} 2 \mathrm{O}}\right) \\
D_{\mathrm{CO} 2, \mathrm{H} 2 \mathrm{O}}=(2.35 \mathrm{e}-06) \cdot \exp (-2119 / T) \\
D_{\mathrm{N} 2 \mathrm{O}, \mathrm{H} 2}=(5.07 \mathrm{e}-06) \cdot \exp (-2371 / T)\end{aligned}$ & $\begin{array}{l}\text { Li and Lai [2] Eq. (2) } \\
\text { Eq. (6) } \\
\text { Eq. (5) }\end{array}$ \\
\hline $\begin{array}{ll}\text { Rate Constant } & k_{2}=\exp \left(c_{8}-c_{9} / T\right) \\
& c_{8}=20.54396 \\
c_{9} & =5612.91378\end{array}$ & $\begin{array}{l}\text { Ali [24] } \\
\quad \text { Regressed from data in Table } 1\end{array}$ \\
\hline
\end{tabular}


To achieve convergence, the calibration routine was run for a total of 110,000 iterations, and Figure 20 and Figure 21 show the results. It can be seen that the posteriors for $c_{1}-c_{7}$ (parameterizing Henry's coefficient and diffusivity) after this calibration are not qualitatively different from the posteriors following the non-reacting calibration. That is, there was not much information about these quantities after combining the experimental and simulated reacting data. The data seemingly only informs the parameterization of the rate constant, but this could be reasonable.

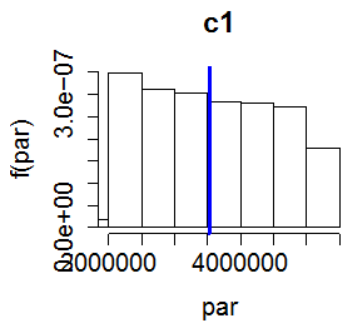

c5

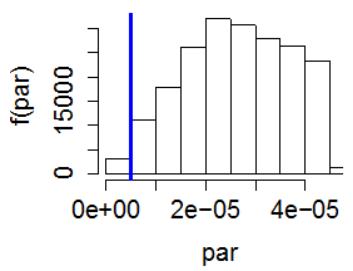

c8

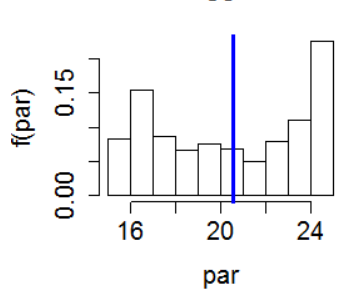

c2

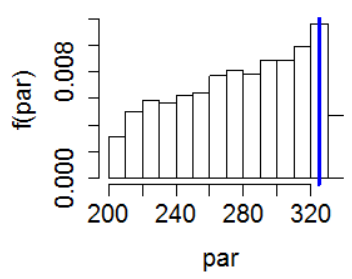

c6

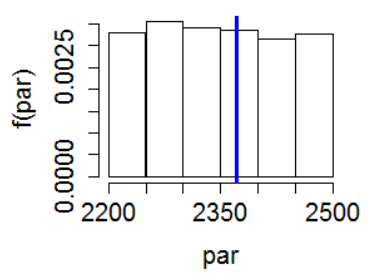

c9

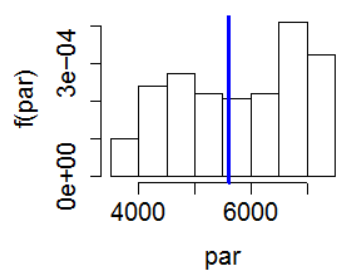

c3

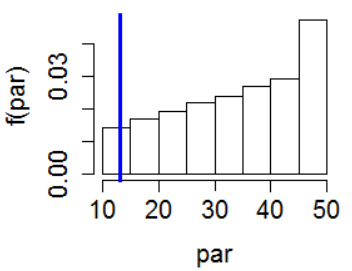

c7

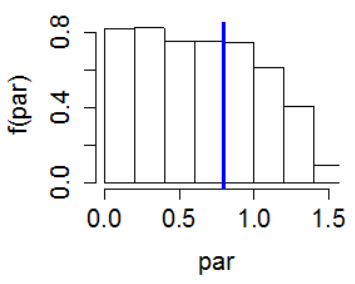

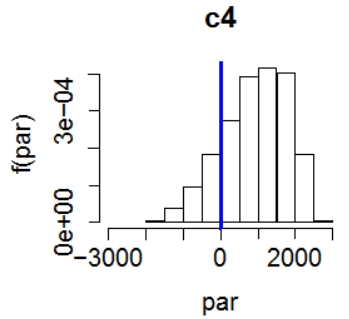

Figure 20 Estimated Marginal Posterior Distributions for the Calibration Parameters of the Reacting Scenario (blue line segments are the point estimates found in the literature) 


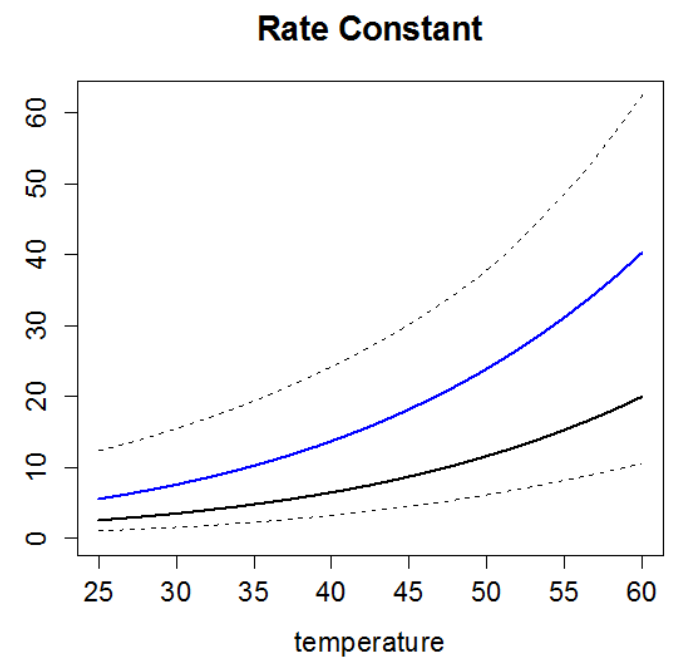

Figure 21 Uncertainty, the Rate Constant, as a Function of Temperature (C) (blue curve is derived from the literature, while the black curve is the median prediction; the dashed lines form pointwise $\mathbf{9 0 \%}$ intervals)

Response Surface Uncertainty

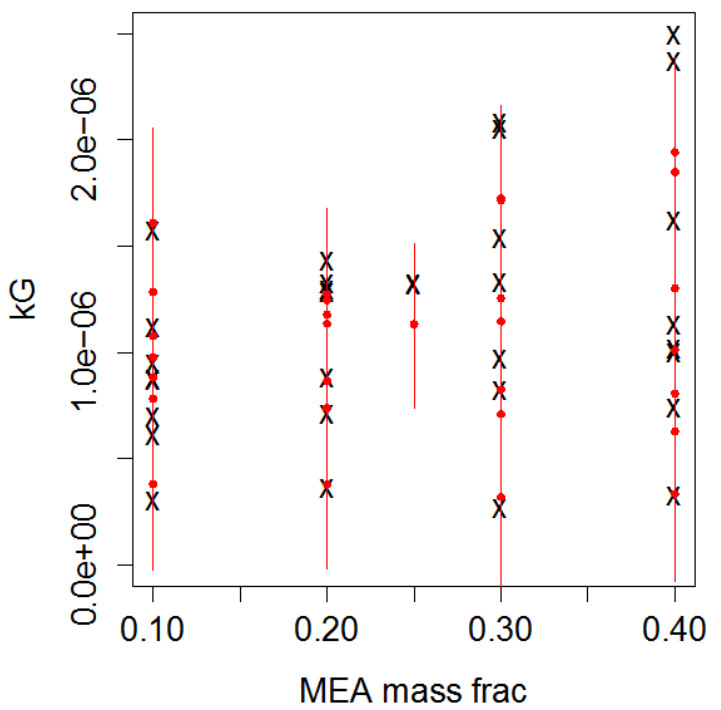

Calibrated Prediction

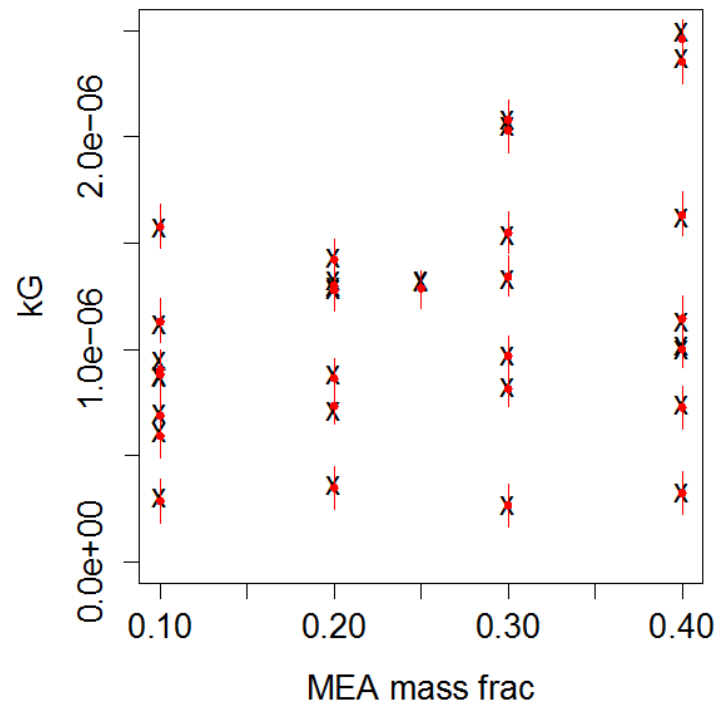

Figure 22 Predictive Diagnostic Plots for the Reacting Scenario (both panels compare the experimental data points (black “ $x$ ") to predicted simulator output (red); refer to the text for more in-depth descriptions)

The panels of Figure 22 tell a similar story: before incorporating the experimental observations, the response surface based upon the simulations has a fair amount of variation that can potentially mimic the trend of the experimental data (left). However, after learning the model discrepancy, the calibrated predictions are centered on the correct values and have uncertainties related purely to small experimental error (right).

By the end of this second analysis, we have demonstrated that the Bayesian calibration methodology can be used to validate models, as well as quantify and propagate parametric 
uncertainties. From here, it would be possible, for example, to pass the samples from the second stage posteriors through a model of an upscaled system to get prediction intervals.

\section{Acknowledgments}

Pacific Northwest National Laboratory is operated by Battelle for the U.S. Department of Energy (DOE) under Contract No. DE-AC05-76RL01830. This work was funded by the DOE Office of Fossil Energy's Carbon Capture Simulation Initiative through the National Energy Technology Laboratory.

\section{References}

1. Sun, X., et al., A Validation Hierarchy for CFD Models of Solvent-based Carbon Capture Systems. 2015, PNNL: Richland, WA

2. Li, M.H. and M.D. Lai, Solubility and Diffusivity of N2o and Co2 in (Monoethanolamine Plus N-Methyldiethanolamine Plus Water) and in (Monoethanolamine Plus 2-Amino-2-Methyl-1-Propanol Plus Water). Journal of Chemical and Engineering Data, 1995. 40(2): p. 486-492.

3. Weiland, R.H., et al., Density and viscosity of some partially carbonated aqueous alkanolamine solutions and their blends. Journal of Chemical and Engineering Data, 1998. 43(3): p. 378-382.

4. Astronautics, A.I.o.A.A., AIAA Guide for the Verification and Validation of Computational Fluid Dynamics Simulations. AIAA G-077-1998. 1998, Renton, VA: American Institute of Aeronautics \& Astronautics.

5. Oberkampf, W.L. and C.J. Roy, Verification and Validation in Scientific Computing. 2010: Cambridge University Press.

6. Aronu, U.E., et al., Solubility of CO2 in 15, 30, 45 and 60 mass\% MEA from 40 to 120 degrees $C$ and model representation using the extended UNIQUAC framework. Chemical Engineering Science, 2011. 66(24): p. 6393-6406.

7. Brackbill, J.U., D.B. Kothe, and C. Zemach, A Continuum Method for Modeling Surface-Tension. Journal of Computational Physics, 1992. 100(2): p. 335-354.

8. Haroun, Y., D. Legendre, and L. Raynal, Direct numerical simulation of reactive absorption in gas-liquid flow on structured packing using interface capturing method. Chemical Engineering Science, 2010. 65(1): p. 351-356.

9. Astarita, G., D.W. Savage, and A. Bistro, Gas Treating with Chemical Solvents. 1983, New York: John Wiley \& Sons.

10. Danckwerts, P.V., Gas-Liquid Reactions. 1970: McGraw-Hill Book Company.

11. Gabrielsen, J., et al., A model for estimating CO2 solubility in aqueous alkanolamines. Industrial \& Engineering Chemistry Research, 2005. 44(9): p. 33483354.

12. Hikita, H., et al., Kinetics of Reactions of Carbon-Dioxide with Monoethanolamine, Diethanolamine and Triethanolamine by a Rapid Mixing Method. Chemical Engineering Journal and the Biochemical Engineering Journal, 1977. 13(1): p. 7-12.

13. Khan, F.M. and T. Mahmud Modelling of Gas Absorbers for Carbon Dioxide Capture Applications. 
14. Snijder, E.D., et al., Diffusion-Coefficients of Several Aqueous Alkanolamine Solutions. Journal of Chemical and Engineering Data, 1993. 38(3): p. 475-480.

15. Wilke, C.R., A Viscosity Equation for Gas Mixtures. Journal of Chemical Physics, 1950. 18(4): p. 517-519.

16. Cussler, E.L., Diffusion: Mass Transfer in Fluid Systems. 2nd ed. 1997: New York: Cambridge University Press.

17. Fu, D., et al., Experiments and model for the surface tension of carbonated monoethanolamine aqueous solutions. Science China-Chemistry, 2012. 55(7): p. 1467-1473.

18. Gao, D., N.B. Morley, and V. Dhir, Numerical simulation of wavy falling film flow using VOF method. Journal of Computational Physics, 2003. 192(2): p. 624-642.

19. Hu, J.G., et al., Numerical simulation of carbon dioxide (CO2) absorption and interfacial mass transfer across vertically wavy falling film. Chemical Engineering Science, 2014. 116: p. 243-253.

20. Xu, Z.F., B.C. Khoo, and N.E. Wijeysundera, Mass transfer across the falling film: Simulations and experiments. Chemical Engineering Science, 2008. 63(9): p. 25592575.

21. Kennedy, M.C. and A. O'Hagan, Bayesian calibration of computer models. Journal of the Royal Statistical Society Series B-Statistical Methodology, 2001. 63: p. 425-450.

22. Penttila, A., et al., The Henry's law constant of $\mathrm{N} 2 \mathrm{O}$ and $\mathrm{CO} 2$ in aqueous binary and ternary amine solutions (MEA, DEA, DIPA, MDEA, and AMP). Fluid Phase Equilibria, 2011. 311: p. 59-66.

23. Versteeg, G.F. and W.P.M. Vanswaaij, Solubility and Diffusivity of Acid Gases (Co2, N2o) in Aqueous Alkanolamine Solutions. Journal of Chemical and Engineering Data, 1988. 33(1): p. 29-34.

24. Ali, S.H., Kinetics of the reaction of carbon dioxide with blends of amines in aqueous media using the stopped-flow technique. International Journal of Chemical Kinetics, 2005. 37(7): p. 391-405.

\section{Appendix}

$\mathrm{N}_{2} \mathrm{O} / \mathrm{MEA}$

\begin{tabular}{|c|c|c|c|c|c|c|c|c|c|}
\hline ID & MEA & $\begin{array}{l}\mathrm{CO}_{2} \\
\text { Loading } \\
\end{array}$ & Temperature & $\begin{array}{l}\text { Solvent } \\
\text { Flow Rate } \\
\end{array}$ & $\begin{array}{l}\text { Gas Flow } \\
\text { Rate } \\
\end{array}$ & $\begin{array}{l}\mathrm{N}_{2} \mathrm{O} \\
\text { Conc. }\end{array}$ & $\begin{array}{l}\text { Henry's } \\
\text { Constant }\end{array}$ & Diffusivity & kG \\
\hline 1 & 0.2992 & 0.464 & 35 & 350 & 200 & 0.15 & 0.474659 & $7.86 \mathrm{E}-010$ & 2.75E-08 \\
\hline 2 & 0.2992 & 0.464 & 45 & 350 & 200 & 0.15 & 0.412627 & $1.04 \mathrm{E}-009$ & $1.83 \mathrm{E}-08$ \\
\hline 3 & 0.2992 & 0.464 & 55 & 350 & 200 & 0.15 & 0.364716 & 1.35E-009 & $1.55 \mathrm{E}-08$ \\
\hline 4 & 0.2992 & 0.5 & 35 & 350 & 200 & 0.15 & 0.474659 & $7.66 \mathrm{E}-010$ & $2.56 \mathrm{E}-08$ \\
\hline 5 & 0.2992 & 0.5 & 45 & 350 & 200 & 0.15 & 0.412627 & $1.01 \mathrm{E}-009$ & $1.74 \mathrm{E}-08$ \\
\hline 6 & 0.2992 & 0.5 & 55 & 350 & 200 & 0.15 & 0.364716 & $1.31 \mathrm{E}-009$ & $1.53 \mathrm{E}-08$ \\
\hline 7 & 0.25 & 0.3 & 42 & 450 & 200 & 0.325 & 0.426731 & $1.30 \mathrm{E}-009$ & 2.37E-08 \\
\hline 8 & 0.1 & 0.1 & 40 & 509.48 & 211.01 & 0.228 & 0.440978 & $2.08 \mathrm{E}-009$ & $3.11 \mathrm{E}-08$ \\
\hline 9 & 0.1 & 0.3 & 37 & 585.92 & 268.38 & 0.43 & 0.466508 & $1.87 \mathrm{E}-009$ & $3.60 \mathrm{E}-08$ \\
\hline 10 & 0.1 & 0.5 & 31 & 381.4 & 137.97 & 0.351 & 0.526328 & $1.55 \mathrm{E}-009$ & 3.34E-08 \\
\hline 11 & 0.2 & 0.1 & 28 & 308.78 & 299.62 & 0.483 & 0.536734 & $1.14 \mathrm{E}-009$ & 2.65E-08 \\
\hline
\end{tabular}




\begin{tabular}{|c|c|c|c|c|c|c|c|c|c|}
\hline ID & MEA & $\begin{array}{l}\mathrm{CO}_{2} \\
\text { Loading } \\
\end{array}$ & Temperature & $\begin{array}{l}\text { Solvent } \\
\text { Flow Rate } \\
\end{array}$ & $\begin{array}{l}\text { Gas Flow } \\
\text { Rate } \\
\end{array}$ & $\begin{array}{l}\mathrm{N}_{2} \mathrm{O} \\
\text { Conc. }\end{array}$ & $\begin{array}{l}\text { Henry's } \\
\text { Constant }\end{array}$ & Diffusivity & kG \\
\hline 12 & 0.2 & 0.3 & 55 & 412.78 & 256.46 & 0.299 & 0.355022 & 2.15E-009 & $1.93 \mathrm{E}-08$ \\
\hline 13 & 0.2 & 0.5 & 58 & 358.49 & 100.34 & 0.435 & 0.342359 & 2.13E-009 & $\mathrm{n} / \mathrm{a}$ \\
\hline 14 & 0.3 & 0.1 & 34 & 431.39 & 232.31 & 0.203 & 0.481741 & $9.78 \mathrm{E}-010$ & $2.96 \mathrm{E}-08$ \\
\hline 15 & 0.3 & 0.5 & 45 & 350 & 200 & 0.15 & 0.412695 & $1.01 \mathrm{E}-009$ & $1.93 \mathrm{E}-08$ \\
\hline 16 & 0.3 & 0.5 & 55 & 350 & 200 & 0.15 & 0.364798 & $1.31 \mathrm{E}-009$ & $1.52 \mathrm{E}-08$ \\
\hline 17 & 0.4 & 0.1 & 43 & 451.47 & 181.52 & 0.289 & 0.435482 & 8.94E-010 & $2.48 \mathrm{E}-08$ \\
\hline 18 & 0.4 & 0.3 & 53 & 557.88 & 170.25 & 0.386 & 0.384308 & $9.51 \mathrm{E}-010$ & $2.32 \mathrm{E}-08$ \\
\hline 19 & 0.4 & 0.5 & 47 & 535.83 & 158.41 & 0.165 & 0.41338 & $6.40 \mathrm{E}-010$ & $6.99 \mathrm{E}-09$ \\
\hline 20 & 0.25 & 0.3 & 42 & 450 & 200 & 0.325 & 0.376731 & $9.98 \mathrm{E}-010$ & $1.97 \mathrm{E}-08$ \\
\hline 21 & 0.25 & 0.3 & 42 & 450 & 200 & 0.325 & 0.401731 & $9.98 \mathrm{E}-010$ & 2.15E-08 \\
\hline 22 & 0.25 & 0.3 & 42 & 450 & 200 & 0.325 & 0.426731 & $9.98 \mathrm{E}-010$ & $2.34 \mathrm{E}-08$ \\
\hline 23 & 0.25 & 0.3 & 42 & 450 & 200 & 0.325 & 0.451731 & $9.98 \mathrm{E}-010$ & $2.55 \mathrm{E}-08$ \\
\hline 24 & 0.25 & 0.3 & 42 & 450 & 200 & 0.325 & 0.476731 & $9.98 \mathrm{E}-010$ & $2.76 \mathrm{E}-08$ \\
\hline 25 & 0.25 & 0.3 & 42 & 450 & 200 & 0.325 & 0.376731 & $1.15 \mathrm{E}-009$ & $1.99 \mathrm{E}-08$ \\
\hline 26 & 0.25 & 0.3 & 42 & 450 & 200 & 0.325 & 0.401731 & $1.15 \mathrm{E}-009$ & 2.16E-08 \\
\hline 27 & 0.25 & 0.3 & 42 & 450 & 200 & 0.325 & 0.426731 & $1.15 \mathrm{E}-009$ & 2.35E-08 \\
\hline 28 & 0.25 & 0.3 & 42 & 450 & 200 & 0.325 & 0.451731 & $1.15 \mathrm{E}-009$ & $2.56 \mathrm{E}-08$ \\
\hline 29 & 0.25 & 0.3 & 42 & 450 & 200 & 0.325 & 0.476731 & $1.15 \mathrm{E}-009$ & $2.78 \mathrm{E}-08$ \\
\hline 30 & 0.25 & 0.3 & 42 & 450 & 200 & 0.325 & 0.376731 & $1.30 \mathrm{E}-009$ & $2.00 \mathrm{E}-08$ \\
\hline 31 & 0.25 & 0.3 & 42 & 450 & 200 & 0.325 & 0.401731 & $1.30 \mathrm{E}-009$ & $2.18 \mathrm{E}-08$ \\
\hline 32 & 0.25 & 0.3 & 42 & 450 & 200 & 0.325 & 0.451731 & 1.30E-009 & $2.58 \mathrm{E}-08$ \\
\hline 33 & 0.25 & 0.3 & 42 & 450 & 200 & 0.325 & 0.476731 & $1.30 \mathrm{E}-009$ & $2.80 \mathrm{E}-08$ \\
\hline 34 & 0.25 & 0.3 & 42 & 450 & 200 & 0.325 & 0.376731 & $1.45 \mathrm{E}-009$ & $2.01 \mathrm{E}-08$ \\
\hline 35 & 0.25 & 0.3 & 42 & 450 & 200 & 0.325 & 0.401731 & $1.45 \mathrm{E}-009$ & $2.19 \mathrm{E}-08$ \\
\hline 36 & 0.25 & 0.3 & 42 & 450 & 200 & 0.325 & 0.426731 & $1.45 \mathrm{E}-009$ & $2.38 \mathrm{E}-08$ \\
\hline 37 & 0.25 & 0.3 & 42 & 450 & 200 & 0.325 & 0.451731 & 1.45E-009 & $2.59 \mathrm{E}-08$ \\
\hline 38 & 0.25 & 0.3 & 42 & 450 & 200 & 0.325 & 0.476731 & $1.45 \mathrm{E}-009$ & $2.81 \mathrm{E}-08$ \\
\hline 39 & 0.25 & 0.3 & 42 & 450 & 200 & 0.325 & 0.376731 & $1.60 \mathrm{E}-009$ & 2.03E-08 \\
\hline 40 & 0.25 & 0.3 & 42 & 450 & 200 & 0.325 & 0.401731 & $1.60 \mathrm{E}-009$ & $2.21 \mathrm{E}-08$ \\
\hline 41 & 0.25 & 0.3 & 42 & 450 & 200 & 0.325 & 0.426731 & $1.60 \mathrm{E}-009$ & $2.44 \mathrm{E}-08$ \\
\hline 42 & 0.25 & 0.3 & 42 & 450 & 200 & 0.325 & 0.451731 & $1.60 \mathrm{E}-009$ & $2.61 \mathrm{E}-08$ \\
\hline 43 & 0.25 & 0.3 & 42 & 450 & 200 & 0.325 & 0.476731 & $1.60 \mathrm{E}-009$ & $2.82 \mathrm{E}-08$ \\
\hline 44 & 0.15 & 0.1 & 30 & 400 & 150 & 0.2 & 0.527175 & 8.64E-10 & 3.23E-08 \\
\hline 45 & 0.15 & 0.1 & 30 & 400 & 150 & 0.2 & 0.527175 & 1.36E-09 & $3.28 \mathrm{E}-08$ \\
\hline 46 & 0.15 & 0.1 & 30 & 400 & 150 & 0.2 & 0.627175 & 2.16E-09 & 4.45E-08 \\
\hline 47 & 0.15 & 0.3 & 40 & 400 & 150 & 0.2 & 0.439575 & 1.67E-09 & $2.51 \mathrm{E}-08$ \\
\hline 48 & 0.15 & 0.3 & 40 & 400 & 150 & 0.2 & 0.539575 & 1.67E-09 & 3.36E-08 \\
\hline 49 & 0.15 & 0.3 & 40 & 400 & 150 & 0.2 & 0.339575 & 2.47E-09 & $1.83 \mathrm{E}-08$ \\
\hline 50 & 0.15 & 0.5 & 50 & 400 & 150 & 0.2 & 0.375588 & $1.50 \mathrm{E}-09$ & $1.99 \mathrm{E}-08$ \\
\hline 51 & 0.15 & 0.5 & 50 & 400 & 150 & 0.2 & 0.375588 & 2.00E-09 & 2.05E-08 \\
\hline
\end{tabular}




\begin{tabular}{|c|c|c|c|c|c|c|c|c|c|}
\hline ID & MEA & $\begin{array}{l}\mathrm{CO}_{2} \\
\text { Loading } \\
\end{array}$ & Temperature & $\begin{array}{l}\text { Solvent } \\
\text { Flow Rate }\end{array}$ & $\begin{array}{l}\text { Gas Flow } \\
\text { Rate }\end{array}$ & $\begin{array}{l}\mathrm{N}_{2} \mathrm{O} \\
\text { Conc. }\end{array}$ & $\begin{array}{l}\text { Henry's } \\
\text { Constant }\end{array}$ & Diffusivity & kG \\
\hline 52 & 0.15 & 0.5 & 50 & 400 & 150 & 0.2 & 0.275588 & 2.80E-09 & $1.45 \mathrm{E}-08$ \\
\hline 53 & 0.25 & 0.1 & 40 & 400 & 150 & 0.2 & 0.439309 & $1.36 \mathrm{E}-09$ & $2.42 \mathrm{E}-08$ \\
\hline 54 & 0.25 & 0.1 & 40 & 400 & 150 & 0.2 & 0.539309 & $1.36 \mathrm{E}-09$ & $3.27 \mathrm{E}-08$ \\
\hline 55 & 0.25 & 0.1 & 40 & 400 & 150 & 0.2 & 0.439309 & 2.16E-09 & 2.47E-08 \\
\hline 56 & 0.25 & 0.3 & 50 & 400 & 150 & 0.2 & 0.382694 & $1.06 \mathrm{E}-09$ & $1.92 \mathrm{E}-08$ \\
\hline 57 & 0.25 & 0.3 & 50 & 400 & 150 & 0.2 & 0.382694 & $1.56 \mathrm{E}-09$ & $1.94 \mathrm{E}-08$ \\
\hline 58 & 0.25 & 0.3 & 50 & 400 & 150 & 0.2 & 0.482694 & $1.56 \mathrm{E}-09$ & 2.73E-08 \\
\hline 59 & 0.25 & 0.5 & 30 & 400 & 150 & 0.2 & 0.512564 & $3.04 \mathrm{E}-10$ & 3.07E-08 \\
\hline 60 & 0.25 & 0.5 & 30 & 400 & 150 & 0.2 & 0.512564 & 8.04E-10 & 3.22E-08 \\
\hline 61 & 0.25 & 0.5 & 30 & 400 & 150 & 0.2 & 0.612564 & $1.60 \mathrm{E}-09$ & 4.31E-08 \\
\hline 62 & 0.35 & 0.1 & 50 & 400 & 150 & 0.2 & 0.492264 & $8.45 \mathrm{E}-10$ & $2.78 \mathrm{E}-08$ \\
\hline 63 & 0.35 & 0.1 & 50 & 400 & 150 & 0.2 & 0.292264 & $1.35 \mathrm{E}-09$ & $1.35 \mathrm{E}-08$ \\
\hline 64 & 0.35 & 0.1 & 50 & 400 & 150 & 0.2 & 0.392264 & $1.35 \mathrm{E}-09$ & $2.02 \mathrm{E}-08$ \\
\hline 65 & 0.35 & 0.3 & 30 & 400 & 150 & 0.2 & 0.515216 & $1.20 \mathrm{E}-10$ & $3.44 \mathrm{E}-08$ \\
\hline 66 & 0.35 & 0.3 & 30 & 400 & 150 & 0.2 & 0.515216 & $6.20 \mathrm{E}-10$ & 3.46E-08 \\
\hline 67 & 0.35 & 0.3 & 30 & 400 & 150 & 0.2 & 0.415216 & 1.42E-09 & 2.83E-08 \\
\hline 68 & 0.35 & 0.5 & 40 & 400 & 150 & 0.2 & 0.546548 & $1.89 \mathrm{E}-10$ & $3.98 \mathrm{E}-08$ \\
\hline 69 & 0.35 & 0.5 & 40 & 400 & 150 & 0.2 & 0.346548 & $6.89 \mathrm{E}-10$ & 2.19E-08 \\
\hline 70 & 0.35 & 0.5 & 40 & 400 & 150 & 0.2 & 0.446548 & $6.89 \mathrm{E}-10$ & 3.01E-08 \\
\hline 71 & 0.15 & 0.1 & 30 & 400 & 250 & 0.2 & 0.627175 & $8.64 \mathrm{E}-10$ & 4.36E-08 \\
\hline 72 & 0.15 & 0.1 & 30 & 400 & 250 & 0.2 & 0.527175 & $1.36 \mathrm{E}-09$ & 3.35E-08 \\
\hline 73 & 0.15 & 0.1 & 30 & 400 & 250 & 0.2 & 0.627175 & 2.16E-09 & 4.53E-08 \\
\hline 74 & 0.15 & 0.3 & 40 & 400 & 250 & 0.2 & 0.439575 & 1.17E-09 & 2.45E-08 \\
\hline 75 & 0.15 & 0.3 & 40 & 400 & 250 & 0.2 & 0.439575 & 1.67E-09 & $2.51 \mathrm{E}-08$ \\
\hline 76 & 0.15 & 0.3 & 40 & 400 & 250 & 0.2 & 0.539575 & 2.47E-09 & 3.53E-08 \\
\hline 77 & 0.15 & 0.5 & 50 & 400 & 250 & 0.2 & 0.475588 & $1.50 \mathrm{E}-09$ & 2.73E-08 \\
\hline 78 & 0.15 & 0.5 & 50 & 400 & 250 & 0.2 & 0.275588 & $2.00 \mathrm{E}-09$ & $1.37 \mathrm{E}-08$ \\
\hline 79 & 0.15 & 0.5 & 50 & 400 & 250 & 0.2 & 0.375588 & $2.00 \mathrm{E}-09$ & 2.05E-08 \\
\hline 80 & 0.25 & 0.1 & 40 & 400 & 250 & 0.2 & 0.339309 & 8.57E-10 & $1.64 \mathrm{E}-08$ \\
\hline 81 & 0.25 & 0.1 & 40 & 400 & 250 & 0.2 & 0.339309 & $1.36 \mathrm{E}-09$ & $1.67 \mathrm{E}-08$ \\
\hline 82 & 0.25 & 0.1 & 40 & 400 & 250 & 0.2 & 0.439309 & $1.36 \mathrm{E}-09$ & 2.42E-08 \\
\hline 83 & 0.25 & 0.3 & 50 & 400 & 250 & 0.2 & 0.282694 & $1.56 \mathrm{E}-09$ & $1.32 \mathrm{E}-08$ \\
\hline 84 & 0.25 & 0.3 & 50 & 400 & 250 & 0.2 & 0.382694 & $1.56 \mathrm{E}-09$ & $2.00 \mathrm{E}-08$ \\
\hline 85 & 0.25 & 0.3 & 50 & 400 & 250 & 0.2 & 0.482694 & 2.36E-09 & 2.85E-08 \\
\hline 86 & 0.25 & 0.5 & 30 & 400 & 250 & 0.2 & 0.612564 & $3.04 \mathrm{E}-10$ & 4.38E-08 \\
\hline 87 & 0.25 & 0.5 & 30 & 400 & 250 & 0.2 & 0.512564 & $8.04 \mathrm{E}-10$ & 3.57E-08 \\
\hline 88 & 0.25 & 0.5 & 30 & 400 & 250 & 0.2 & 0.412564 & $1.60 \mathrm{E}-09$ & $2.85 \mathrm{E}-08$ \\
\hline 89 & 0.35 & 0.1 & 50 & 400 & 250 & 0.2 & 0.392264 & $1.35 \mathrm{E}-09$ & $2.02 \mathrm{E}-08$ \\
\hline 90 & 0.35 & 0.1 & 50 & 400 & 250 & 0.2 & 0.292264 & $2.15 \mathrm{E}-09$ & $1.38 \mathrm{E}-08$ \\
\hline 91 & 0.35 & 0.1 & 50 & 400 & 250 & 0.2 & 0.492264 & 2.15E-09 & $2.86 \mathrm{E}-08$ \\
\hline
\end{tabular}




\begin{tabular}{|c|c|c|c|c|c|c|c|c|c|}
\hline ID & MEA & $\begin{array}{l}\mathrm{CO}_{2} \\
\text { Loading } \\
\end{array}$ & Temperature & $\begin{array}{l}\text { Solvent } \\
\text { Flow Rate } \\
\end{array}$ & $\begin{array}{l}\text { Gas Flow } \\
\text { Rate } \\
\end{array}$ & $\begin{array}{l}\mathrm{N}_{2} \mathrm{O} \\
\text { Conc. }\end{array}$ & $\begin{array}{l}\text { Henry's } \\
\text { Constant }\end{array}$ & Diffusivity & kG \\
\hline 92 & 0.35 & 0.3 & 30 & 400 & 250 & 0.2 & 0.415216 & $1.20 \mathrm{E}-10$ & 2.35E-08 \\
\hline 93 & 0.35 & 0.3 & 30 & 400 & 250 & 0.2 & 0.515216 & $6.20 \mathrm{E}-10$ & $3.12 \mathrm{E}-08$ \\
\hline 94 & 0.35 & 0.3 & 30 & 400 & 250 & 0.2 & 0.415216 & $1.42 \mathrm{E}-09$ & $2.46 \mathrm{E}-08$ \\
\hline 95 & 0.35 & 0.5 & 40 & 400 & 250 & 0.2 & 0.446548 & $1.89 \mathrm{E}-10$ & $2.90 \mathrm{E}-08$ \\
\hline 96 & 0.35 & 0.5 & 40 & 400 & 250 & 0.2 & 0.346548 & $6.89 \mathrm{E}-10$ & $2.19 \mathrm{E}-08$ \\
\hline 97 & 0.35 & 0.5 & 40 & 400 & 250 & 0.2 & 0.446548 & $6.89 \mathrm{E}-10$ & 2.93E-08 \\
\hline 98 & 0.15 & 0.1 & 30 & 500 & 150 & 0.4 & 0.427175 & $8.64 \mathrm{E}-10$ & $2.56 \mathrm{E}-08$ \\
\hline 99 & 0.15 & 0.1 & 30 & 500 & 150 & 0.4 & 0.527175 & $8.64 \mathrm{E}-10$ & 3.36E-08 \\
\hline 100 & 0.15 & 0.1 & 30 & 500 & 150 & 0.4 & 0.527175 & $1.36 \mathrm{E}-09$ & 3.49E-08 \\
\hline 101 & 0.15 & 0.3 & 40 & 500 & 150 & 0.4 & 0.539575 & $1.17 \mathrm{E}-09$ & $3.48 \mathrm{E}-08$ \\
\hline 102 & 0.15 & 0.3 & 40 & 500 & 150 & 0.4 & 0.439575 & 1.67E-09 & 2.83E-08 \\
\hline 103 & 0.15 & 0.3 & 40 & 500 & 150 & 0.4 & 0.539575 & 1.67E-09 & 3.65E-08 \\
\hline 104 & 0.15 & 0.5 & 50 & 500 & 150 & 0.4 & 0.275588 & $1.50 \mathrm{E}-09$ & $1.62 \mathrm{E}-08$ \\
\hline 105 & 0.15 & 0.5 & 50 & 500 & 150 & 0.4 & 0.475588 & $1.50 \mathrm{E}-09$ & 3.03E-08 \\
\hline 106 & 0.15 & 0.5 & 50 & 500 & 150 & 0.4 & 0.375588 & $2.00 \mathrm{E}-09$ & $2.45 \mathrm{E}-08$ \\
\hline 107 & 0.25 & 0.1 & 40 & 500 & 150 & 0.4 & 0.439309 & 8.57E-10 & $2.44 \mathrm{E}-08$ \\
\hline 108 & 0.25 & 0.1 & 40 & 500 & 150 & 0.4 & 0.439309 & $1.36 \mathrm{E}-09$ & $2.52 \mathrm{E}-08$ \\
\hline 109 & 0.25 & 0.1 & 40 & 500 & 150 & 0.4 & 0.539309 & $1.36 \mathrm{E}-09$ & $3.43 \mathrm{E}-08$ \\
\hline 110 & 0.25 & 0.3 & 50 & 500 & 150 & 0.4 & 0.482694 & $1.06 \mathrm{E}-09$ & $2.80 \mathrm{E}-08$ \\
\hline 111 & 0.25 & 0.3 & 50 & 500 & 150 & 0.4 & 0.282694 & $1.56 \mathrm{E}-09$ & $1.48 \mathrm{E}-08$ \\
\hline 112 & 0.25 & 0.3 & 50 & 500 & 150 & 0.4 & 0.382694 & $1.56 \mathrm{E}-09$ & $2.12 \mathrm{E}-08$ \\
\hline 113 & 0.25 & 0.5 & 30 & 500 & 150 & 0.4 & 0.512564 & $8.04 \mathrm{E}-10$ & 3.76E-08 \\
\hline 114 & 0.25 & 0.5 & 30 & 500 & 150 & 0.4 & 0.612564 & 8.04E-10 & 4.95E-08 \\
\hline 115 & 0.25 & 0.5 & 30 & 500 & 150 & 0.4 & 0.512564 & $1.60 \mathrm{E}-09$ & 3.93E-08 \\
\hline 116 & 0.35 & 0.1 & 50 & 500 & 150 & 0.4 & 0.492264 & $8.45 \mathrm{E}-10$ & $2.71 \mathrm{E}-08$ \\
\hline 117 & 0.35 & 0.1 & 50 & 500 & 150 & 0.4 & 0.292264 & 1.35E-09 & $1.46 \mathrm{E}-08$ \\
\hline 118 & 0.35 & 0.1 & 50 & 500 & 150 & 0.4 & 0.392264 & $1.35 \mathrm{E}-09$ & $2.05 \mathrm{E}-08$ \\
\hline 119 & 0.35 & 0.3 & 30 & 500 & 150 & 0.4 & 0.415216 & $1.20 \mathrm{E}-10$ & 3.04E-08 \\
\hline 120 & 0.35 & 0.3 & 30 & 500 & 150 & 0.4 & 0.515216 & $6.20 \mathrm{E}-10$ & 4.08E-08 \\
\hline 121 & 0.35 & 0.3 & 30 & 500 & 150 & 0.4 & 0.415216 & $1.42 \mathrm{E}-09$ & 3.07E-08 \\
\hline 122 & 0.35 & 0.5 & 40 & 500 & 150 & 0.4 & 0.446548 & $6.89 \mathrm{E}-10$ & 3.89E-08 \\
\hline 123 & 0.35 & 0.5 & 40 & 500 & 150 & 0.4 & 0.546548 & $6.89 \mathrm{E}-10$ & $5.00 \mathrm{E}-08$ \\
\hline 124 & 0.35 & 0.5 & 40 & 500 & 150 & 0.4 & 0.446548 & $1.49 \mathrm{E}-09$ & $4.41 \mathrm{E}-08$ \\
\hline 125 & 0.15 & 0.1 & 30 & 500 & 250 & 0.4 & 0.527175 & $1.36 \mathrm{E}-09$ & $3.51 \mathrm{E}-08$ \\
\hline 126 & 0.15 & 0.1 & 30 & 500 & 250 & 0.4 & 0.427175 & 2.16E-09 & 2.77E-08 \\
\hline 127 & 0.15 & 0.1 & 30 & 500 & 250 & 0.4 & 0.527175 & 2.16E-09 & 3.73E-08 \\
\hline 128 & 0.15 & 0.3 & 40 & 500 & 250 & 0.4 & 0.339575 & $1.17 \mathrm{E}-09$ & 2.02E-08 \\
\hline 129 & 0.15 & 0.3 & 40 & 500 & 250 & 0.4 & 0.439575 & $1.67 \mathrm{E}-09$ & 2.83E-08 \\
\hline 130 & 0.15 & 0.3 & 40 & 500 & 250 & 0.4 & 0.539575 & 2.47E-09 & $3.91 \mathrm{E}-08$ \\
\hline 131 & 0.15 & 0.5 & 50 & 500 & 250 & 0.4 & 0.375588 & $1.50 \mathrm{E}-09$ & 2.32E-08 \\
\hline
\end{tabular}




\begin{tabular}{|c|c|c|c|c|c|c|c|c|c|}
\hline ID & MEA & $\begin{array}{l}\mathrm{CO}_{2} \\
\text { Loading }\end{array}$ & Temperature & $\begin{array}{l}\text { Solvent } \\
\text { Flow Rate } \\
\end{array}$ & $\begin{array}{l}\text { Gas Flow } \\
\text { Rate }\end{array}$ & $\begin{array}{l}\mathrm{N}_{2} \mathrm{O} \\
\text { Conc. }\end{array}$ & $\begin{array}{l}\text { Henry's } \\
\text { Constant }\end{array}$ & Diffusivity & kG \\
\hline 132 & 0.15 & 0.5 & 50 & 500 & 250 & 0.4 & 0.375588 & 2.00E-09 & $2.45 \mathrm{E}-08$ \\
\hline 133 & 0.15 & 0.5 & 50 & 500 & 250 & 0.4 & 0.375588 & $2.80 \mathrm{E}-09$ & $2.64 \mathrm{E}-08$ \\
\hline 134 & 0.25 & 0.1 & 40 & 500 & 250 & 0.4 & 0.439309 & 1.36E-09 & 2.53E-08 \\
\hline 135 & 0.25 & 0.1 & 40 & 500 & 250 & 0.4 & 0.539309 & 1.36E-09 & $3.42 \mathrm{E}-08$ \\
\hline 136 & 0.25 & 0.1 & 40 & 500 & 250 & 0.4 & 0.539309 & 2.16E-09 & $3.60 \mathrm{E}-08$ \\
\hline 137 & 0.25 & 0.3 & 50 & 500 & 250 & 0.4 & 0.382694 & $1.06 \mathrm{E}-09$ & 2.02E-08 \\
\hline 138 & 0.25 & 0.3 & 50 & 500 & 250 & 0.4 & 0.282694 & $1.56 \mathrm{E}-09$ & $1.48 \mathrm{E}-08$ \\
\hline 139 & 0.25 & 0.3 & 50 & 500 & 250 & 0.4 & 0.382694 & 1.56E-09 & $2.12 \mathrm{E}-08$ \\
\hline 140 & 0.25 & 0.5 & 30 & 500 & 250 & 0.4 & 0.412564 & $3.04 \mathrm{E}-10$ & $2.78 \mathrm{E}-08$ \\
\hline 141 & 0.25 & 0.5 & 30 & 500 & 250 & 0.4 & 0.512564 & 8.04E-10 & $3.98 \mathrm{E}-08$ \\
\hline 142 & 0.25 & 0.5 & 30 & 500 & 250 & 0.4 & 0.412564 & 1.60E-09 & $2.78 \mathrm{E}-08$ \\
\hline 143 & 0.35 & 0.1 & 50 & 500 & 250 & 0.4 & 0.392264 & 1.35E-09 & 2.05E-08 \\
\hline 144 & 0.35 & 0.1 & 50 & 500 & 250 & 0.4 & 0.392264 & 2.15E-09 & $2.20 \mathrm{E}-08$ \\
\hline 145 & 0.35 & 0.1 & 50 & 500 & 250 & 0.4 & 0.492264 & 2.15E-09 & $2.96 \mathrm{E}-08$ \\
\hline 146 & 0.35 & 0.3 & 30 & 500 & 250 & 0.4 & 0.515216 & $6.20 \mathrm{E}-10$ & $4.24 \mathrm{E}-08$ \\
\hline 147 & 0.35 & 0.3 & 30 & 500 & 250 & 0.4 & 0.615216 & $6.20 \mathrm{E}-10$ & $5.00 \mathrm{E}-08$ \\
\hline 148 & 0.35 & 0.3 & 30 & 500 & 250 & 0.4 & 0.515216 & 1.42E-09 & 4.37E-08 \\
\hline 149 & 0.35 & 0.5 & 40 & 500 & 250 & 0.4 & 0.346548 & 1.89E-10 & $2.66 \mathrm{E}-08$ \\
\hline 150 & 0.35 & 0.5 & 40 & 500 & 250 & 0.4 & 0.446548 & $6.89 \mathrm{E}-10$ & 3.47E-08 \\
\hline 151 & 0.35 & 0.5 & 40 & 500 & 250 & 0.4 & 0.446548 & 1.49E-09 & 3.56E-08 \\
\hline
\end{tabular}

$\mathrm{CO}_{2}$ /MEA Batch 1

\begin{tabular}{|c|c|c|c|c|c|c|c|c|c|c|}
\hline ID & MEA & $\begin{array}{l}\mathrm{CO}_{2} \\
\text { Loading } \\
\end{array}$ & Temp & $\begin{array}{l}\text { Solvent } \\
\text { Flow Rate } \\
\end{array}$ & $\begin{array}{l}\text { Gas Flow } \\
\text { Rate }\end{array}$ & $\begin{array}{l}\mathrm{CO}_{2} \\
\text { Conc. }\end{array}$ & $\begin{array}{l}\text { Rate } \\
\text { Constant }\end{array}$ & $\begin{array}{l}\text { Henry's } \\
\text { Constant }\end{array}$ & Diffusivity & kG \\
\hline 1 & 0.25 & 0.3 & 42 & 450 & 4000 & 0.115 & 11.38922 & 0.511896 & 8.04E-10 & $9.03 \mathrm{E}-07$ \\
\hline 2 & 0.25 & 0.3 & 42 & 450 & 4000 & 0.115 & 11.38922 & 0.601896 & 8.04E-10 & $9.14 \mathrm{E}-07$ \\
\hline 3 & 0.25 & 0.3 & 42 & 450 & 4000 & 0.115 & 11.38922 & 0.671896 & $8.04 \mathrm{E}-10$ & $9.19 \mathrm{E}-07$ \\
\hline 4 & 0.25 & 0.3 & 42 & 450 & 4000 & 0.115 & 11.38922 & 0.511896 & 1.30E-09 & $1.04 \mathrm{E}-06$ \\
\hline 5 & 0.25 & 0.3 & 42 & 450 & 4000 & 0.115 & 11.38922 & 0.601896 & 1.30E-09 & $1.05 \mathrm{E}-06$ \\
\hline 6 & 0.25 & 0.3 & 42 & 450 & 4000 & 0.115 & 11.38922 & 0.671896 & 1.30E-09 & $1.05 \mathrm{E}-06$ \\
\hline 7 & 0.25 & 0.3 & 42 & 450 & 4000 & 0.115 & 11.38922 & 0.511896 & $1.80 \mathrm{E}-09$ & $1.14 \mathrm{E}-06$ \\
\hline 8 & 0.25 & 0.3 & 42 & 450 & 4000 & 0.115 & 11.38922 & 0.601896 & $1.80 \mathrm{E}-09$ & $1.15 \mathrm{E}-06$ \\
\hline 9 & 0.25 & 0.3 & 42 & 450 & 4000 & 0.115 & 11.38922 & 0.671896 & $1.80 \mathrm{E}-09$ & $1.16 \mathrm{E}-06$ \\
\hline 10 & 0.25 & 0.3 & 42 & 450 & 4000 & 0.115 & 15.38922 & 0.511896 & $8.04 \mathrm{E}-10$ & $9.75 \mathrm{E}-07$ \\
\hline 11 & 0.25 & 0.3 & 42 & 450 & 4000 & 0.115 & 15.38922 & 0.601896 & 8.04E-10 & $9.81 \mathrm{E}-07$ \\
\hline 12 & 0.25 & 0.3 & 42 & 450 & 4000 & 0.115 & 15.38922 & 0.671896 & 8.04E-10 & $9.86 \mathrm{E}-07$ \\
\hline 13 & 0.25 & 0.3 & 42 & 450 & 4000 & 0.115 & 15.38922 & 0.511896 & 1.30E-09 & $1.11 \mathrm{E}-06$ \\
\hline 14 & 0.25 & 0.3 & 42 & 450 & 4000 & 0.115 & 15.38922 & 0.601896 & 1.30E-09 & $1.12 \mathrm{E}-06$ \\
\hline 15 & 0.25 & 0.3 & 42 & 450 & 4000 & 0.115 & 15.38922 & 0.671896 & $1.30 \mathrm{E}-09$ & $1.13 \mathrm{E}-06$ \\
\hline 16 & 0.25 & 0.3 & 42 & 450 & 4000 & 0.115 & 15.38922 & 0.511896 & $1.80 \mathrm{E}-09$ & $1.21 \mathrm{E}-06$ \\
\hline 17 & 0.25 & 0.3 & 42 & 450 & 4000 & 0.115 & 15.38922 & 0.601896 & 1.80E-09 & $1.22 \mathrm{E}-06$ \\
\hline
\end{tabular}




\begin{tabular}{|c|c|c|c|c|c|c|c|c|c|c|}
\hline ID & MEA & $\begin{array}{l}\mathrm{CO}_{2} \\
\text { Loading } \\
\end{array}$ & Temp & $\begin{array}{l}\text { Solvent } \\
\text { Flow Rate } \\
\end{array}$ & $\begin{array}{l}\text { Gas Flow } \\
\text { Rate } \\
\end{array}$ & $\begin{array}{l}\mathrm{CO}_{2} \\
\text { Conc. }\end{array}$ & $\begin{array}{l}\text { Rate } \\
\text { Constant } \\
\end{array}$ & $\begin{array}{l}\text { Henry's } \\
\text { Constant }\end{array}$ & Diffusivity & kG \\
\hline 18 & 0.25 & 0.3 & 42 & 450 & 4000 & 0.115 & 15.38922 & 0.671896 & $1.80 \mathrm{E}-09$ & $1.23 \mathrm{E}-06$ \\
\hline 19 & 0.25 & 0.3 & 42 & 450 & 4000 & 0.115 & 19.38922 & 0.511896 & 8.04E-10 & $1.03 \mathrm{E}-06$ \\
\hline 20 & 0.25 & 0.3 & 42 & 450 & 4000 & 0.115 & 19.38922 & 0.601896 & 8.04E-10 & $1.04 \mathrm{E}-06$ \\
\hline 21 & 0.25 & 0.3 & 42 & 450 & 4000 & 0.115 & 19.38922 & 0.671896 & 8.04E-10 & $1.04 \mathrm{E}-06$ \\
\hline 22 & 0.25 & 0.3 & 42 & 450 & 4000 & 0.115 & 19.38922 & 0.511896 & $1.30 \mathrm{E}-09$ & $1.17 \mathrm{E}-06$ \\
\hline 23 & 0.25 & 0.3 & 42 & 450 & 4000 & 0.115 & 19.38922 & 0.601896 & $1.30 \mathrm{E}-09$ & $1.18 \mathrm{E}-06$ \\
\hline 24 & 0.25 & 0.3 & 42 & 450 & 4000 & 0.115 & 19.38922 & 0.671896 & $1.30 \mathrm{E}-09$ & $1.18 \mathrm{E}-06$ \\
\hline 25 & 0.25 & 0.3 & 42 & 450 & 4000 & 0.115 & 19.38922 & 0.511896 & $1.80 \mathrm{E}-09$ & $1.27 \mathrm{E}-06$ \\
\hline 26 & 0.25 & 0.3 & 42 & 450 & 4000 & 0.115 & 19.38922 & 0.601896 & $1.80 \mathrm{E}-09$ & $1.28 \mathrm{E}-06$ \\
\hline 27 & 0.25 & 0.3 & 42 & 450 & 4000 & 0.115 & 19.38922 & 0.671896 & $1.80 \mathrm{E}-09$ & $1.29 \mathrm{E}-06$ \\
\hline 28 & 0.1 & 0.1 & 45 & 494.75 & 4343.63 & 0.07 & 14.20342 & 0.631912 & $2.36 \mathrm{E}-09$ & $1.23 \mathrm{E}-06$ \\
\hline 29 & 0.1 & 0.1 & 45 & 494.75 & 4343.63 & 0.07 & 14.20342 & 0.631912 & $2.76 \mathrm{E}-09$ & $1.28 \mathrm{E}-06$ \\
\hline 30 & 0.1 & 0.1 & 45 & 494.75 & 4343.63 & 0.07 & 18.20342 & 0.571912 & $2.36 \mathrm{E}-09$ & $1.29 \mathrm{E}-06$ \\
\hline 31 & 0.1 & 0.1 & 45 & 494.75 & 4343.63 & 0.07 & 22.20342 & 0.571912 & $1.96 \mathrm{E}-09$ & $1.29 \mathrm{E}-06$ \\
\hline 32 & 0.1 & 0.1 & 45 & 494.75 & 4343.63 & 0.07 & 22.20342 & 0.631912 & $2.76 \mathrm{E}-09$ & $1.41 \mathrm{E}-06$ \\
\hline 33 & 0.1 & 0.2 & 27 & 590.24 & 2126.49 & 0.191 & 2.319231 & 0.709204 & $1.52 \mathrm{E}-09$ & $5.36 \mathrm{E}-07$ \\
\hline 34 & 0.1 & 0.2 & 27 & 590.24 & 2126.49 & 0.191 & 2.319231 & 0.709204 & $1.92 \mathrm{E}-09$ & $5.72 \mathrm{E}-07$ \\
\hline 35 & 0.1 & 0.2 & 27 & 590.24 & 2126.49 & 0.191 & 6.319231 & 0.789204 & $1.52 \mathrm{E}-09$ & 7.32E-07 \\
\hline 36 & 0.1 & 0.2 & 27 & 590.24 & 2126.49 & 0.191 & 10.31923 & 0.789204 & $1.12 \mathrm{E}-09$ & $7.68 \mathrm{E}-07$ \\
\hline 37 & 0.1 & 0.2 & 27 & 590.24 & 2126.49 & 0.191 & 10.31923 & 0.789204 & $1.92 \mathrm{E}-09$ & $8.89 \mathrm{E}-07$ \\
\hline 38 & 0.1 & 0.2 & 49 & 351.91 & 2724.41 & 0.086 & 18.66149 & 0.458428 & 2.92E-09 & $1.15 \mathrm{E}-06$ \\
\hline 39 & 0.1 & 0.2 & 49 & 351.91 & 2724.41 & 0.086 & 22.66149 & 0.598428 & 2.12E-09 & $1.12 \mathrm{E}-06$ \\
\hline 40 & 0.1 & 0.2 & 49 & 351.91 & 2724.41 & 0.086 & 22.66149 & 0.538428 & 2.52E-09 & $1.16 \mathrm{E}-06$ \\
\hline 41 & 0.1 & 0.2 & 49 & 351.91 & 2724.41 & 0.086 & 26.66149 & 0.458428 & $2.52 \mathrm{E}-09$ & $1.19 \mathrm{E}-06$ \\
\hline 42 & 0.1 & 0.2 & 49 & 351.91 & 2724.41 & 0.086 & 26.66149 & 0.598428 & $2.52 \mathrm{E}-09$ & $1.20 \mathrm{E}-06$ \\
\hline 43 & 0.1 & 0.3 & 55 & 550.02 & 2557.81 & 0.164 & 27.16327 & 0.49553 & 2.79E-09 & $1.49 \mathrm{E}-06$ \\
\hline 44 & 0.1 & 0.3 & 55 & 550.02 & 2557.81 & 0.164 & 31.16327 & 0.49553 & 2.39E-09 & $1.48 \mathrm{E}-06$ \\
\hline 45 & 0.1 & 0.3 & 55 & 550.02 & 2557.81 & 0.164 & 31.16327 & 0.49553 & 2.79E-09 & $1.52 \mathrm{E}-06$ \\
\hline 46 & 0.1 & 0.3 & 55 & 550.02 & 2557.81 & 0.164 & 35.16327 & 0.41553 & 2.79E-09 & $1.54 \mathrm{E}-06$ \\
\hline 47 & 0.1 & 0.3 & 55 & 550.02 & 2557.81 & 0.164 & 35.16327 & 0.55553 & $3.19 \mathrm{E}-09$ & $1.59 \mathrm{E}-06$ \\
\hline 48 & 0.1 & 0.4 & 47 & 318.21 & 2284.11 & 0.183 & 16.32441 & 0.554637 & $2.71 \mathrm{E}-09$ & $6.95 \mathrm{E}-07$ \\
\hline 49 & 0.1 & 0.4 & 47 & 318.21 & 2284.11 & 0.183 & 20.32441 & 0.474637 & $1.91 \mathrm{E}-09$ & $6.69 \mathrm{E}-07$ \\
\hline 50 & 0.1 & 0.4 & 47 & 318.21 & 2284.11 & 0.183 & 20.32441 & 0.554637 & 2.31E-09 & 7.07E-07 \\
\hline 51 & 0.1 & 0.4 & 47 & 318.21 & 2284.11 & 0.183 & 24.32441 & 0.474637 & $1.91 \mathrm{E}-09$ & $6.98 \mathrm{E}-07$ \\
\hline 52 & 0.1 & 0.4 & 47 & 318.21 & 2284.11 & 0.183 & 24.32441 & 0.554637 & $2.31 \mathrm{E}-09$ & $7.36 \mathrm{E}-07$ \\
\hline 53 & 0.1 & 0.4 & 59 & 404.19 & 3474.06 & 0.158 & 34.29151 & 0.531131 & $2.96 \mathrm{E}-09$ & 8.73E-07 \\
\hline 54 & 0.1 & 0.4 & 59 & 404.19 & 3474.06 & 0.158 & 38.29151 & 0.391131 & $2.56 \mathrm{E}-09$ & $8.54 \mathrm{E}-07$ \\
\hline 55 & 0.1 & 0.4 & 59 & 404.19 & 3474.06 & 0.158 & 38.29151 & 0.471131 & $2.96 \mathrm{E}-09$ & 8.89E-07 \\
\hline 56 & 0.1 & 0.4 & 59 & 404.19 & 3474.06 & 0.158 & 42.29151 & 0.471131 & $3.36 \mathrm{E}-09$ & $9.34 \mathrm{E}-07$ \\
\hline 57 & 0.1 & 0.4 & 59 & 404.19 & 3474.06 & 0.158 & 42.29151 & 0.531131 & 3.36E-09 & 9.39E-07 \\
\hline
\end{tabular}




\begin{tabular}{|c|c|c|c|c|c|c|c|c|c|c|}
\hline ID & MEA & $\begin{array}{l}\mathrm{CO}_{2} \\
\text { Loading } \\
\end{array}$ & Temp & $\begin{array}{l}\text { Solvent } \\
\text { Flow Rate } \\
\end{array}$ & $\begin{array}{l}\text { Gas Flow } \\
\text { Rate } \\
\end{array}$ & $\begin{array}{l}\mathrm{CO}_{2} \\
\text { Conc. }\end{array}$ & $\begin{array}{l}\text { Rate } \\
\text { Constant } \\
\end{array}$ & $\begin{array}{l}\text { Henry's } \\
\text { Constant }\end{array}$ & Diffusivity & kG \\
\hline 58 & 0.1 & 0.5 & 32 & 557.6 & 2681.27 & 0.056 & 4.584946 & 0.635721 & $1.22 \mathrm{E}-09$ & 5.79E-08 \\
\hline 59 & 0.1 & 0.5 & 32 & 557.6 & 2681.27 & 0.056 & 4.584946 & 0.635721 & 2.02E-09 & $6.14 \mathrm{E}-08$ \\
\hline 60 & 0.1 & 0.5 & 32 & 557.6 & 2681.27 & 0.056 & 8.584946 & 0.715721 & $1.62 \mathrm{E}-09$ & $6.51 \mathrm{E}-08$ \\
\hline 61 & 0.1 & 0.5 & 32 & 557.6 & 2681.27 & 0.056 & 8.584946 & 0.775721 & $1.62 \mathrm{E}-09$ & $6.72 \mathrm{E}-08$ \\
\hline 62 & 0.1 & 0.5 & 32 & 557.6 & 2681.27 & 0.056 & 12.58495 & 0.715721 & 1.22E-09 & $6.48 \mathrm{E}-08$ \\
\hline 63 & 0.2 & 0.1 & 30 & 321.91 & 2341.68 & 0.032 & 3.603876 & 0.776831 & $1.66 \mathrm{E}-09$ & 9.63E-07 \\
\hline 64 & 0.2 & 0.1 & 30 & 321.91 & 2341.68 & 0.032 & 7.603876 & 0.716831 & $1.26 \mathrm{E}-09$ & $1.10 \mathrm{E}-06$ \\
\hline 65 & 0.2 & 0.1 & 30 & 321.91 & 2341.68 & 0.032 & 11.60388 & 0.716831 & $8.59 \mathrm{E}-10$ & $1.09 \mathrm{E}-06$ \\
\hline 66 & 0.2 & 0.1 & 30 & 321.91 & 2341.68 & 0.032 & 11.60388 & 0.636831 & $1.66 \mathrm{E}-09$ & $1.28 \mathrm{E}-06$ \\
\hline 67 & 0.2 & 0.1 & 30 & 321.91 & 2341.68 & 0.032 & 11.60388 & 0.776831 & $1.66 \mathrm{E}-09$ & $1.29 \mathrm{E}-06$ \\
\hline 68 & 0.2 & 0.2 & 31 & 425.77 & 3734.86 & 0.142 & 4.081145 & 0.765778 & 8.35E-10 & $7.49 \mathrm{E}-07$ \\
\hline 69 & 0.2 & 0.2 & 31 & 425.77 & 3734.86 & 0.142 & 8.081145 & 0.625778 & 8.35E-10 & $9.02 \mathrm{E}-07$ \\
\hline 70 & 0.2 & 0.2 & 31 & 425.77 & 3734.86 & 0.142 & 8.081145 & 0.765778 & $8.35 \mathrm{E}-10$ & $9.12 \mathrm{E}-07$ \\
\hline 71 & 0.2 & 0.2 & 31 & 425.77 & 3734.86 & 0.142 & 8.081145 & 0.625778 & $1.23 \mathrm{E}-09$ & $9.87 \mathrm{E}-07$ \\
\hline 72 & 0.2 & 0.2 & 31 & 425.77 & 3734.86 & 0.142 & 8.081145 & 0.705778 & $1.23 \mathrm{E}-09$ & $9.95 \mathrm{E}-07$ \\
\hline 73 & 0.2 & 0.2 & 38 & 465.98 & 3898.82 & 0.064 & 8.239964 & 0.635165 & 1.47E-09 & $1.14 \mathrm{E}-06$ \\
\hline 74 & 0.2 & 0.2 & 38 & 465.98 & 3898.82 & 0.064 & 8.239964 & 0.555165 & $1.87 \mathrm{E}-09$ & $1.20 \mathrm{E}-06$ \\
\hline 75 & 0.2 & 0.2 & 38 & 465.98 & 3898.82 & 0.064 & 12.23996 & 0.635165 & 1.07E-09 & $1.18 \mathrm{E}-06$ \\
\hline 76 & 0.2 & 0.2 & 38 & 465.98 & 3898.82 & 0.064 & 12.23996 & 0.635165 & $1.47 \mathrm{E}-09$ & $1.27 \mathrm{E}-06$ \\
\hline 77 & 0.2 & 0.2 & 38 & 465.98 & 3898.82 & 0.064 & 12.23996 & 0.695165 & $1.47 \mathrm{E}-09$ & $1.28 \mathrm{E}-06$ \\
\hline 78 & 0.2 & 0.3 & 53 & 338.13 & 5548.92 & 0.134 & 24.06018 & 0.520141 & $1.98 \mathrm{E}-09$ & $1.36 \mathrm{E}-06$ \\
\hline 79 & 0.2 & 0.3 & 53 & 338.13 & 5548.92 & 0.134 & 28.06018 & 0.520141 & $1.98 \mathrm{E}-09$ & $1.42 \mathrm{E}-06$ \\
\hline 80 & 0.2 & 0.3 & 53 & 338.13 & 5548.92 & 0.134 & 28.06018 & 0.580141 & 2.38E-09 & $1.47 \mathrm{E}-06$ \\
\hline 81 & 0.2 & 0.3 & 53 & 338.13 & 5548.92 & 0.134 & 32.06018 & 0.520141 & $1.58 \mathrm{E}-09$ & $1.40 \mathrm{E}-06$ \\
\hline 82 & 0.2 & 0.3 & 53 & 338.13 & 5548.92 & 0.134 & 32.06018 & 0.580141 & $1.98 \mathrm{E}-09$ & $1.47 \mathrm{E}-06$ \\
\hline 83 & 0.2 & 0.4 & 43 & 410.45 & 3345.21 & 0.127 & 12.28105 & 0.651671 & $1.51 \mathrm{E}-09$ & 8.57E-07 \\
\hline 84 & 0.2 & 0.4 & 43 & 410.45 & 3345.21 & 0.127 & 16.28105 & 0.591671 & $1.51 \mathrm{E}-09$ & $8.91 \mathrm{E}-07$ \\
\hline 85 & 0.2 & 0.4 & 43 & 410.45 & 3345.21 & 0.127 & 16.28105 & 0.651671 & $1.51 \mathrm{E}-09$ & $8.96 \mathrm{E}-07$ \\
\hline 86 & 0.2 & 0.4 & 43 & 410.45 & 3345.21 & 0.127 & 20.28105 & 0.511671 & $1.11 \mathrm{E}-09$ & $8.60 \mathrm{E}-07$ \\
\hline 87 & 0.2 & 0.4 & 43 & 410.45 & 3345.21 & 0.127 & 20.28105 & 0.591671 & $1.11 \mathrm{E}-09$ & $8.65 \mathrm{E}-07$ \\
\hline 88 & 0.2 & 0.4 & 56 & 474.71 & 3635.41 & 0.043 & 28.82553 & 0.422243 & $2.01 \mathrm{E}-09$ & $9.86 \mathrm{E}-07$ \\
\hline 89 & 0.2 & 0.4 & 56 & 474.71 & 3635.41 & 0.043 & 28.82553 & 0.502243 & $2.41 \mathrm{E}-09$ & $1.02 \mathrm{E}-06$ \\
\hline 90 & 0.2 & 0.4 & 56 & 474.71 & 3635.41 & 0.043 & 32.82553 & 0.422243 & 2.01E-09 & $1.02 \mathrm{E}-06$ \\
\hline 91 & 0.2 & 0.4 & 56 & 474.71 & 3635.41 & 0.043 & 32.82553 & 0.502243 & $2.01 \mathrm{E}-09$ & $1.04 \mathrm{E}-06$ \\
\hline 92 & 0.2 & 0.4 & 56 & 474.71 & 3635.41 & 0.043 & 36.82553 & 0.562243 & $2.01 \mathrm{E}-09$ & $1.05 \mathrm{E}-06$ \\
\hline 93 & 0.2 & 0.5 & 39 & 521.42 & 2861.28 & 0.147 & 8.968154 & 0.62602 & $9.08 \mathrm{E}-10$ & $6.75 \mathrm{E}-08$ \\
\hline 94 & 0.2 & 0.5 & 39 & 521.42 & 2861.28 & 0.147 & 12.96815 & 0.62602 & $9.08 \mathrm{E}-10$ & $6.83 \mathrm{E}-08$ \\
\hline 95 & 0.2 & 0.5 & 39 & 521.42 & 2861.28 & 0.147 & 12.96815 & 0.62602 & $1.31 \mathrm{E}-09$ & $7.06 \mathrm{E}-08$ \\
\hline 96 & 0.2 & 0.5 & 39 & 521.42 & 2861.28 & 0.147 & 16.96815 & 0.54602 & $9.08 \mathrm{E}-10$ & $6.63 \mathrm{E}-08$ \\
\hline 97 & 0.2 & 0.5 & 39 & 521.42 & 2861.28 & 0.147 & 16.96815 & 0.54602 & $1.71 \mathrm{E}-09$ & $6.98 \mathrm{E}-08$ \\
\hline
\end{tabular}




\begin{tabular}{|c|c|c|c|c|c|c|c|c|c|c|}
\hline ID & MEA & $\begin{array}{l}\mathrm{CO}_{2} \\
\text { Loading }\end{array}$ & Temp & $\begin{array}{l}\text { Solvent } \\
\text { Flow Rate } \\
\end{array}$ & $\begin{array}{l}\text { Gas Flow } \\
\text { Rate }\end{array}$ & $\begin{array}{l}\mathrm{CO}_{2} \\
\text { Conc. }\end{array}$ & $\begin{array}{l}\text { Rate } \\
\text { Constant }\end{array}$ & $\begin{array}{l}\text { Henry's } \\
\text { Constant }\end{array}$ & Diffusivity & kG \\
\hline 98 & 0.3 & 0.1 & 41 & 362.63 & 4681.85 & 0.106 & 10.54102 & 0.673696 & $1.65 \mathrm{E}-09$ & $1.39 \mathrm{E}-06$ \\
\hline 99 & 0.3 & 0.1 & 41 & 362.63 & 4681.85 & 0.106 & 14.54102 & 0.533696 & $1.25 \mathrm{E}-09$ & $1.41 \mathrm{E}-06$ \\
\hline 100 & 0.3 & 0.1 & 41 & 362.63 & 4681.85 & 0.106 & 14.54102 & 0.613696 & $1.25 \mathrm{E}-09$ & $1.41 \mathrm{E}-06$ \\
\hline 101 & 0.3 & 0.1 & 41 & 362.63 & 4681.85 & 0.106 & 14.54102 & 0.533696 & 1.65E-09 & $1.50 \mathrm{E}-06$ \\
\hline 102 & 0.3 & 0.1 & 41 & 362.63 & 4681.85 & 0.106 & 18.54102 & 0.533696 & $1.25 \mathrm{E}-09$ & $1.49 \mathrm{E}-06$ \\
\hline 103 & 0.3 & 0.2 & 33 & 532.28 & 5130.34 & 0.175 & 9.116552 & 0.680085 & $9.37 \mathrm{E}-10$ & $1.25 \mathrm{E}-06$ \\
\hline 104 & 0.3 & 0.2 & 33 & 532.28 & 5130.34 & 0.175 & 13.11655 & 0.680085 & 5.37E-10 & $1.16 \mathrm{E}-06$ \\
\hline 105 & 0.3 & 0.2 & 33 & 532.28 & 5130.34 & 0.175 & 13.11655 & 0.740085 & $5.37 \mathrm{E}-10$ & $1.19 \mathrm{E}-06$ \\
\hline 106 & 0.3 & 0.2 & 33 & 532.28 & 5130.34 & 0.175 & 13.11655 & 0.680085 & 9.37E-10 & $1.35 \mathrm{E}-06$ \\
\hline 107 & 0.3 & 0.2 & 33 & 532.28 & 5130.34 & 0.175 & 13.11655 & 0.740085 & $9.37 \mathrm{E}-10$ & $1.36 \mathrm{E}-06$ \\
\hline 108 & 0.3 & 0.2 & 56 & 374.68 & 5241.26 & 0.049 & 28.82553 & 0.436609 & $1.26 \mathrm{E}-09$ & $1.53 \mathrm{E}-06$ \\
\hline 109 & 0.3 & 0.2 & 56 & 374.68 & 5241.26 & 0.049 & 28.82553 & 0.436609 & $1.66 \mathrm{E}-09$ & $1.63 \mathrm{E}-06$ \\
\hline 110 & 0.3 & 0.2 & 56 & 374.68 & 5241.26 & 0.049 & 32.82553 & 0.436609 & $1.26 \mathrm{E}-09$ & $1.57 \mathrm{E}-06$ \\
\hline 111 & 0.3 & 0.2 & 56 & 374.68 & 5241.26 & 0.049 & 32.82553 & 0.516609 & $1.26 \mathrm{E}-09$ & $1.58 \mathrm{E}-06$ \\
\hline 112 & 0.3 & 0.2 & 56 & 374.68 & 5241.26 & 0.049 & 32.82553 & 0.516609 & $1.66 \mathrm{E}-09$ & $1.68 \mathrm{E}-06$ \\
\hline 113 & 0.3 & 0.3 & 52 & 488.41 & 3106.5 & 0.11 & 26.61363 & 0.459154 & $1.39 \mathrm{E}-09$ & $1.27 \mathrm{E}-06$ \\
\hline 114 & 0.3 & 0.3 & 52 & 488.41 & 3106.5 & 0.11 & 26.61363 & 0.539154 & $1.39 \mathrm{E}-09$ & $1.28 \mathrm{E}-06$ \\
\hline 115 & 0.3 & 0.3 & 52 & 488.41 & 3106.5 & 0.11 & 26.61363 & 0.599154 & $1.79 \mathrm{E}-09$ & $1.37 \mathrm{E}-06$ \\
\hline 116 & 0.3 & 0.3 & 52 & 488.41 & 3106.5 & 0.11 & 30.61363 & 0.459154 & $1.79 \mathrm{E}-09$ & $1.39 \mathrm{E}-06$ \\
\hline 117 & 0.3 & 0.3 & 52 & 488.41 & 3106.5 & 0.11 & 30.61363 & 0.539154 & $1.79 \mathrm{E}-09$ & $1.39 \mathrm{E}-06$ \\
\hline 118 & 0.3 & 0.4 & 41 & 431.89 & 4189.3 & 0.102 & 14.54102 & 0.533696 & $5.87 \mathrm{E}-10$ & $6.72 \mathrm{E}-07$ \\
\hline 119 & 0.3 & 0.4 & 41 & 431.89 & 4189.3 & 0.102 & 14.54102 & 0.613696 & $9.87 \mathrm{E}-10$ & 7.64E-07 \\
\hline 120 & 0.3 & 0.4 & 41 & 431.89 & 4189.3 & 0.102 & 14.54102 & 0.673696 & $9.87 \mathrm{E}-10$ & 7.67E-07 \\
\hline 121 & 0.3 & 0.4 & 41 & 431.89 & 4189.3 & 0.102 & 18.54102 & 0.613696 & $5.87 \mathrm{E}-10$ & 7.07E-07 \\
\hline 122 & 0.3 & 0.4 & 41 & 431.89 & 4189.3 & 0.102 & 18.54102 & 0.673696 & $5.87 \mathrm{E}-10$ & 7.23E-07 \\
\hline 123 & 0.3 & 0.4 & 51 & 457.97 & 4839.27 & 0.079 & 21.2334 & 0.545156 & $1.26 \mathrm{E}-09$ & $1.02 \mathrm{E}-06$ \\
\hline 124 & 0.3 & 0.4 & 51 & 457.97 & 4839.27 & 0.079 & 21.2334 & 0.605156 & $1.66 \mathrm{E}-09$ & $1.09 \mathrm{E}-06$ \\
\hline 125 & 0.3 & 0.4 & 51 & 457.97 & 4839.27 & 0.079 & 25.2334 & 0.605156 & $8.56 \mathrm{E}-10$ & $9.89 \mathrm{E}-07$ \\
\hline 126 & 0.3 & 0.4 & 51 & 457.97 & 4839.27 & 0.079 & 25.2334 & 0.545156 & $1.26 \mathrm{E}-09$ & $1.07 \mathrm{E}-06$ \\
\hline 127 & 0.3 & 0.4 & 51 & 457.97 & 4839.27 & 0.079 & 29.2334 & 0.545156 & $1.26 \mathrm{E}-09$ & $1.12 \mathrm{E}-06$ \\
\hline 128 & 0.3 & 0.5 & 25 & 307.68 & 5990.52 & 0.196 & 1.574234 & 0.676031 & $6.01 \mathrm{E}-10$ & $1.36 \mathrm{E}-07$ \\
\hline 129 & 0.3 & 0.5 & 25 & 307.68 & 5990.52 & 0.196 & 5.574234 & 0.756031 & $6.01 \mathrm{E}-10$ & $1.38 \mathrm{E}-07$ \\
\hline 130 & 0.3 & 0.5 & 25 & 307.68 & 5990.52 & 0.196 & 5.574234 & 0.816031 & $6.01 \mathrm{E}-10$ & $1.39 \mathrm{E}-07$ \\
\hline 131 & 0.3 & 0.5 & 25 & 307.68 & 5990.52 & 0.196 & 9.574234 & 0.676031 & $2.01 \mathrm{E}-10$ & $1.34 \mathrm{E}-07$ \\
\hline 132 & 0.3 & 0.5 & 25 & 307.68 & 5990.52 & 0.196 & 9.574234 & 0.816031 & $2.01 \mathrm{E}-10$ & $1.35 \mathrm{E}-07$ \\
\hline 133 & 0.4 & 0.1 & 46 & 536.81 & 4430.56 & 0.116 & 19.23802 & 0.653598 & $6.61 \mathrm{E}-10$ & $1.43 \mathrm{E}-06$ \\
\hline 134 & 0.4 & 0.1 & 46 & 536.81 & 4430.56 & 0.116 & 19.23802 & 0.593598 & $1.06 \mathrm{E}-09$ & $1.56 \mathrm{E}-06$ \\
\hline 135 & 0.4 & 0.1 & 46 & 536.81 & 4430.56 & 0.116 & 19.23802 & 0.653598 & $1.06 \mathrm{E}-09$ & $1.56 \mathrm{E}-06$ \\
\hline 136 & 0.4 & 0.1 & 46 & 536.81 & 4430.56 & 0.116 & 19.23802 & 0.593598 & $1.46 \mathrm{E}-09$ & $1.63 \mathrm{E}-06$ \\
\hline 137 & 0.4 & 0.1 & 46 & 536.81 & 4430.56 & 0.116 & 23.23802 & 0.593598 & $1.46 \mathrm{E}-09$ & 1.62E-06 \\
\hline
\end{tabular}




\begin{tabular}{|c|c|c|c|c|c|c|c|c|c|c|}
\hline ID & MEA & $\begin{array}{l}\mathrm{CO}_{2} \\
\text { Loading }\end{array}$ & Temp & $\begin{array}{l}\text { Solvent } \\
\text { Flow Rate } \\
\end{array}$ & $\begin{array}{l}\text { Gas Flow } \\
\text { Rate }\end{array}$ & $\begin{array}{l}\mathrm{CO}_{2} \\
\text { Conc. }\end{array}$ & $\begin{array}{l}\text { Rate } \\
\text { Constant }\end{array}$ & $\begin{array}{l}\text { Henry's } \\
\text { Constant }\end{array}$ & Diffusivity & kG \\
\hline 138 & 0.4 & 0.2 & 36 & 513.12 & 4065.71 & 0.121 & 6.891733 & 0.590771 & $1.12 \mathrm{E}-09$ & $9.05 \mathrm{E}-07$ \\
\hline 139 & 0.4 & 0.2 & 36 & 513.12 & 4065.71 & 0.121 & 6.891733 & 0.670771 & $1.12 \mathrm{E}-09$ & $9.26 \mathrm{E}-07$ \\
\hline 140 & 0.4 & 0.2 & 36 & 513.12 & 4065.71 & 0.121 & 10.89173 & 0.670771 & $7.18 \mathrm{E}-10$ & $9.11 \mathrm{E}-07$ \\
\hline 141 & 0.4 & 0.2 & 36 & 513.12 & 4065.71 & 0.121 & 14.89173 & 0.670771 & $7.18 \mathrm{E}-10$ & $9.34 \mathrm{E}-07$ \\
\hline 142 & 0.4 & 0.2 & 36 & 513.12 & 4065.71 & 0.121 & 14.89173 & 0.730771 & 1.12E-09 & $9.66 \mathrm{E}-07$ \\
\hline 143 & 0.4 & 0.2 & 59 & 569.82 & 5672.76 & 0.179 & 34.29151 & 0.436382 & $1.31 \mathrm{E}-09$ & $1.67 \mathrm{E}-06$ \\
\hline 144 & 0.4 & 0.2 & 59 & 569.82 & 5672.76 & 0.179 & 34.29151 & 0.576382 & $1.71 \mathrm{E}-09$ & $1.80 \mathrm{E}-06$ \\
\hline 145 & 0.4 & 0.2 & 59 & 569.82 & 5672.76 & 0.179 & 38.29151 & 0.516382 & $1.31 \mathrm{E}-09$ & $1.69 \mathrm{E}-06$ \\
\hline 146 & 0.4 & 0.2 & 59 & 569.82 & 5672.76 & 0.179 & 38.29151 & 0.576382 & $1.31 \mathrm{E}-09$ & $1.69 \mathrm{E}-06$ \\
\hline 147 & 0.4 & 0.2 & 59 & 569.82 & 5672.76 & 0.179 & 42.29151 & 0.516382 & $9.12 \mathrm{E}-10$ & $1.58 \mathrm{E}-06$ \\
\hline 148 & 0.4 & 0.3 & 34 & 378.28 & 5300.57 & 0.04 & 5.677291 & 0.608123 & $1.00 \mathrm{E}-09$ & 1.17E-06 \\
\hline 149 & 0.4 & 0.3 & 34 & 378.28 & 5300.57 & 0.04 & 9.677291 & 0.688123 & $6.05 \mathrm{E}-10$ & $1.18 \mathrm{E}-06$ \\
\hline 150 & 0.4 & 0.3 & 34 & 378.28 & 5300.57 & 0.04 & 9.677291 & 0.608123 & $1.00 \mathrm{E}-09$ & $1.24 \mathrm{E}-06$ \\
\hline 151 & 0.4 & 0.3 & 34 & 378.28 & 5300.57 & 0.04 & 9.677291 & 0.748123 & $1.00 \mathrm{E}-09$ & $1.24 \mathrm{E}-06$ \\
\hline 152 & 0.4 & 0.3 & 34 & 378.28 & 5300.57 & 0.04 & 13.67729 & 0.748123 & $1.00 \mathrm{E}-09$ & $1.29 \mathrm{E}-06$ \\
\hline 153 & 0.4 & 0.4 & 28 & 588.01 & 5790.45 & 0.093 & 2.724073 & 0.743758 & $4.54 \mathrm{E}-10$ & 4.49E-07 \\
\hline 154 & 0.4 & 0.4 & 28 & 588.01 & 5790.45 & 0.093 & 6.724073 & 0.743758 & $4.54 \mathrm{E}-10$ & $5.90 \mathrm{E}-07$ \\
\hline 155 & 0.4 & 0.4 & 28 & 588.01 & 5790.45 & 0.093 & 10.72407 & 0.663758 & $4.54 \mathrm{E}-10$ & $6.70 \mathrm{E}-07$ \\
\hline 156 & 0.4 & 0.4 & 28 & 588.01 & 5790.45 & 0.093 & 10.72407 & 0.743758 & $4.54 \mathrm{E}-10$ & $6.73 \mathrm{E}-07$ \\
\hline 157 & 0.4 & 0.4 & 28 & 588.01 & 5790.45 & 0.093 & 10.72407 & 0.803758 & $4.54 \mathrm{E}-10$ & $6.76 \mathrm{E}-07$ \\
\hline 158 & 0.4 & 0.4 & 49 & 449.33 & 4869.33 & 0.153 & 18.66149 & 0.633549 & $4.06 \mathrm{E}-10$ & $9.96 \mathrm{E}-07$ \\
\hline 159 & 0.4 & 0.4 & 49 & 449.33 & 4869.33 & 0.153 & 18.66149 & 0.633549 & $8.06 \mathrm{E}-10$ & $1.04 \mathrm{E}-06$ \\
\hline 160 & 0.4 & 0.4 & 49 & 449.33 & 4869.33 & 0.153 & 22.66149 & 0.633549 & $4.06 \mathrm{E}-10$ & $1.01 \mathrm{E}-06$ \\
\hline 161 & 0.4 & 0.4 & 49 & 449.33 & 4869.33 & 0.153 & 22.66149 & 0.573549 & $8.06 \mathrm{E}-10$ & $1.05 \mathrm{E}-06$ \\
\hline 162 & 0.4 & 0.4 & 49 & 449.33 & 4869.33 & 0.153 & 22.66149 & 0.633549 & $1.21 \mathrm{E}-09$ & $1.08 \mathrm{E}-06$ \\
\hline 163 & 0.4 & 0.5 & 37 & 394.64 & 3189.22 & 0.078 & 7.548359 & 0.582332 & $5.23 \mathrm{E}-10$ & $1.84 \mathrm{E}-07$ \\
\hline 164 & 0.4 & 0.5 & 37 & 394.64 & 3189.22 & 0.078 & 7.548359 & 0.662332 & $9.23 \mathrm{E}-10$ & $1.85 \mathrm{E}-07$ \\
\hline 165 & 0.4 & 0.5 & 37 & 394.64 & 3189.22 & 0.078 & 11.54836 & 0.662332 & $5.23 \mathrm{E}-10$ & $1.85 \mathrm{E}-07$ \\
\hline 166 & 0.4 & 0.5 & 37 & 394.64 & 3189.22 & 0.078 & 11.54836 & 0.722332 & $5.23 \mathrm{E}-10$ & $1.85 \mathrm{E}-07$ \\
\hline 167 & 0.4 & 0.5 & 37 & 394.64 & 3189.22 & 0.078 & 15.54836 & 0.722332 & $1.23 \mathrm{E}-10$ & $1.84 \mathrm{E}-07$ \\
\hline
\end{tabular}

$\mathrm{CO}_{2}$ /MEA Batch 2

\begin{tabular}{|c|c|c|c|c|c|c|c|c|c|c|}
\hline ID & MEA & $\begin{array}{l}\mathrm{CO}_{2} \\
\text { Loading }\end{array}$ & Temp & $\begin{array}{l}\text { Solvent } \\
\text { Flow Rate }\end{array}$ & $\begin{array}{l}\text { Gas Flow } \\
\text { Rate }\end{array}$ & $\begin{array}{l}\mathrm{CO}_{2} \\
\text { Conc. }\end{array}$ & $\begin{array}{l}\text { Rate } \\
\text { Constant } \\
\end{array}$ & $\begin{array}{l}\text { Henry's } \\
\text { Constant }\end{array}$ & Diffusivity & kG \\
\hline 1 & 0.25 & 0.3 & 42 & 450 & 4000 & 0.115 & 26.8653 & 0.508248 & $9.49 \mathrm{E}-09$ & 1.91E-06 \\
\hline 2 & 0.25 & 0.3 & 42 & 450 & 4000 & 0.115 & 25.13401 & 0.508248 & $9.49 \mathrm{E}-09$ & $1.90 \mathrm{E}-06$ \\
\hline 3 & 0.25 & 0.3 & 42 & 450 & 4000 & 0.115 & 11.3627 & 0.508248 & $9.49 \mathrm{E}-09$ & 1.67E-06 \\
\hline 4 & 0.25 & 0.3 & 42 & 450 & 4000 & 0.115 & 23.5143 & 0.508248 & $9.49 \mathrm{E}-09$ & $1.88 \mathrm{E}-06$ \\
\hline 5 & 0.25 & 0.3 & 42 & 450 & 4000 & 0.115 & 11.83765 & 0.508248 & $9.49 \mathrm{E}-09$ & $1.68 \mathrm{E}-06$ \\
\hline 6 & 0.25 & 0.3 & 42 & 450 & 4000 & 0.115 & 24.49717 & 0.508248 & $9.49 \mathrm{E}-09$ & 1.89E-06 \\
\hline 7 & 0.25 & 0.3 & 42 & 450 & 4000 & 0.115 & 22.91849 & 0.508248 & $9.49 \mathrm{E}-09$ & 1.87E-06 \\
\hline
\end{tabular}




\begin{tabular}{|c|c|c|c|c|c|c|c|c|c|c|}
\hline ID & MEA & $\begin{array}{l}\mathrm{CO}_{2} \\
\text { Loading } \\
\end{array}$ & Temp & $\begin{array}{l}\text { Solvent } \\
\text { Flow Rate } \\
\end{array}$ & $\begin{array}{l}\text { Gas Flow } \\
\text { Rate } \\
\end{array}$ & $\begin{array}{l}\mathrm{CO}_{2} \\
\text { Conc. }\end{array}$ & $\begin{array}{l}\text { Rate } \\
\text { Constant } \\
\end{array}$ & $\begin{array}{l}\text { Henry's } \\
\text { Constant }\end{array}$ & Diffusivity & kG \\
\hline 8 & 0.25 & 0.3 & 42 & 450 & 4000 & 0.115 & 9.945389 & 0.508248 & 9.49E-09 & $1.63 \mathrm{E}-06$ \\
\hline 9 & 0.25 & 0.3 & 42 & 450 & 4000 & 0.115 & 4.315762 & 0.508248 & 9.49E-09 & $1.33 \mathrm{E}-06$ \\
\hline 10 & 0.25 & 0.3 & 42 & 450 & 4000 & 0.115 & 23.87646 & 0.508248 & $9.49 \mathrm{E}-09$ & $1.88 \mathrm{E}-06$ \\
\hline 11 & 0.25 & 0.3 & 42 & 450 & 4000 & 0.115 & 4.03764 & 0.508248 & 9.49E-09 & $1.31 \mathrm{E}-06$ \\
\hline 12 & 0.25 & 0.3 & 42 & 450 & 4000 & 0.115 & 8.35561 & 0.508248 & $9.49 \mathrm{E}-09$ & $1.57 \mathrm{E}-06$ \\
\hline 13 & 0.25 & 0.3 & 42 & 450 & 4000 & 0.115 & 22.33779 & 0.508248 & 9.49E-09 & $1.87 \mathrm{E}-06$ \\
\hline 14 & 0.25 & 0.3 & 42 & 450 & 4000 & 0.115 & 4.206409 & 0.508248 & 9.49E-09 & 1.33E-06 \\
\hline 15 & 0.25 & 0.3 & 42 & 450 & 4000 & 0.115 & 8.704866 & 0.508248 & 9.49E-09 & $1.58 \mathrm{E}-06$ \\
\hline 16 & 0.25 & 0.3 & 42 & 450 & 4000 & 0.115 & 12.52239 & 0.508248 & 9.49E-09 & $1.70 \mathrm{E}-06$ \\
\hline 17 & 0.25 & 0.3 & 42 & 450 & 4000 & 0.115 & 23.27148 & 0.508248 & $9.49 \mathrm{E}-09$ & $1.88 \mathrm{E}-06$ \\
\hline 18 & 0.25 & 0.3 & 42 & 450 & 4000 & 0.115 & 3.935335 & 0.508248 & 9.49E-09 & $1.30 \mathrm{E}-06$ \\
\hline 19 & 0.25 & 0.3 & 42 & 450 & 4000 & 0.115 & 10.52068 & 0.508248 & $9.49 \mathrm{E}-09$ & $1.64 \mathrm{E}-06$ \\
\hline 20 & 0.25 & 0.3 & 42 & 450 & 4000 & 0.115 & 21.7718 & 0.508248 & $9.49 \mathrm{E}-09$ & $1.86 \mathrm{E}-06$ \\
\hline 21 & 0.25 & 0.3 & 42 & 450 & 4000 & 0.115 & 4.099828 & 0.508248 & $9.49 \mathrm{E}-09$ & $1.32 \mathrm{E}-06$ \\
\hline 22 & 0.25 & 0.3 & 42 & 450 & 4000 & 0.115 & 20.36875 & 0.508248 & $9.49 \mathrm{E}-09$ & $1.84 \mathrm{E}-06$ \\
\hline 23 & 0.25 & 0.3 & 42 & 450 & 4000 & 0.115 & 8.838938 & 0.508248 & $9.49 \mathrm{E}-09$ & $1.59 \mathrm{E}-06$ \\
\hline 24 & 0.25 & 0.3 & 42 & 450 & 4000 & 0.115 & 3.835622 & 0.508248 & 9.49E-09 & $1.29 \mathrm{E}-06$ \\
\hline 25 & 0.25 & 0.3 & 42 & 450 & 4000 & 0.115 & 11.41857 & 0.508248 & 9.49E-09 & 1.67E-06 \\
\hline 26 & 0.25 & 0.3 & 42 & 450 & 4000 & 0.115 & 21.22014 & 0.508248 & $9.49 \mathrm{E}-09$ & $1.85 \mathrm{E}-06$ \\
\hline 27 & 0.25 & 0.3 & 42 & 450 & 4000 & 0.115 & 3.995947 & 0.508248 & $9.49 \mathrm{E}-09$ & $1.31 \mathrm{E}-06$ \\
\hline 28 & 0.25 & 0.3 & 42 & 450 & 4000 & 0.115 & 19.85265 & 0.508248 & 9.49E-09 & $1.83 \mathrm{E}-06$ \\
\hline 29 & 0.25 & 0.3 & 42 & 450 & 4000 & 0.115 & 3.738435 & 0.508248 & 9.49E-09 & $1.28 \mathrm{E}-06$ \\
\hline 30 & 0.25 & 0.3 & 42 & 450 & 4000 & 0.115 & 7.736427 & 0.508248 & $9.49 \mathrm{E}-09$ & $1.54 \mathrm{E}-06$ \\
\hline 31 & 0.25 & 0.3 & 42 & 450 & 4000 & 0.115 & 8.059802 & 0.508248 & $9.49 \mathrm{E}-09$ & $1.56 \mathrm{E}-06$ \\
\hline 32 & 0.25 & 0.3 & 42 & 450 & 4000 & 0.115 & 3.497519 & 0.508248 & $9.49 \mathrm{E}-09$ & $1.26 \mathrm{E}-06$ \\
\hline 33 & 0.25 & 0.3 & 42 & 450 & 4000 & 0.115 & 8.396693 & 0.508248 & 9.49E-09 & $1.57 \mathrm{E}-06$ \\
\hline 34 & 0.25 & 0.3 & 42 & 450 & 4000 & 0.115 & 3.643711 & 0.508248 & $9.49 \mathrm{E}-09$ & $1.27 \mathrm{E}-06$ \\
\hline 35 & 0.25 & 0.3 & 42 & 450 & 4000 & 0.115 & 3.408899 & 0.508248 & $9.49 \mathrm{E}-09$ & $1.25 \mathrm{E}-06$ \\
\hline 36 & 0.25 & 0.3 & 42 & 450 & 4000 & 0.115 & 3.954685 & 0.508248 & 9.49E-09 & $1.30 \mathrm{E}-06$ \\
\hline 37 & 0.25 & 0.3 & 42 & 450 & 4000 & 0.115 & 15.13453 & 0.508248 & $9.49 \mathrm{E}-09$ & $1.76 \mathrm{E}-06$ \\
\hline 38 & 0.25 & 0.3 & 30 & 450 & 4000 & 0.115 & 15.00799 & 0.598017 & 7.12E-09 & $1.66 \mathrm{E}-06$ \\
\hline 39 & 0.25 & 0.3 & 30 & 450 & 4000 & 0.115 & 13.80372 & 0.598017 & 7.12E-09 & $1.64 \mathrm{E}-06$ \\
\hline 40 & 0.25 & 0.3 & 30 & 450 & 4000 & 0.115 & 6.135064 & 0.598017 & 7.12E-09 & 1.39E-06 \\
\hline 41 & 0.25 & 0.3 & 30 & 450 & 4000 & 0.115 & 12.69608 & 0.598017 & 7.12E-09 & $1.61 \mathrm{E}-06$ \\
\hline 42 & 0.25 & 0.3 & 30 & 450 & 4000 & 0.115 & 6.310382 & 0.598017 & 7.12E-09 & $1.40 \mathrm{E}-06$ \\
\hline 43 & 0.25 & 0.3 & 30 & 450 & 4000 & 0.115 & 13.05889 & 0.598017 & 7.12E-09 & $1.62 \mathrm{E}-06$ \\
\hline 44 & 0.25 & 0.3 & 30 & 450 & 4000 & 0.115 & 12.01102 & 0.598017 & 7.12E-09 & $1.60 \mathrm{E}-06$ \\
\hline 45 & 0.25 & 0.3 & 30 & 450 & 4000 & 0.115 & 5.189988 & 0.598017 & 7.12E-09 & $1.33 \mathrm{E}-06$ \\
\hline 46 & 0.25 & 0.3 & 30 & 450 & 4000 & 0.115 & 2.242606 & 0.598017 & 7.12E-09 & 1.07E-06 \\
\hline 47 & 0.25 & 0.3 & 30 & 450 & 4000 & 0.115 & 12.35425 & 0.598017 & 7.12E-09 & $1.60 \mathrm{E}-06$ \\
\hline
\end{tabular}




\begin{tabular}{|c|c|c|c|c|c|c|c|c|c|c|}
\hline ID & MEA & $\begin{array}{l}\mathrm{CO}_{2} \\
\text { Loading } \\
\end{array}$ & Temp & $\begin{array}{l}\text { Solvent } \\
\text { Flow Rate } \\
\end{array}$ & $\begin{array}{l}\text { Gas Flow } \\
\text { Rate } \\
\end{array}$ & $\begin{array}{l}\mathrm{CO}_{2} \\
\text { Conc. } \\
\end{array}$ & $\begin{array}{l}\text { Rate } \\
\text { Constant } \\
\end{array}$ & $\begin{array}{l}\text { Henry's } \\
\text { Constant } \\
\end{array}$ & Diffusivity & kG \\
\hline 48 & 0.25 & 0.3 & 30 & 450 & 4000 & 0.115 & 2.062655 & 0.598017 & 7.12E-09 & $1.05 \mathrm{E}-06$ \\
\hline 49 & 0.25 & 0.3 & 30 & 450 & 4000 & 0.115 & 4.268518 & 0.598017 & 7.12E-09 & $1.27 \mathrm{E}-06$ \\
\hline 50 & 0.25 & 0.3 & 30 & 450 & 4000 & 0.115 & 11.36292 & 0.598017 & 7.12E-09 & $1.58 \mathrm{E}-06$ \\
\hline 51 & 0.25 & 0.3 & 30 & 450 & 4000 & 0.115 & 2.121598 & 0.598017 & 7.12E-09 & $1.06 \mathrm{E}-06$ \\
\hline 52 & 0.25 & 0.3 & 30 & 450 & 4000 & 0.115 & 4.390496 & 0.598017 & 7.12E-09 & $1.28 \mathrm{E}-06$ \\
\hline 53 & 0.25 & 0.3 & 30 & 450 & 4000 & 0.115 & 6.315953 & 0.598017 & 7.12E-09 & $1.40 \mathrm{E}-06$ \\
\hline 54 & 0.25 & 0.3 & 30 & 450 & 4000 & 0.115 & 11.68763 & 0.598017 & 7.12E-09 & $1.59 \mathrm{E}-06$ \\
\hline 55 & 0.25 & 0.3 & 30 & 450 & 4000 & 0.115 & 1.951357 & 0.598017 & 7.12E-09 & $1.03 \mathrm{E}-06$ \\
\hline 56 & 0.25 & 0.3 & 30 & 450 & 4000 & 0.115 & 5.19457 & 0.598017 & 7.12E-09 & $1.34 \mathrm{E}-06$ \\
\hline 57 & 0.25 & 0.3 & 30 & 450 & 4000 & 0.115 & 10.74979 & 0.598017 & 7.12E-09 & $1.56 \mathrm{E}-06$ \\
\hline 58 & 0.25 & 0.3 & 30 & 450 & 4000 & 0.115 & 2.007119 & 0.598017 & 7.12E-09 & $1.04 \mathrm{E}-06$ \\
\hline 59 & 0.25 & 0.3 & 30 & 450 & 4000 & 0.115 & 9.887209 & 0.598017 & 7.12E-09 & $1.54 \mathrm{E}-06$ \\
\hline 60 & 0.25 & 0.3 & 30 & 450 & 4000 & 0.115 & 4.272286 & 0.598017 & 7.12E-09 & $1.27 \mathrm{E}-06$ \\
\hline 61 & 0.25 & 0.3 & 30 & 450 & 4000 & 0.115 & 1.846064 & 0.598017 & 7.12E-09 & $1.01 \mathrm{E}-06$ \\
\hline 62 & 0.25 & 0.3 & 30 & 450 & 4000 & 0.115 & 5.495695 & 0.598017 & 7.12E-09 & $1.35 \mathrm{E}-06$ \\
\hline 63 & 0.25 & 0.3 & 30 & 450 & 4000 & 0.115 & 10.16975 & 0.598017 & 7.12E-09 & $1.54 \mathrm{E}-06$ \\
\hline 64 & 0.25 & 0.3 & 30 & 450 & 4000 & 0.115 & 1.898818 & 0.598017 & 7.12E-09 & $1.02 \mathrm{E}-06$ \\
\hline 65 & 0.25 & 0.3 & 30 & 450 & 4000 & 0.115 & 9.353709 & 0.598017 & 7.12E-09 & $1.52 \mathrm{E}-06$ \\
\hline 66 & 0.25 & 0.3 & 30 & 450 & 4000 & 0.115 & 1.746453 & 0.598017 & 7.12E-09 & $9.98 \mathrm{E}-07$ \\
\hline 67 & 0.25 & 0.3 & 30 & 450 & 4000 & 0.115 & 3.614161 & 0.598017 & 7.12E-09 & $1.22 \mathrm{E}-06$ \\
\hline 68 & 0.25 & 0.3 & 30 & 450 & 4000 & 0.115 & 3.717441 & 0.598017 & 7.12E-09 & $1.23 \mathrm{E}-06$ \\
\hline 69 & 0.25 & 0.3 & 30 & 450 & 4000 & 0.115 & 1.606315 & 0.598017 & 7.12E-09 & $9.73 \mathrm{E}-07$ \\
\hline 70 & 0.25 & 0.3 & 30 & 450 & 4000 & 0.115 & 3.823671 & 0.598017 & 7.12E-09 & $1.24 \mathrm{E}-06$ \\
\hline 71 & 0.25 & 0.3 & 30 & 450 & 4000 & 0.115 & 1.652217 & 0.598017 & 7.12E-09 & $9.82 \mathrm{E}-07$ \\
\hline 72 & 0.25 & 0.3 & 30 & 450 & 4000 & 0.115 & 1.51964 & 0.598017 & 7.12E-09 & $9.57 \mathrm{E}-07$ \\
\hline 73 & 0.25 & 0.3 & 30 & 450 & 4000 & 0.115 & 1.747995 & 0.598017 & 7.12E-09 & $9.98 \mathrm{E}-07$ \\
\hline 74 & 0.25 & 0.3 & 30 & 450 & 4000 & 0.115 & 7.472653 & 0.598017 & 7.12E-09 & $1.45 \mathrm{E}-06$ \\
\hline
\end{tabular}

